\title{
Women's experience of diabetes and diabetes management in pregnancy: A systematic review of qualitative literature
}

A thesis submitted as fulfilment for the award of Master of Clinical Science

(Evidence-based Health Care)

January 2014

School of Translational Health Science

The Joanna Briggs Institute

University of Adelaide

Lynn Costi B. Pharm. 


\section{Supervisory Team}

Associate Professor Craig Lockwood, PhD

Postgraduate Coordinator, School of Translational Health Science;

Director Translation Science, The Joanna Briggs Institute, Faculty of Health Sciences, The University of Adelaide, SA 5005 Adelaide

Dr Zachary Munn, PhD

Senior Research Fellow, School of Translational Health Science,

The Joanna Briggs Institute, Faculty of Health Sciences, The University of Adelaide,

SA 5005 Adelaide

Associate Professor Zoe Jordan, PhD

Deputy Head of School, School of Translational Health Science,

Director Communication Science, The Joanna Briggs Institute, Faculty of Health Sciences, The University of Adelaide, SA 5005 Adelaide 


\section{Executive summary}

\section{Background}

Pre-existing medical conditions, or medical conditions developing during pregnancy, may have an effect on pregnancy outcome or conversely may be affected by the pregnancy. Preexisting or gestational diabetes mellitus are such conditions. Generally, convention suggests that good control can assist to mitigate the negative effects of these conditions.

Qualitative research is necessary to better inform health care workers and to help them understand the experience of the pregnant woman with diabetes and how the experience may influence her attitudes to treatment. Some issues identified in the literature include shock at the time of diagnosis (both of gestational diabetes and pregnancy in the woman with preexisting diabetes), fear for the unborn child and the importance of timely and appropriate professional and personal support. There is a worthwhile qualitative literature base focusing on the patient experience of diabetes in pregnancy. As there is no current qualitative synthesis of the literature it is timely and worthwhile to produce a systematic review to identify and summarise the existing qualitative literature exploring women's experience of diabetes and diabetes management in pregnancy.

\section{Objectives}

To identify and describe from the available qualitative literature the experience of pregnant women with pre-existing or gestational diabetes and their experiences of adhering (or not) to prescribed treatment regimes.

\section{Inclusion criteria}

Studies that were qualitative in design that included currently pregnant women who had preexisting diabetes mellitus or gestational diabetes mellitus.

\section{Search strategy}


The search strategy aimed to find both published and unpublished studies and was conducted on 22 and 23 October 2012. No time limits were imposed in this search strategy. A three-step search strategy was utilised in this review.

\section{Methodological quality}

All studies that met the inclusion criteria were selected for retrieval. They were subsequently assessed by two independent reviewers for methodological rigor prior to inclusion in the review using standardised critical appraisal instruments from the Joanna Briggs Institute Qualitative Assessment and Review Instrument.

\section{Data extraction}

Data was extracted from the papers included in the review using standardised critical appraisal instruments from the Joanna Briggs Institute Qualitative Assessment and Review Instrument.

\section{Data synthesis}

Research findings were pooled using the Joanna Briggs Institute Qualitative Assessment and Review Instrument.

\section{Results}

Following the search and critical appraisal process, 22 studies were identified that were assessed as being of suitable quality to be included in the review, From these 22 studies a total of 172 study findings were included in the categories. A total of six categories were created on the basis of similarities of meaning, and from these, two synthesised findings (meta-synthesis) were produced. These were synthesised finding 1 - Health professionals should be aware that their attitudes and practices in the care of women with diabetes during pregnancy needs to be empathetic and based upon a collaborative model of care and synthesised finding 2 - Women with perceived low adherence need time to adjust and education; these are major factors positively affecting women's motivation for adherence to treatment for diabetes in pregnancy. 


\section{Conclusions}

The findings of this review highlight the need for health professionals to recognise that pregnant women's experiences of their medical conditions and treatments can affect their adherence to treatment regimes and therefore their continued health and perinatal outcomes. Health professionals also need to acknowledge that both the medical condition and pregnancy are only part of women's complex lives and that treatment regimes should accommodate this as far as possible. Treatment of the pregnant diabetic involves a number of different health professionals and it is important that these professions work in synchrony and appointments made in a timely and appropriate time frame.

\section{Keywords}

qualitative, experience, pregnancy, maternal, maternity, antenatal, prenatal, diabetes, adherence 


\section{Thesis Declaration}

I certify that this work contains no material which has been accepted for the award of any other degree or diploma in any university or other tertiary institution and, to the best of my knowledge and belief, contains no material previously published or written by another person, except where due reference has been made in the text. In addition, I certify that no part of this work will, in the future, be used in a submission for any other degree or diploma in any university or other tertiary institution without the prior approval of the University of Adelaide and where applicable, any partner institution responsible for the joint-award of this degree.

I give consent to this copy of my thesis, when deposited in the University Library, being made available for loan and photocopying, subject to the provisions of the Copyright Act 1968. I also give permission for the digital version of my thesis to be made available on the web, via the University's digital research repository, the Library catalogue and also through web search engines, unless permission has been granted by the University to restrict access for a period of time.

Signed

Date 


\section{Acknowledgments}

I would like to thank Mark McMillan who was second reviewer for critical appraisal of retrieved articles. Mark's 'can-do' attitude, friendliness and insight have been invaluable.

I would like to express my gratitude to my quality supervisory team. They have willingly given me guidance and advice during the course of study and I am grateful for their support. My principal supervisor Craig Lockwood, who throughout my candidature has always been able to spot where my comfort zone is and direct me away from it with good humour and kindness, Zachary Munn, who has helped steer me back from some of the interesting detours I made and who's insight and suggestions have been very much appreciated, and Zoe Jordan, who willingly stepped in when administrative difficulties required a third supervisor, to all of you my thanks.

Thanks also to my husband Eric, who has encouraged me, listened endlessly and sometimes cajoled me to undertake and continue this project. His love, support and wise counsel have enabled me to undertake new interests and he has been by my side throughout this adventure. Thanks also to my children - Nathan, Elyse and Ben - who have all encouraged this endeavour, provided some IT support and kept me grounded (theoretically). Thanks also go to my parents Marie and Arthur Drummond, who have always made clear the value of education.

Thanks to Marion Volckman for guidance with initial search strategies.

My thanks also go to my colleagues Cath Leggett, Chris Onishko, Sharelle Campbell, Jill Phelps and Kingsley Coulthard, who have been encouraging and interested in this project from beginning to end. 


\section{Table of contents}

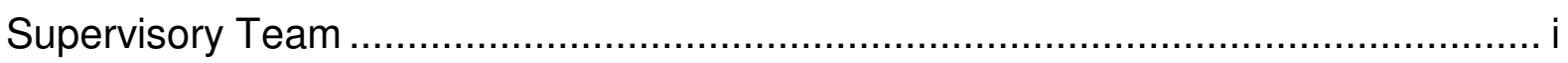

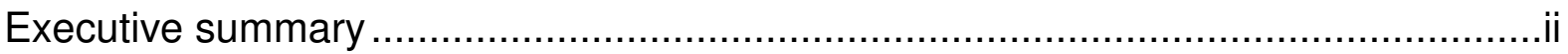

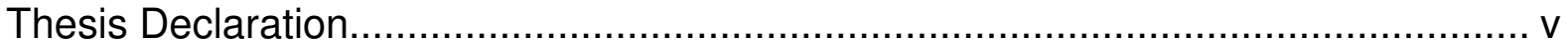

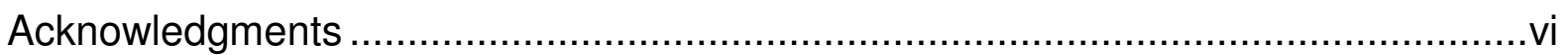

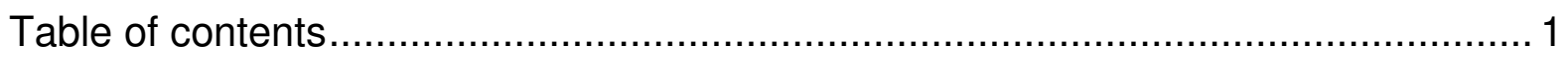

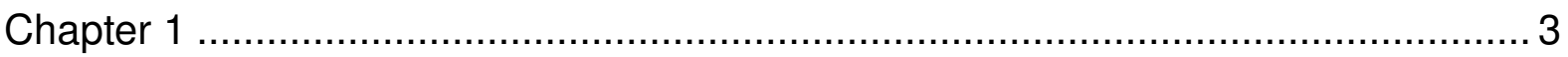

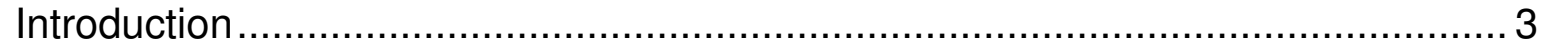

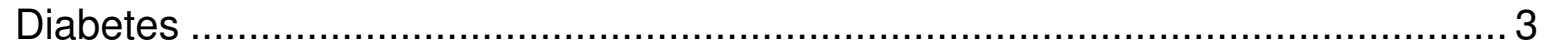

Diabetes in Pregnancy ............................................................................... 4

Sources of information regarding drugs and conditions in pregnancy ................... 6

Adherence to treatment regimens.................................................................. 6

Research Methods and Methodologies ...................................................... 9

Qualitative Synthesis .......................................................................... 12

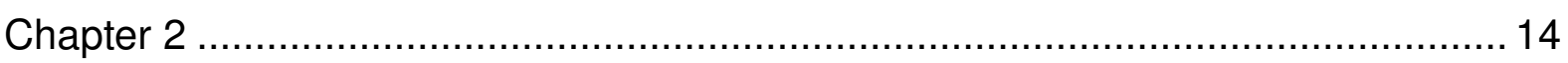

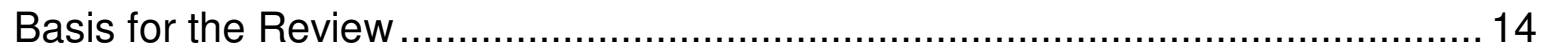

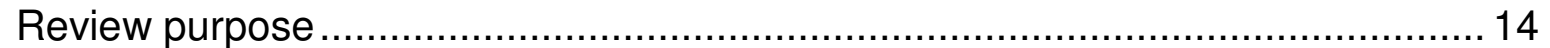

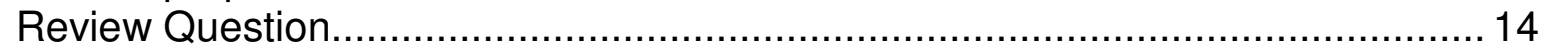

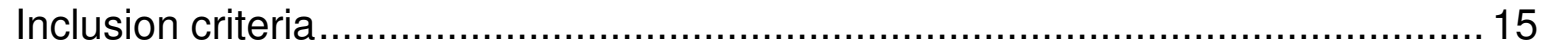

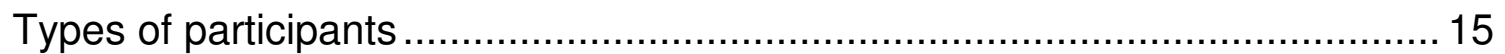

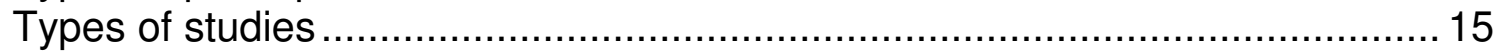

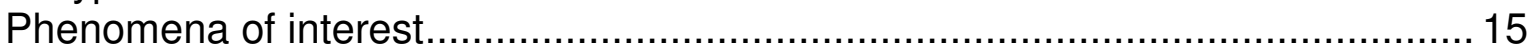

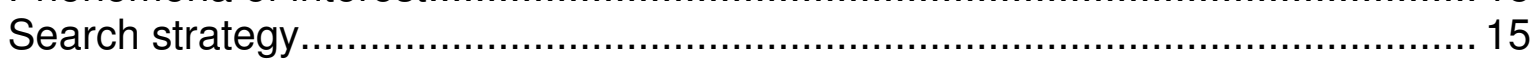

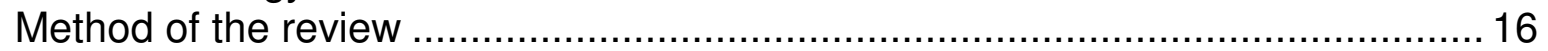

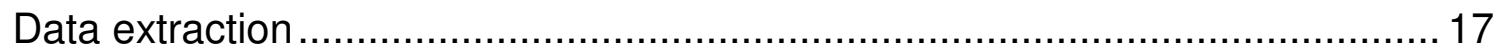

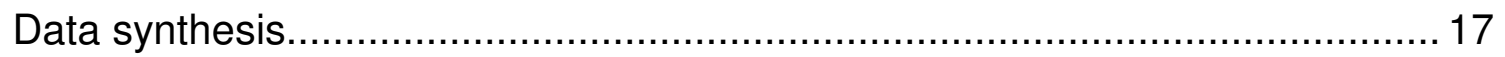

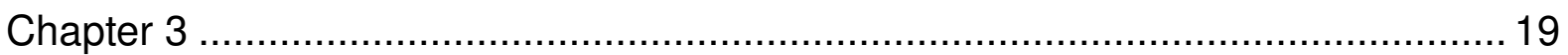

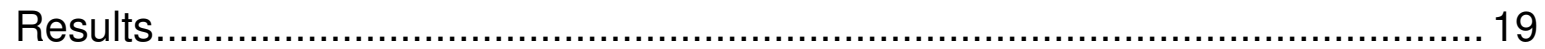

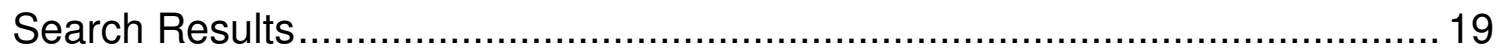

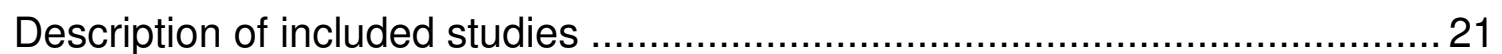

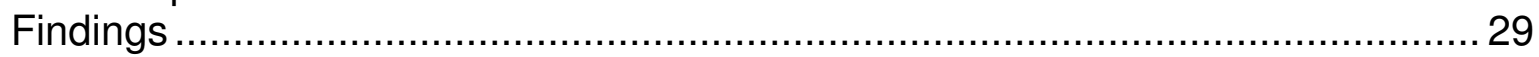

Categorisation and synthesis of qualitative research findings ......................... 75

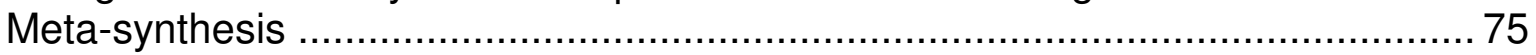

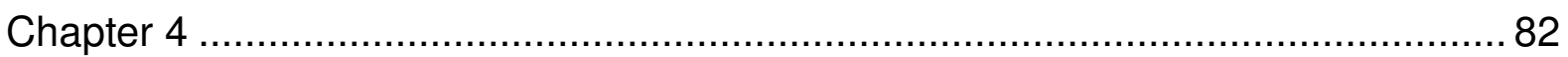




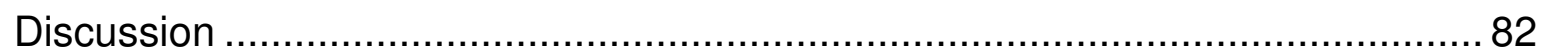

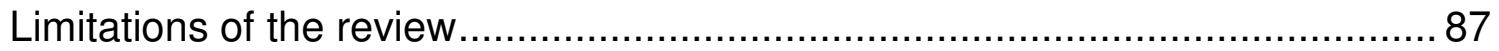

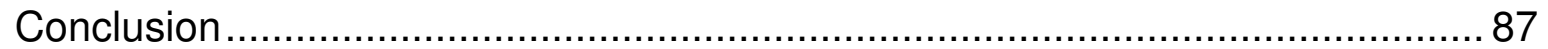

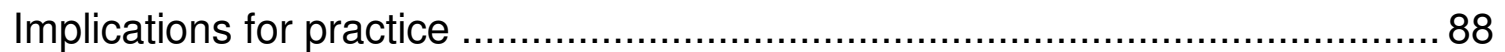

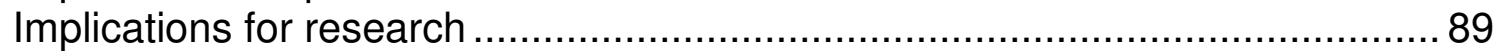

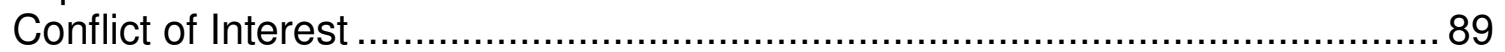

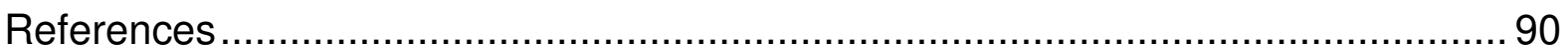

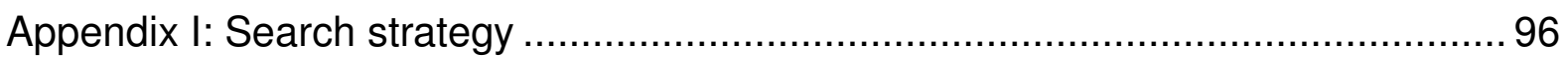

Appendix II: Appraisal instrument......................................................... 100

Appendix III: Data extraction instruments ................................................... 103

Appendix IV: Qari graph - Alternative presentation of synthesised findings and

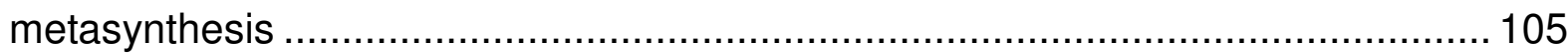




\section{Chapter 1}

\section{Introduction}

Pre-existing medical conditions, or medical conditions developing during pregnancy, may have an effect on pregnancy outcome or conversely may be affected by the pregnancy. Generally, convention suggests that good control can assist to mitigate the negative effects. Type 1 and Type 2 diabetes (pre-existing medical conditions) and gestational diabetes (a pregnancy related medical condition) are conditions where these negative effects may occur. ${ }^{1,2}$

\section{Diabetes}

There are many different classifications of types of diabetes. The American Diabetes Association ${ }^{3}$ identifies Type 1 and Type 2 diabetes and gestational diabetes mellitus as well as 'other specific types of diabetes' including genetic defects of beta-cell function, including Maturity Onset Diabetes of the Young (MODY, also termed monogenic diabetes), genetic defects in insulin action, diseases of the exocrine pancreas, endocrinopathies, drug or chemically induced (e.g. with glucocorticoids), genetic syndromes sometimes associated with diabetes (e.g. Down syndrome, Klinefelter syndrome, Turner syndrome and others), infections (e.g. congenital rubella) and uncommon forms of immunemediated diabetes (e.g. "Stiff-man" syndrome). Monogenic diabetes is particularly interesting in the context of pregnancy as optimal treatment may include the use of glibenclamide (also known as glyburide) and is also dependent on the foetal phenotype. ${ }^{4}$ However, these 'other specific types of diabetes' are rare and in the context of this review diabetes mellitus is referred to as Type 1, Type 2 or gestational diabetes mellitus.

Pre-existing diabetes mellitus can be divided into Type 1 (insulin-dependent diabetes mellitus) and Type 2 (non-insulin-dependent diabetes mellitus). Type 1 diabetes mellitus usually presents in childhood or early adulthood and is not associated with increased age or being overweight. Type 1 diabetes was previously referred to as insulin dependent diabetes or juvenile-onset diabetes, and results from a cellular-mediated autoimmune destruction of the beta-cells of the pancreas, usually 
leading to absolute insulin deficiency. Also included in Type 1 diabetes is an idiopathic diabetes with no evidence of autoimmunity. Idiopathic Type 1 diabetes is strongly genetically determined and shows no evidence of beta-cell autoimmunity. ${ }^{3}$

Type 2 diabetes mellitus is associated with increased age and weight and is more common in various ethnic groups. Type 2 diabetes mellitus was previously referred to as non-insulin-dependent diabetes, or adult onset diabetes, and encompasses individuals who have insulin resistance and who usually have relative (rather than absolute) insulin deficiency.

Gestational diabetes (GDM) is defined as carbohydrate intolerance of variable severity with onset or first recognition during the present pregnancy and therefore can include a subset of women with preexisting but previously undiagnosed diabetes mellitus. ${ }^{5}$

\section{Diabetes in Pregnancy}

In the UK, Type 2 diabetes is more common in Asian, Afro-Caribbean and Middle Eastern immigrants. ${ }^{5}$ In the USA, Hispanic mothers were more likely to have had diabetes than non-Hispanic Whites and non-Hispanic Blacks, with women aged 40-54 years being at highest risk of diabetes during pregnancy while women under 20 years of age were least likely to have diabetes during pregnancy. ${ }^{6}$ In Australia, Aboriginal and Torres Strait Islanders and mothers born in high-diabetes-risk regions, such as Polynesia, Asia and the Middle East are shown to have increased rates of both preexisting diabetes and GDM. ${ }^{7}$ A similar age related trend to the USA has been observed in Australia where women who gave birth with Type 2 diabetes and those with GDM tended to be older than other women who gave birth. ${ }^{7}$

An Australian study of women attending obstetric outpatient services in a major obstetric hospital ${ }^{8}$ reported that $39.3 \%$ of women reported at least one ongoing health condition. Diabetes mellitus (including GDM) was reported in $8.7 \%$, with $5.2 \%$ of all patients taking anti-diabetic medications. ${ }^{8}$ These figures are consistent with an Australian government report where it was reported that pre- 
existing diabetes in pregnancy affected less than $1 \%$ of pregnancies, and GDM affected about $5 \%{ }^{7}$

Pre-existing maternal diabetes with poor blood glucose control is associated with increased rates of congenital malformation. ${ }^{9}$ Sacral agenesis, neural tube defects, cardiac defects and skeletal defects are increased compared to the background rate of abnormalities if glycaemic control is poor in the first seven weeks post conception. ${ }^{9}$ The generally accepted background rate of congenital abnormalities in western countries is 2 to $3 \%$ at birth. The increased level of risk of birth defects is directly related to glycated haemoglobin levels $(\mathrm{HbA} 1 \mathrm{C})$. Where $\mathrm{HbA} 1 \mathrm{C}$ levels are less than $8 \%$ the congenital malformation rate is about $5 \%$; if $\mathrm{HbA} 1 \mathrm{C}$ is over $10 \%$ that rate increases to about $25 \%$. Gestational diabetes mellitus usually presents after the first trimester, so apart from those women with pre-existing diabetes, the children of women with GDM do not have an increase in the rate of congenital abnormalities. Poor glycaemic control in both pre-existing and gestational diabetes is associated with pregnancy complications including preeclampsia, polyhydramnios, preterm birth, macrosomia or growth restriction, intrauterine foetal death, shoulder dystocia and operative delivery. Neonatal complications include neonatal hypoglycaemia, jaundice and respiratory distress. Children of women with either pre-existing or gestational diabetes are at increased risk of obesity and of developing diabetes themselves. Tight control of glucose levels in late pregnancy has been shown to improve perinatal and obstetric complications. ${ }^{1}$ Women with pre-existing diabetes are at increased risk of deterioration of retinopathy during pregnancy and increased risk of pre-eclampsia, especially those with nephropathy and hypertension. ${ }^{5}$

Treatment for diabetes mellitus consists of a multifaceted approach including diet, exercise and often medications. All Type 1 diabetics require insulin. Some pregnant women with Type 2 Diabetes Mellitus and GDM will require either insulin or oral hypoglycaemics. Frequent blood glucose testing and adjustment of therapy is required. In the management of Type 2 diabetes in pregnancy, oral hypoglycaemics were traditionally discontinued and insulin therapy substituted, but there is increasing acceptance of the use of metformin and glibenclamide for both pre-existing Type 2 diabetes in pregnancy and GDM where clinically appropriate. ${ }^{5}$ 


\section{Sources of information regarding drugs and conditions in}

\section{pregnancy}

A number of countries have developed categorisation systems for the risks of drugs in pregnancy. Concerns have been raised regarding the lack of understanding of these systems by health practitioners and both the FDA and the Australian health authorities have flagged proposed changes to these systems. ${ }^{10,11}$ While these categorisation systems from different countries have similarities, there are distinct differences required in their interpretation, and it is not always apparent which system is being used (especially where information is obtained from the internet).

Nordeng et al. reported an overestimation of teratogenic risk of medications by Norwegian women in an internet based survey and nearly $70 \%$ of women in this study reported that they had chosen not to use a drug because they feared it was not safe, suggesting that non-adherence to medications in pregnancy may be more common than previously documented. ${ }^{12}$

It is thought that between a third and a half of all medicines prescribed for long-term conditions are not taken as recommended. ${ }^{13}$ Swedish studies of the experiences of obstetricians and midwives in treating women with GDM revealed uncertainty regarding roles and resigned frustration with those women who were nonadherent with advice given. ${ }^{14,15}$ An Australian study ${ }^{8}$ found that nearly $60 \%$ of women attending a major Australian maternity outpatient service were non-adherent with their medications.

\section{Adherence to treatment regimens}

In 1919, Franz Kafka wrote in his essay 'A Country Doctor' "it's easy to write prescriptions, but difficult to come to an understanding with people."16 In 1975, Becker commented "patient noncompliance has become the best documented, but least understood, health-related behaviour." ${ }^{17}$ In the same paper Becker references a 1966 article by Kasl and Cobb who noted that, in general, studies of reactions to 
illness have dealt mostly with "... superficial demographic and background variables rather than with fundamental, theoretically derived attitudes and subjective perceptions. This has an advantage in the area of measurement, but the disadvantage that one does not always understand well the meaning of such associations" suggesting the need for in-depth qualitative inquiry to the issue of compliance or adherence.

Women obtain advice regarding their pregnancies and treatments from a variety of sources and this impacts on their experience and behaviours. The internet is increasingly an important source of information. ${ }^{18}$ In Lagan et al.'s study (where participants were recruited from pregnancy related internet sites) almost $94 \%$ of women used the Internet to supplement information already provided by health professionals and $83 \%$ used it to influence their pregnancy decision-making. Nearly half of the respondents reported dissatisfaction with information given by health professionals (48.6\%) and lack of time to ask health professionals questions (46.5\%) as key factors influencing them to access the Internet. ${ }^{18}$

Compliance, adherence, concordance and persistence are all terms that are used to describe whether a patient takes their medication or adheres to a treatment regime. ${ }^{19}$ The terms concordance and adherence are sometimes used interchangeably, and imply that some discussion and agreement of the treatment course has been reached between prescriber and patient. Persistence is the continued adherence over time to the prescribed treatment regime. ${ }^{19} \mathrm{~A}$ consensus document of standardised terminology and taxonomy concerning adherence to medication was produced and published in 2012 by the $\mathrm{ABC}$ (Ascertaining Barriers to Compliance) project, which is an international collaboration of European research groups in the field of adherence to medications funded by the European Commission. ${ }^{20}$ This group assert that while the term 'patient compliance' is synonymous with medication adherence, use of the term should be discouraged as there are negative connotations of '(non-) compliance', and the term can be ambiguous in that it has multiple unrelated uses (e.g. compliance with drug regulations, compliance with good clinical practice, compliance with good manufacturing practice) ${ }^{20}$ 
Three elements were identified, being Adherence to medications, Management of adherence and Adherence-related sciences.

'Adherence to medications' is the process by which patients take medications as prescribed for them. Adherence has three components: initiation, implementation, and discontinuation.

- 'Initiation' is when the patient takes the first dose of a prescribed medication.

- 'Implementation' is defined as the extent to which a patient's actual dosing corresponds to the prescribed dosing regimen, from initiation until the last dose is taken.

- 'Discontinuation' marks the end of therapy, when the next dose to be taken is omitted and no more doses are taken thereafter.

Non-adherence to medications can occur in a number of situations including late or non-initiation of the prescribed treatment, sub-optimal implementation of the dosing regimen or early discontinuation of the treatment.

Management of adherence is the process of monitoring and supporting patients' adherence to medications by health care systems, providers, patients, and their social networks (i.e. interventions to improve or monitor adherence).

Adherence-related sciences include the disciplines that study the causes or consequences of differences between the prescribed (i.e. intended) and actual exposures to medicines. This field attracts attention from many disciplines including medicine, pharmacy, nursing, psychology, health economics and biostatistics. ${ }^{20}$

There are many causes of non-adherence but they fall into two broad categories: intentional and unintentional. Unintentional non-adherence occurs when the patient wants to follow the agreed treatment but is prevented from doing so by barriers that are beyond their control. Examples include poor recall or difficulties in understanding the instructions, problems with using the treatment, inability to pay for the treatment, or simply forgetting to take it. ${ }^{19}$ Intentional non-adherence occurs when the patient decides not to follow the treatment recommendations. The patient's beliefs and preferences influence their perceptions of the treatment and their motivation to start and continue with it. ${ }^{19,21}$ It 
follows that to promote adherence to treatment consideration needs to be given to beliefs and preferences that influence motivation to start and continue with treatment, as well as the practical factors that influence patients' ability to adhere to the agreed treatment. ${ }^{19}$ Patients who have few concerns about their treatment and are accepting of its necessity are more likely to be adherent to treatment regimes than those who have high concerns about the safety of the treatment and are perhaps sceptical of its necessity. ${ }^{19}$

Non-adherence may limit the benefits of medicines or other treatment regimes, resulting in lack of improvement, or deterioration, in health. In the case of pregnant women non-adherence could result in a deterioration of their own long-term health or perinatal complications, with consequences to their unborn child. ${ }^{22}$ Women's experiences and attitudes to their condition and its treatment may affect their adherence to treatment regimes and affect their long-term and perinatal outcomes.

\section{Research Methods and Methodologies}

Qualitative methods seek to take a holistic view which takes into account the complexities of human behaviour, and as such are relevant to the study of adherence to treatment regimes. ${ }^{23,24}$ Qualitative research seeks answers to questions that emphasise how social experience is created and given meaning in the context of the human experience. Qualitative data is generally collected through interviews, focus groups, textual analysis or direct observations of activities or behaviour. The delivery of effective healthcare is informed from a variety of both qualitative and quantitative research methods. Quantitative research methods such as randomised controlled trials, clinical trials and cohort studies provide essential knowledge on the effectiveness of interventions and qualitative research methods such as phenomenology and ethnography can help us understand how the care is being contextualised and/or experienced by the health care recipient. Evidence gained from qualitative research is invaluable in understanding how individuals and communities perceive health, manage their own health and make decisions related to health service usage. The knowledge obtained from qualitative studies can play a major role in increasing our understanding of the culture of communities and health units in relation to implementing change and overcoming barriers to the 
use of new knowledge and techniques. This information of how service users experience health, illness and the health system can be used to evaluate components and activities of health services that cannot be measured in quantitative outcomes. ${ }^{25}$

All research is based on some underlying assumptions about what constitutes 'valid' research and reality, and research follows three different philosophical perspectives or paradigms, being positivist, interpretive and critical.

Positivism suggests that all knowledge is grounded in empirical data and controlled experiments are used to discover and establish causal relationships. Positivist philosophy most closely informs quantitative research and scientific method. Positivists generally assume that reality can be described by measurable properties, which are independent of the observer and positivist research values observation and measurement, whether of scientific measurements or of attitudes, behaviours and opinions through surveys and questionnaires. Positivist research tests a hypothesis generated at the beginning of the research and analysis of the data is generally achieved through the use of mathematical or statistical techniques. ${ }^{26}$

Interpretive research methodologies explore 'lived experience'. Interpretive research attempts to understand phenomena through the meanings that people assign to them. The interpretive paradigm suggests that reality is socially constructed, subjective and unique to each individual human being. Interpretive research suggests that individuals access reality through social constructions such as language. Interpretive research is philosophically based in phenomenology and hermeneutics and does not predefine variables, but looks for historically situated and culturally derived interpretations of the social-life world. ${ }^{26}$ Phenomenology is a research methodology that fits within the interpretive paradigm. Phenomenology suggests that that by revisiting the immediate experience of a phenomenon, while ignoring, as much as possible, prevailing understandings and rationalisations of that phenomenon, that new meaning or greater understanding of that experience may emerge. Phenomenology is uncritical of its subject's responses and attempts to identify, describe, understand and maintain the subjective experiences of respondents. Interpretive research also incorporates 
hermeneutic theory. Hermeneutics is the notion that humans are "languaged" beings and that language is central to situations and experiences and the understandings that humans attach to those experiences. Hermeneutics is grounded in the interpretation of meanings from texts. It has its traditions in early Greek, Rabbinical and Judeo-Christian interpretations of literature and religious writings, uncovering deeper meanings to narratives. Modern hermeneutics includes written, verbal, and nonverbal communication. ${ }^{26}$

Critical methodologies address issues of power and oppression and critique prevailing social conditions and systems of social constraints. They consider the relationships between human interests, knowledge, power and forms of social control. Critical theorists suggest that reality is historically constituted and that some groups in society are more privileged than other groups and that oppression occurs when the less privileged group accept their lower social status as natural, necessary or inevitable. Critical theorists contend that an individual's ability to change social and economic circumstances is constrained by culture; as such they call current ideology into question, and initiate action, in the cause of social justice and emancipation. Critical research is action focused. Critical theorists contend that the culture they explore and the accounts it informs may be founded on a cultural tradition of exploitation, domination and oppression, and that culture should be brought into question. This can be contrasted with interpretivism, which is content to adopt an uncritical view of the culture it explores. ${ }^{26}$

The methodology of research, that is the strategy or design behind the choice of particular research methods (the procedure used to gather or analyse data related to a research question) is informed by the research paradigm and provides a context for the process. ${ }^{26}$

Methodologies associated with interpretive research include phenomenology, ethnography and grounded theory. As such, phenomenology seeks to understand people's individual real-life experiences and interpretations of the world and data is collected by undertaking interviews; ethnography seeks to understand the social meanings of activities, rituals and events within a particular culture or sub-culture and data may be collected by focus groups and observations by the researcher; and grounded theory seeks to generate theory that is grounded in the real world. The 
data itself defines the boundaries and directs development of theory. Data is collected by observations, purposeful interviews and textual analysis. ${ }^{25}$

Methodologies associated with critical theory include action research, feminist research, critical theory and discourse analysis. More specifically, action research involves researchers participating with subjects being researched to effect change. Data can be collected by group work and reflective journaling. Quantitative methods may also be used. Feminist research seeks to address inequities for women and effect social change. Focus groups and in-depth interviewing are usually utilised to collect data for this type of research. Quantitative methods may also be used. Critical Theory is concerned with issues of power and justice and is often centred on issues of race, gender, class and economic equality. Data can be collected by in-depth interviews and reflective dialogue. Discourse Analysis assumes that language socially and historically constructs how we think about and experience ourselves, and our relationships with others and data is collected by the study of written texts and other communications. ${ }^{25}$

\section{Qualitative Synthesis}

With the proliferation of research studies the systematic review including meta-analysis is considered the gold standard for analysis of quantitative data from two or more papers. Meta-analysis is a systematic method that uses statistical techniques for combining results from different studies to obtain a quantitative estimate of the overall effect of a particular intervention or variable on a defined outcome and produces a stronger conclusion than can be provided by any individual study. Quantitative meta-analysis aims to increase certainty in cause and effect conclusions, whereas qualitative meta-synthesis seeks to understand and explain phenomena. ${ }^{25,27,28}$ Meta-synthesis of qualitative research is a parallel technique to meta-analysis of quantitative data.

Meta-aggregation or meta-synthesis involves assembling the findings of studies (variously reported as themes, metaphors, categories or concepts) and pooling the findings through further aggregation based on similarity in meaning. The aim is to summarise findings from studies where concepts are 
assumed to be largely secure and well specified. Aggregation produces theories of causality, in addition to claims about generalisability. ${ }^{25,27,28}$ 


\section{Chapter 2}

\section{Basis for the Review}

After a search of the Joanna Briggs Institute library of systematic reviews, the Cochrane Database of systematic reviews, Medline and $\mathrm{CINAHL}$, no systematic reviews of qualitative literature were identified that addressed the issue of women's experience of diabetes and diabetes management in pregnancy. Therefore, it was the aim of this systematic review to establish the experience of diabetes and diabetes management among pregnant women, and how these experiences relate to their understanding of their condition and adherence to treatment regimes.

\section{Review purpose}

The purpose of this review was to collate, critically appraise, synthesise and present the best available evidence exploring the experience of diabetes and diabetes management among pregnant women.

\section{Review Question}

The objective of this review was to identify and describe from the available qualitative literature the experience of pregnant women with pre-existing or gestational diabetes and their experiences of adhering (or not) to prescribed treatment regimes. 


\section{Inclusion criteria}

\section{Types of participants}

This review considered studies that include pregnant women who have pre-existing diabetes mellitus or GDM.

This review only included studies where the investigation was conducted whilst the participant was currently pregnant, to minimise recall bias. ${ }^{29}$

\section{Types of studies}

This review considered studies that focused on qualitative data including, but not limited to, designs such as phenomenology, grounded theory, qualitative description, ethnography, action research and feminist research.

The search was limited to English language studies and there was no date restriction.

In the absence of research studies, other text such as opinion papers and reports were to be considered in a narrative summary, however this was unnecessary as sufficient research studies were identified.

\section{Phenomena of interest}

This review considered studies that investigated the experience of pregnant women with pre-existing or GDM and factors that they identified as enablers or barriers to adhering (or not) to prescribed treatment regimes.

\section{Search strategy}

The search strategy aimed to find both published and unpublished studies. A three-step search strategy was utilised in this review. An initial limited search of MEDLINE and CINAHL was undertaken 
followed by analysis of the text words contained in the title and abstract, and of the index terms used to describe the article. A second search using all identified keywords and index terms was then undertaken across all included databases. Thirdly, the reference list of all identified reports and articles was searched for additional studies. Studies published in the English language were considered for inclusion in this review. Studies published in any year where there was access to the full paper were considered for inclusion in this review.

The databases searched included:

PubMed, Embase, Biosis Previews, Academic Search Premier, CINAHL, PsycINFO

The search for unpublished studies included:

EThOS, Index to Theses, Proquest Dissertations \& Theses, Mednar

Initial keywords used were:

qualitative, experience, perception, understand, understanding, belief

pregnancy, maternal, maternity, antenatal, prenatal

diabetes

A full detailed list of search strategies for individual databases is detailed in Appendix I.

Databases were searched on the $22^{\text {nd }}$ and $23^{\text {rd }}$ of October 2012.

\section{Method of the review}

Prior to critical appraisal articles were read to ensure that inclusion criteria were met. Papers selected for retrieval were assessed by two independent reviewers for methodological rigor prior to inclusion in the review using standardised critical appraisal instruments from the Joanna Briggs Institute Qualitative Assessment and Review Instrument (JBI-QARI) (Appendix II). No disagreements arose between the reviewers and therefore involvement of a third reviewer was not required. 
The purpose of appraisal was to examine the quality of papers under analysis, and provide an objective critique of the internal validity of papers prior to considering their inclusions in the review.

The JBI-QARI appraisal tool comprises 10 questions that address congruency between the philosophical basis of the study, study methodology and methods, how the data is represented and the interpretation of the results. Also scrutinised are the influences or biases of the researcher and the relationship between what the participants said and conclusions drawn by the researcher.

The JBI-QARI appraisal tool requires the reviewer to allocate findings of 'yes', 'no', 'unclear' or 'not applicable". Papers were included in the review if half of the appraisal questions were answered 'yes' and there was agreement between the reviewers.

The Final Assessment Table presented in Appendix lla represents the agreed allocation of findings of the appraisal questions according to the JBI-QARI appraisal tool.

\section{Data extraction}

Data was extracted from papers included in the review using the standardised data extraction tool from JBI-QARI (Appendix III). The data extracted included specific details about the phenomena of interest, populations, study methods and outcomes of significance to the review question and specific objectives.

\section{Data synthesis}

Qualitative research findings were pooled using JBI-QARI. This involved the aggregation or synthesis of findings to generate a set of statements that represent that aggregation, through assembling the findings rated according to their quality, and categorising these findings on the basis of similarity in meaning. These categories were then subjected to a meta-synthesis in order to produce a single comprehensive set of synthesised findings that can be used as a basis for evidence-based practice.

Findings, as reported by the individual paper's author, were extracted as were supporting illustrations 
(quotes) that best illustrated that finding. These were entered into the QARI module. The finding, illustration and reference was printed and cut up, so that each finding could be separately perused and assigned to groups with other findings (from all included papers) based on similarity of meaning. These groups were read and reread and findings reallocated if necessary. Some findings were allocated to multiple groups. These groups were then further refined to form the final six categories.

Each finding was assigned a level of credibility according to the QARI module. The levels of credibility are as follows:

Unequivocal - evidence beyond reasonable doubt that may include findings that are matter of fact, directly reported/observed and not open to challenge.

Credible - albeit an interpretation, plausible in light of the data and theoretical framework. The interpretations can be logically inferred from the data, but because the findings are essentially interpretive, can be challenged.

Unsupported - findings are not supported by the data, or data is lacking. Unsupported findings were not included in the subsequent synthesis as the findings could not be verified by the data or illustrations provided in the respective papers. 


\section{Chapter 3}

\section{Results}

\section{Search Results}

Following the comprehensive search conducted on the $22^{\text {nd }}$ and $23^{\text {rd }}$ of October 2012, 4556 titles were identified (PubMed - 1178, Embase -705, Cinahl - 140, Psychlnfo -220, Proquest dissertations and Thesis - 223, Ethos - one, Index to Thesis - six, Mednar - 1309, Biosis Previews - 749, through Academic Premier - 25). There were 1061 duplicates identified by the automated duplicate finding function on Endnote x4 (1988-2010 Thomson Reuters) and hand searching, leaving 3495 titles (where both a thesis and published paper were identified of the same work the published paper only was included and the thesis excluded as a duplicate). These titles were screened by title and abstract for relevance with 54 being identified for full-text retrieval. After reading the full-text, 21 papers were deemed to meet the inclusion criteria and were selected for critical appraisal. Further, the references of these 21 articles were hand-searched for papers not previously identified and one extra paper was selected for critical appraisal (in press at time of search). In total 22 papers were subject to the critical appraisal process. All 22 papers were independently appraised by both reviewers and it was agreed that all 22 of these papers should be included in the review.

The search process for the review is depicted in Flowchart 1. 


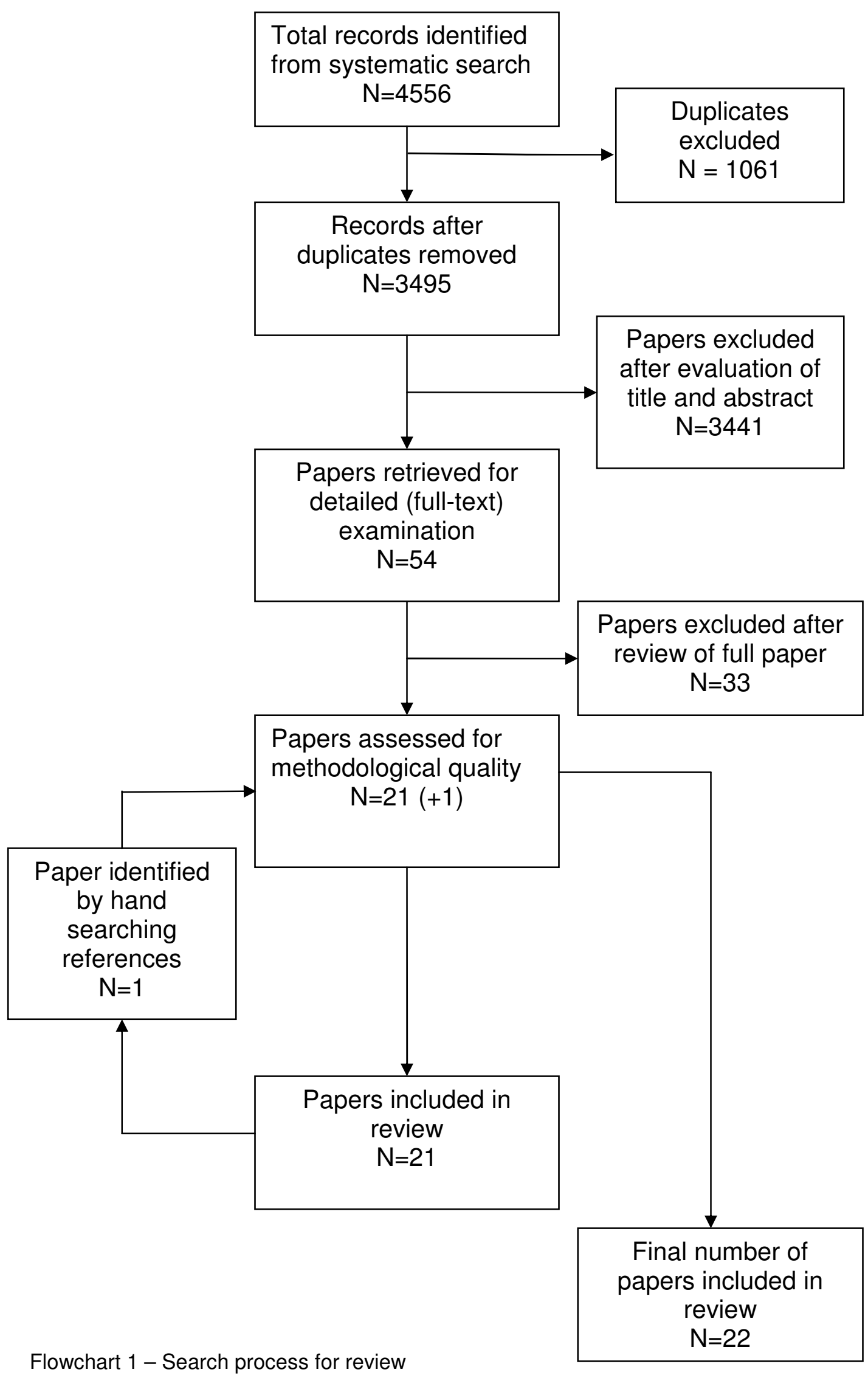




\section{Description of included studies}

All 22 studies included in this review were of qualitative design, and although they were of varying study methodologies and quality, they were all were deemed to be of sufficient methodological quality according to the QARI appraisal tool for inclusion in the review. Prior to appraisal it was determined that studies scoring five or more out of ten on the QARI appraisal tool would be included in the review. The 22 studies were comprised of nine various descriptive qualitative approaches with no explicitly stated methodology, ${ }^{30} 3132333435363738$ eight phenomenological studies, ${ }^{39} 40414243444546$ four grounded theory studies ${ }^{4748} 49$ and one ethnographic study. ${ }^{51}$ Five of the studies were theses and 17 were published papers.

The majority of studies scored well in critical appraisal criteria relating to congruity between the research question and methodology, methods used to collect data, representation and analysis of data and interpretation of results. They were also strong in questions addressing adequate representation of participant's voices; approval by ethics committees and that conclusions are drawn from the analysis or interpretation of the data. Few studies located the researcher culturally or theoretically or addressed the influence of the researcher on the research. Only about half of the studies included stated a philosophical framework to the study.

Disagreements between the independent reviewers of critical appraisal criteria were resolved by discussion. The questions that addressed the location of the researcher culturally or theoretically and the influence of the researcher on the research were the main sources of incongruence between the reviewers.

The final assessment table for critical appraisal is presented in Appendix Ila

Refer to table 1 for a summary of the included studies.

Table 1: summary of the included studies

\begin{tabular}{|l|l|l|l|ll|}
\hline Study & Methodology & Methods & Participants & Phenomena of \\
& & & & & interest \\
\hline Bandyopadh & Qualitative (no & Face-to-face in- & 17 immigrant & Experiences and \\
\hline
\end{tabular}




\begin{tabular}{|c|c|c|c|c|}
\hline $\begin{array}{l}\text { yay et al } \\
2011^{30}\end{array}$ & $\begin{array}{l}\text { specific mention } \\
\text { of philosophical } \\
\text { framework) }\end{array}$ & $\begin{array}{l}\text { depth interview at } \\
\text { two time points: in } \\
\text { pregnancy, } \\
\text { following GDM } \\
\text { diagnosis, and at six } \\
\text { weeks post-partum }\end{array}$ & $\begin{array}{ll}\text { women } & \text { from } \\
\text { South } & \text { Asia } \\
\text { diagnosed } & \text { with } \\
\text { GDM. } & \end{array}$ & $\begin{array}{l}\text { understandings of } \\
\text { South Asian } \\
\text { women } \\
\text { Melbourne, } \\
\text { Australia, after } \\
\text { diagnosis with } \\
\text { GDM. }\end{array}$ \\
\hline Berg $2005^{39}$ & $\begin{array}{l}\text { Husserlian } \\
\text { phenomenology }\end{array}$ & Open interviews & $\begin{array}{l}18 \text { pregnant } \\
\text { women } \\
\text { primiparous and } \\
\text { eight multiparous) } \\
\text { aged between } 25 \\
\text { and } 38 \text { years. }\end{array}$ & $\begin{array}{l}\text { Experience of } \\
\text { women with Type } 1 \\
\text { diabetes and how } \\
\text { they handle their } \\
\text { challenges during } \\
\text { pregnancy. }\end{array}$ \\
\hline $\begin{array}{l}\text { Berg \& } \\
\text { Honkasalo } \\
2000^{40}\end{array}$ & $\begin{array}{l}\text { Hermeneutic } \\
\text { phenomenology }\end{array}$ & Open interview & $\begin{array}{l}14 \quad \text { pregnant } \\
\text { women with pre- } \\
\text { existing insulin } \\
\text { dependent } \\
\text { diabetes aged 25- } \\
38 \text { years. }\end{array}$ & $\begin{array}{l}\text { Women's } \\
\text { experiences of } \\
\text { being pregnant and } \\
\text { having insulin- } \\
\text { dependent } \\
\text { diabetes mellitus } \\
\text { (IDDM), particularly } \\
\text { regarding what the } \\
\text { crucial elements of } \\
\text { the experience are } \\
\text { during pregnancy. }\end{array}$ \\
\hline Bieda $2009^{31}$ & $\begin{array}{l}\text { Qualitative - } \\
\text { theory of } \\
\text { planned } \\
\text { behaviour used }\end{array}$ & $\begin{array}{l}\text { Face-to-face, semi- } \\
\text { structured interview. }\end{array}$ & $\begin{array}{l}25 \text { African- } \\
\text { American mothers } \\
\text { diagnosed with } \\
\text { GDM at two high- }\end{array}$ & $\begin{array}{l}\text { African-American } \\
\text { mothers' } \\
\text { knowledge of Type } \\
2 \text { diabetes risk as }\end{array}$ \\
\hline
\end{tabular}




\begin{tabular}{|c|c|c|c|c|}
\hline & & & $\begin{array}{l}\text { risk prenatal } \\
\text { clinics in Detroit, } \\
\text { MI. }\end{array}$ & $\begin{array}{l}\text { well as their } \\
\text { intentions to } \\
\text { participate in } \\
\text { preventive } \\
\text { behaviours after a } \\
\text { pregnancy } \\
\text { complicated by } \\
\text { GDM. }\end{array}$ \\
\hline $\begin{array}{l}\text { Brooks } \\
2002^{32}\end{array}$ & $\begin{array}{l}\text { Qualitative (no } \\
\text { specific mention } \\
\text { of philosophical } \\
\text { framework) }\end{array}$ & $\begin{array}{l}\text { Open-ended } \\
\text { interview and } \\
\text { questionnaires }\end{array}$ & $\begin{array}{l}32 \text { African } \\
\text { American women } \\
\text { aged } 18 \text { to } 49 \\
\text { with pregnancies } \\
\text { complicated by } \\
\text { Type } 2 \text { or GDM }\end{array}$ & $\begin{array}{l}\text { Aspects of the } \\
\text { diabetes treatment } \\
\text { regimen that are } \\
\text { most difficult to } \\
\text { adhere to among } \\
\text { pregnant African- } \\
\text { American women } \\
\text { with diabetes. }\end{array}$ \\
\hline $\begin{array}{l}\text { Carolan } \\
2013^{41}\end{array}$ & $\begin{array}{l}\text { Interpretive } \\
\text { phenomenology }\end{array}$ & $\begin{array}{l}\text { Semi-structured } \\
\text { interviews and one } \\
\text { focus group }\end{array}$ & $\begin{array}{l}15 \text { women with a } \\
\text { diagnosis of GDM } \\
\text { who had } \\
\text { experienced self- } \\
\text { management of } \\
\text { their condition. }\end{array}$ & $\begin{array}{l}\text { Women's } \\
\text { experiences of self- } \\
\text { managing their } \\
\text { GDM. }\end{array}$ \\
\hline $\begin{array}{l}\text { Carolan et al } \\
2012^{42}\end{array}$ & $\begin{array}{l}\text { Interpretative } \\
\text { phenomenology }\end{array}$ & $\begin{array}{l}\text { Semi-structured } \\
\text { interviews and a } \\
\text { focus group }\end{array}$ & $\begin{array}{l}15 \text { pregnant } \\
\text { women, with a } \\
\text { diagnosis of } \\
\text { GDM, at 28-38 } \\
\text { weeks gestation. }\end{array}$ & $\begin{array}{l}\text { To explore the } \\
\text { factors that } \\
\text { facilitated or } \\
\text { inhibited GDM self- } \\
\text { management } \\
\text { among women in a }\end{array}$ \\
\hline
\end{tabular}




\begin{tabular}{|c|c|c|c|c|}
\hline & & & & $\begin{array}{l}\text { socially deprived } \\
\text { area. }\end{array}$ \\
\hline $\begin{array}{l}\text { Evans \& } \\
\text { O'Brien, } \\
2005^{43}\end{array}$ & $\begin{array}{l}\text { Heideggerian- } \\
\text { Gadamerian } \\
\text { hermeneutic } \\
\text { phenomenology }\end{array}$ & $\begin{array}{l}\text { Conversational } \\
\text { interviews }\end{array}$ & $\begin{array}{l}12 \text { pregnant } \\
\text { women who were } \\
\text { diagnosed with } \\
\text { and being treated } \\
\text { for diabetes }\end{array}$ & $\begin{array}{l}\text { What are the } \\
\text { meanings that } \\
\text { pregnant women } \\
\text { attach to their } \\
\text { experience of a } \\
\text { pregnancy that is } \\
\text { judged at risk as a } \\
\text { consequence of } \\
\text { GDM? }\end{array}$ \\
\hline $\begin{array}{l}\text { Hamel } \\
2003^{47}\end{array}$ & $\begin{array}{l}\text { Grounded } \\
\text { theory }\end{array}$ & $\begin{array}{l}\text { Open-ended, semi- } \\
\text { structured } \\
\text { interviews }\end{array}$ & $\begin{array}{l}\text { Seven } \\
\text { participants } \\
\text { residing in } \\
\text { Northern New } \\
\text { England having a } \\
\text { diagnosis of GDM }\end{array}$ & $\begin{array}{l}\text { The experience of } \\
\text { being a woman } \\
\text { diagnosed with } \\
\text { GDM. }\end{array}$ \\
\hline $\begin{array}{l}\text { Hirst et al } \\
2012^{33}\end{array}$ & $\begin{array}{l}\text { Qualitative (no } \\
\text { specific mention } \\
\text { of philosophical } \\
\text { framework) }\end{array}$ & Focus groups & $\begin{array}{l}\text { Four focus groups } \\
\text { involving } \\
\text { pregnant women } \\
\text { aged over } 18 \\
\text { years, with GDM }\end{array}$ & $\begin{array}{l}\text { Attitudes and } \\
\text { health behaviours } \\
\text { of pregnant women } \\
\text { with GDM in } \\
\text { Vietnam. }\end{array}$ \\
\hline $\begin{array}{ll}\text { Hjelm } & \text { K } \\
2012^{34} & \end{array}$ & $\begin{array}{l}\text { Qualitative (no } \\
\text { specific mention } \\
\text { of philosophical } \\
\text { framework) }\end{array}$ & $\begin{array}{l}\text { Semi-structured } \\
\text { interviews. }\end{array}$ & $\begin{array}{l}\text { Consecutive } \\
\text { sample of women } \\
\text { diagnosed with } \\
\text { GDM, } 13 \text { born in } \\
\text { Sweden and ten } \\
\text { born in Africa, }\end{array}$ & $\begin{array}{l}\text { Beliefs about } \\
\text { health and illness } \\
\text { in women with } \\
\text { GDM born in } \\
\text { Sweden and Africa } \\
\text { living in Sweden }\end{array}$ \\
\hline
\end{tabular}




\begin{tabular}{|c|c|c|c|c|}
\hline & & & $\begin{array}{l}\text { from a diabetes } \\
\text { clinic in Sweden. }\end{array}$ & $\begin{array}{l}\text { and the influence of } \\
\text { beliefs on self-care } \\
\text { and care seeking }\end{array}$ \\
\hline $\begin{array}{l}\text { Hjelm et al } \\
2005^{35}\end{array}$ & $\begin{array}{l}\text { Qualitative (no } \\
\text { specific mention } \\
\text { of philosophical } \\
\text { framework) }\end{array}$ & $\begin{array}{l}\text { Semi-structured } \\
\text { interviews }\end{array}$ & $\begin{array}{l}\text { Consecutive } \\
\text { sample of women } \\
\text { with GD; } 13 \text { born } \\
\text { in Sweden and } 14 \\
\text { born in the Middle } \\
\text { East }\end{array}$ & $\begin{array}{l}\text { To compare beliefs } \\
\text { about health and } \\
\text { illness between } \\
\text { women born in } \\
\text { Sweden and the } \\
\text { Middle East who } \\
\text { developed GDM. }\end{array}$ \\
\hline $\begin{array}{l}\text { Hjelm et al } \\
2007^{36}\end{array}$ & $\begin{array}{l}\text { Qualitative (no } \\
\text { specific mention } \\
\text { of philosophical } \\
\text { framework) }\end{array}$ & $\begin{array}{l}\text { Semi-structured } \\
\text { interview }\end{array}$ & $\begin{array}{l}\text { Females with } \\
\text { GDM, } 13 \text { born in } \\
\text { Sweden and } 14 \\
\text { born in the Middle } \\
\text { East. }\end{array}$ & $\begin{array}{l}\text { Patients evaluation } \\
\text { of a specialised } \\
\text { diabetes clinic for } \\
\text { management of } \\
\text { women with GDM } \\
\text { born in Sweden } \\
\text { and the Middle } \\
\text { East and its } \\
\text { contribution to a } \\
\text { decreased level of } \\
\text { stress and } \\
\text { improved coping } \\
\text { capability to } \\
\text { promote health in } \\
\text { patients receiving } \\
\text { care }\end{array}$ \\
\hline $\begin{array}{l}\text { Hjelm et al } \\
2008^{37}\end{array}$ & $\begin{array}{l}\text { Qualitative (no } \\
\text { specific mention }\end{array}$ & $\begin{array}{l}\text { An explorative } \\
\text { qualitative study }\end{array}$ & $\begin{array}{l}\text { A consecutive } \\
\text { sample of }\end{array}$ & $\begin{array}{l}\text { Beliefs about } \\
\text { health, illness and }\end{array}$ \\
\hline
\end{tabular}




\begin{tabular}{|c|c|c|c|c|}
\hline & $\begin{array}{l}\text { of philosophical } \\
\text { framework) }\end{array}$ & $\begin{array}{l}\text { using } \\
\text { structured } \\
\text { interviews. }\end{array}$ & $\begin{array}{l}\text { Swedish women } \\
\text { diagnosed with } \\
\text { GDM; } \\
\text { managed in clinic } \\
\text { A and ten } \\
\text { managed in clinic } \\
\text { B. }\end{array}$ & $\begin{array}{l}\text { health care in } \\
\text { women with GDM } \\
\text { managed in two } \\
\text { different } \\
\text { organisations } \\
\text { based on } \\
\text { diabetology or } \\
\text { obstetrics. }\end{array}$ \\
\hline $\begin{array}{l}\text { Horrocks } \\
2009^{48}\end{array}$ & $\begin{array}{l}\text { Grounded } \\
\text { theory }\end{array}$ & $\begin{array}{l}\text { Semi-structured } \\
\text { interviews }\end{array}$ & $\begin{array}{l}\text { Nine white British } \\
\text { women who were } \\
\text { first-time mothers } \\
\text { and currently } \\
\text { pregnant and } \\
\text { receiving } \\
\text { specialist support } \\
\text { from a diabetes } \\
\text { antenatal clinic }\end{array}$ & $\begin{array}{l}\text { The psychological } \\
\text { and emotional } \\
\text { impact } \\
\text { pregnancy in the } \\
\text { context of Type } 1 \\
\text { diabetes for first } \\
\text { time mothers. }\end{array}$ \\
\hline $\begin{array}{l}\text { Lavender et } \\
\text { al } 2010^{44}\end{array}$ & $\begin{array}{l}\text { Hermeneutic } \\
\text { phenomenologic } \\
\text { al approach } \\
\text { based on } \\
\text { Heidegger }\end{array}$ & $\begin{array}{l}\text { Focus groups and } \\
\text { one-to-one } \\
\text { interviews }\end{array}$ & $\begin{array}{l}22 \text { women with } \\
\text { Type } 1 \text { or Type } 2 \\
\text { diabetes of } \\
\text { different parity } \\
\text { and ethnicity } \\
\text { (Note only } 14 \\
\text { pregnant at } \\
\text { interview - only } \\
\text { these included) }\end{array}$ & $\begin{array}{l}\text { To explore the } \\
\text { experiences of } \\
\text { White British and } \\
\text { South East Asian } \\
\text { women with Type } 1 \\
\text { and Type } 2 \\
\text { diabetes, and the } \\
\text { perceived impact of } \\
\text { diabetes on their } \\
\text { reproductive } \\
\text { health. }\end{array}$ \\
\hline
\end{tabular}




\begin{tabular}{|c|c|c|c|c|}
\hline $\begin{array}{l}\text { Lawson \& } \\
\text { Rajaram } \\
1994^{51}\end{array}$ & Ethnography & $\begin{array}{l}\text { Semi-structured } \\
\text { interviews }\end{array}$ & $\begin{array}{l}17 \text { women } \\
\text { between the ages } \\
\text { of } 24 \text { and } 36 \text {, with } \\
\text { no previous } \\
\text { history of GDM }\end{array}$ & $\begin{array}{l}\text { The meaning } \\
\text { women attach to } \\
\text { GDM }\end{array}$ \\
\hline $\begin{array}{l}\text { Neufeld } \\
2011^{38}\end{array}$ & $\begin{array}{l}\text { Qualitative (no } \\
\text { specific mention } \\
\text { of philosophical } \\
\text { framework) }\end{array}$ & $\begin{array}{l}\text { Semi-structured } \\
\text { explanatory model } \\
\text { interviews }\end{array}$ & $\begin{array}{l}29 \text { self-declared } \\
\text { Aboriginal women } \\
\text { who had received } \\
\text { a diagnosis of } \\
\text { GDM within the } \\
\text { last five years - } 16 \\
\text { pregnant at time } \\
\text { of interview (two } \\
\text { of these without } \\
\text { current } \\
\text { diagnosis). Of the } \\
14 \text { pregnant and } \\
\text { diagnosed with } \\
\text { diabetes four with } \\
\text { Type } 2 \text { diabetes } \\
\text { and ten with } \\
\text { current diagnosis } \\
\text { of GDM }\end{array}$ & $\begin{array}{l}\text { How Aboriginal } \\
\text { women in an urban } \\
\text { setting perceive } \\
\text { dietary treatment } \\
\text { recommendations } \\
\text { associated with } \\
\text { GDM. }\end{array}$ \\
\hline $\begin{array}{l}\text { Persson et al } \\
2010^{49}\end{array}$ & $\begin{array}{l}\text { Grounded } \\
\text { Theory }\end{array}$ & $\begin{array}{l}\text { Semi-structured } \\
\text { interviews }\end{array}$ & $\begin{array}{l}\text { Ten women - all } \\
\text { except one of } \\
\text { Swedish origin - } \\
\text { one immigrant } \\
\text { who had lived in }\end{array}$ & $\begin{array}{l}\text { The experiences of } \\
\text { pregnant women } \\
\text { being diagnosed } \\
\text { with GDM and its } \\
\text { impact on their }\end{array}$ \\
\hline
\end{tabular}




\begin{tabular}{|c|c|c|c|c|}
\hline & & & $\begin{array}{l}\text { Sweden since her } \\
\text { teens, was well } \\
\text { established within } \\
\text { Swedish society } \\
\text { and was fluent in } \\
\text { Swedish }\end{array}$ & daily life \\
\hline $\begin{array}{l}\text { Richmond } \\
2009^{45}\end{array}$ & $\begin{array}{l}\text { A qualitative } \\
\text { phenomenologic } \\
\text { al methodology } \\
\text { following } \\
\text { Husserl's } \\
\text { philosophy }\end{array}$ & Interviews & $\begin{array}{l}11 \text { women with } \\
\text { Type } 1 \text { diabetes } \\
\text { attending the joint } \\
\text { obstetric/diabetic } \\
\text { clinic in a district } \\
\text { general hospital } \\
\text { between October } \\
2001 \text { and April } \\
2004\end{array}$ & $\begin{array}{l}\text { How identity was } \\
\text { linked to the } \\
\text { improvement, and } \\
\text { deterioration, of } \\
\text { blood glucose } \\
\text { control in pregnant } \\
\text { women with Type } 1 \\
\text { diabetes. }\end{array}$ \\
\hline $\begin{array}{l}\text { Sheffer } \\
2000^{46}\end{array}$ & $\begin{array}{l}\text { Interpretive } \\
\text { phenomenology }\end{array}$ & $\begin{array}{l}\text { Audio taped semi- } \\
\text { focused one-on-one } \\
\text { interviews }\end{array}$ & $\begin{array}{l}\text { Eight participants, } \\
\text { who had lived } \\
\text { with IDDM from } \\
\text { four to twenty } \\
\text { years }\end{array}$ & $\begin{array}{l}\text { The lived } \\
\text { experience of } \\
\text { pregnancy for } \\
\text { women with pre- } \\
\text { existing insulin } \\
\text { dependent } \\
\text { diabetes mellitus } \\
\text { (IDDM) }\end{array}$ \\
\hline $\begin{array}{l}\text { Stenhouse } \\
\text { et al } 2012^{50}\end{array}$ & $\begin{array}{l}\text { Grounded } \\
\text { theory }\end{array}$ & $\begin{array}{l}\text { In-depth interviews } \\
\text { utilising one-to-one, } \\
\text { dyad and group } \\
\text { interviews }\end{array}$ & $\begin{array}{l}12 \text { pregnant } \\
\text { women with Type } \\
1 \text { diabetes and } \\
\text { Type } 2 \text { diabetes } \\
\text { and eight of their }\end{array}$ & $\begin{array}{l}\text { The experience of } \\
\text { maternity care } \\
\text { services used by } \\
\text { women whose } \\
\text { pregnancy is }\end{array}$ \\
\hline
\end{tabular}




\begin{tabular}{|l|l|l|l|l|}
\hline & & & significant others & complicated by pre- \\
existing diabetes
\end{tabular}

\section{Findings}

From the 22 included studies 153 (four unsupported) findings were extracted. These findings and studies they were extracted from are detailed below.

Paper 1: Lived experience of gestational diabetes mellitus among immigrant South Asian women in Australia. ${ }^{30}$

This paper by Bandyopadhyay et al. $2011^{30}$ aimed to investigate the experiences and understandings of South Asian women in Melbourne, Australia, after diagnosis with GDM. The information was gathered by face-to-face in-depth interview at two time points, following GDM diagnosis, and at six weeks post-partum and analysed by thematic analysis. This paper scored five out of ten in the QARI critical appraisal tool. Participants were 17 immigrant women from South Asia diagnosed with GDM attending a tertiary maternity hospital in Melbourne, Australia.

Finding $1 \quad$ Response to GDM diagnosis (Credibility - Credible)

Illustration "upset" - gdm- p362

Finding 2 Difficulties experienced with dietary advice (Credibility -Unequivocal)

Illustration

'your diet is restricted, and the quantity is reduced, and you have limited choice, then the baby does not get proper nutrition to grow' - gdm- p362

Finding $3 \quad$ Weight issues and exercise (Credibility - Credible) 
Illustration

Finding 4

Illustration

Finding 5

Illustration

Finding 6

Illustration

Finding 7

Illustration
Women described feeling weak after exercising, their muscles "pained" and that "can't be good for the baby or the mother". - gdm- p363

Concern for the baby (Credibility -Unequivocal)

"your only thought is for the baby and for a favourable pregnancy outcome gdm".-p363

Achieving a "good reading" and response to insulin (Credibility - Unsupported)

Their preoccupation with testing and maintaining good sugar levels was because of their fear about injecting insulin. The worst part of being diagnosed with GDM for women was that they required insulin to control their blood glucose levels. - gdm - p363

Positive effects on well-being and women's views on care and information provision (Credibility - Unsupported)

Although they were happy with the care they received, they nevertheless felt overwhelmed by frequent visits - gdm- p363

Maintaining changes (Credibility - Unsupported)

Women were unsure about maintaining their current diet and lifestyle pattern postnatally, as they felt that lifetime control and management was challenging. - gdm- p 363

\section{Paper 2: Pregnancy and diabetes: how women handle the challenges. ${ }^{39}$}

This paper based on Husserlian phenomenology by Berg $2005^{39}$ aimed to investigate the experience of women with Type 1 diabetes and how they handle their challenges during pregnancy. This paper 
scored nine out of ten in the QARI critical appraisal tool. Information was gathered through open interview and analysed with thematic analysis. Theme and subtheme were used as the finding as this was considered more illustrative than the theme by itself. Participants were 18 pregnant women (ten primiparous and eight multiparous) with Type 1 diabetes aged between 25 and 38 years at a University hospital in the Western region of Sweden

Finding $1 \quad$ Meaningfulness/meaninglessness: Acceptance (Credibility - Unequivocal)

Illustration

As soon as one sees a poor value, you know that there is another person being affected. That is what probably results in anxiety, but at the same time it is a challenge. . . I know that I must do what I can for it to be healthy. (Paula Type 1 diabetic) p26

Finding 2 Meaningfulness/meaninglessness: Ambivalence (Credibility - Unequivocal)

She explained what happens in my body, et cetera, but very little about me as a person, what happens in my head. Very little about what I actually think Illustration about being pregnant and whether it was planned. How I felt about it. . . One can still be ambivalent - did I really want this to happen? (Fanny - Type 1 diabetic) p26

Finding $3 \quad$ Meaningfulness/meaninglessness: Hope (Credibility - Unequivocal)

Illustration

I know now that I can have healthy children despite having diabetes ... I know that I can influence it (Sara - Type 1 diabetic) p26

Finding $4 \quad$ Meaningfulness/meaninglessness: Hopelessness (Credibility - Unequivocal)

Illustration

Something could go wrong for somebody and that somebody will probably be me. This is confirmed by the statistics (Paula - Type 1 diabetic) p26

Finding 5 Meaningfulness/meaninglessness: Confirmed normality (Credibility - 
Unequivocal)

Illustration

Finding 6 Meaningfulness/meaninglessness: Fortified malaise (Credibility - Unequivocal)

The negative aspect was that of being special-special. It had the opposite effect on me. The feeling of being sick came back. So far, everything had gone Illustration so well and now it was just waiting for the big disappointment, because something had to happen. The delivery feels like one big complication and the baby is probably huge. (Gabriella - Type 1 diabetic) p26

Finding 7 Reconciliation/Conflict: Acceptance (Credibility - Unequivocal)

You live with the disease as part of the fullness of life. . . I have diabetes Illustration because it is part of my life. And now I am pregnant. (Rosa - Type 1 diabetic) p27

Finding 8 Reconciliation/Conflict: opposition (Credibility - Unequivocal)

Blood sugar lives its own life. .., it doesn't matter what I do - I hardly dare Illustration move. . . I haven't tried to find a solution because I don't think there is one. (Ingrid - Type 1 diabetic) p27

Finding 9 Reconciliation/Conflict: self-understanding (Credibility - Unequivocal)

When I became pregnant for the first time, I didn't realise the implications. So, Illustration before my second child, I understood that it required a certain mental awareness before starting this once again. . . It largely concerns knowing 
one's own limits and weaknesses. (Olivia - Type 1 diabetic) p27

Finding 10

Illustration

Finding 11

Illustration

Finding 12

Finding 13

Illustration

Finding 14

Illustration
Reconciliation/Conflict: Lack of self-understanding (Credibility - Unequivocal)

It makes no difference what one changes because the blood glucose seems to have a life of its own anyway (Ingrid - Type 1 diabetic) p27

Reconciliation/Conflict: Rejoice in the present (Credibility - Unequivocal)

We must not build up a lot around it in case something should go wrong, but should try to be happy about the situation as it is. To try to push the diabetes aside and just be pregnant. I feel an inner security. Oh! It feels great throughout my whole body. (Nancy - Type 1 diabetic) p28

Reconciliation/Conflict: suppressed joy (Credibility - Unequivocal)

One doesn't dare to be too happy in advance, not before everything is seen to be okay, when the baby is born and you can see that it is a healthy child (Sara - Type 1 diabetic) p28

Shared control/unwillingly controlled: responsibility/surrendered responsibility (Credibility - Unequivocal)

It is me who is steering the diabetes and not the diabetes steering me. . . It's me who is in control. It is me who has responsibility for this. . . I don't feel like a slave. Being able to measure blood sugar is a benefit. It gives me control. What would it have been otherwise? (Nancy - Type 1 diabetic) p28

Shared control/unwillingly controlled: health-care staff as a supportive resource or as a controlling factor (Credibility - Unequivocal)

You have to demonstrate how you have looked after yourself and how you live. Sometimes one may feel that, no, I don't want to go there and take a lot of 
samples - I just want to skip the lot. If it's working well, you can be proud to show your blood sugar book. But if it's not so good, then you would prefer to have left it at home. You need to have help to realise that you are pregnant and what is happening and that one can get this thing about samples out of one's head. (Maria - Type 1 diabetic) p28

Finding 15 Shared control/unwillingly controlled: Relatives and employers who provide support or increase the pressure (Credibility - Unequivocal)

Illustration Support is being there. When, for example, I am worried, then he says that everything is okay, it will be okay.(Rosa - Type 1 diabetic) p29

\section{Paper 3: Pregnancy and diabetes--a hermeneutic phenomenological study of women's experiences. $^{40}$}

This paper based on hermeneutic phenomenology by Berg and Honkasalo ${ }^{40}$ aimed to investigate women's experiences of being pregnant and having insulin-dependent diabetes mellitus (IDDM), particularly regarding what the crucial elements of the experience are during pregnancy. The information was gathered by open interview and analysed with thematic analysis partially informed by van Manen. Participants were 14 pregnant women with pre-existing insulin dependent diabetes aged 25-38 years having treatment in the antenatal care unit of a district hospital in Sweden. This article scored eight out of ten in the QARI critical appraisal tool.

Finding $1 \quad$ Objectification: an unwell body - a risk (Credibility - Unequivocal)

Illustration $\quad$ You're told about the risks at once (interviewee 1 - Type 1 diabetic) p41

Finding $2 \quad$ Objectification: almost like getting diabetes again (Credibility - Unequivocal)

Illustration the hard thing was that, when I got pregnant, I suddenly had to think about my 
diabetes a lot, how to spend my days, what to choose to eat and when to eat it...it felt a bit like when I first got diabetes....It became a crisis...It's like mourning...I haven't finished crying yet...almost like a burden (Interviewee 7 Type 1 diabetic) p41

Finding 3 Objectification: you'll get hit sooner or later (Credibility - Unequivocal)

Illustration

It can't run smooth all the way, something will happen, you'll get hit sooner or later (Interviewee 7 - Type 1 diabetic) p42

Finding 4

Loss of control: wishing for a normal life with control (Credibility Unequivocal)

What I mostly wish, is that I carry the baby to full term and that I have a normal Illustration delivery...It would be so exciting if the diabetes is one thing on its own and now I'm going to give birth, not that I give birth because of the diabetes (Interviewee 12 - Type 1 diabetic) p42

Finding 5 Loss of control: Not knowing my own body (Credibility - Unequivocal)

I like to be in control of my body, and in a way you can't when you have another life inside of you making a mess...like with the blood sugars and Illustration such...and it makes me a bit...well, insufficient, hysterical...and very frustrated (interviewee 11 - Type 1 diabetic) p42

Finding 6 Loss of control: controlled and dependent (Credibility - Unequivocal)

the blood sugar controls everything...I always have to take a blood sample Illustration before I do anything...It is because I am pregnant, it is on my mind all the time, asleep as well as awake (Interviewee 12 - Type 1 diabetic) p43

Finding 7 Exaggerated responsibility: Constant worry (Credibility - Unequivocal) 
I'm so scared and frightened that the ultrasound will show something's wrong

Illustration with the child or a child with two heads, such are the nightmares I have...I'm so

Finding 8 scared my blood glucose levels have caused problems and abnormalities. (Interviewee 11 - Type 1 diabetic) p44

Exaggerated responsibility: Constantly under pressure (Credibility Unequivocal)

I do feel insufficient. If you add it all up, I think that's a general feeling I've had all along...to feel you're inadequate. I think it's linked together with a diabetic's Illustration bad conscience. You can make it up to a point....under some pressure, you may slightly improve a bit more, but somewhere along the line you've reached your limit. I think I found that the hardest (Interviewee 6 - Type 1 diabetic) p44

Finding 9 Exaggerated responsibility: constant self-blame (Credibility - Unequivocal)

You constantly have a slice of bad conscience. You may always improve. You Illustration easily feel guilty when you have got diabetes. If anything's wrong with the child or if something had shown up at the ultrasound, you would easily have blamed yourself a lot (Interviewee 7 - Type 1 diabetic) p44

\section{Paper 4: Perceptions of risk for the development of Type 2 diabetes in African-American women with gestational diabetes. ${ }^{31}$}

This qualitative thesis by Bieda $2009^{31}$ aimed to investigate African-American mothers' knowledge of Type 2 diabetes risk as well as their intentions to participate in preventive behaviours after a pregnancy complicated by GDM. The information was gathered through face-to-face, semi-structured interview and analysed with thematic analysis. The emphasis of this study is regarding subsequent development of Type 2 diabetes, but there are useful findings regarding emotional response to 
diagnosis and treatment, barriers/enablers to treatment and preventative behaviours. Participants were 25 African- American mothers diagnosed with GDM at two high-risk prenatal clinics in Detroit, MI. The themes developed by the study authors were broader than diabetes, therefore only those themes specific to GDM were extracted. This paper scored eight out of ten in the QARI critical appraisal tool.

Finding 1 Emotional Responses to the Diagnosis of GDM (Credibility - Unequivocal)

Illustration

I was nervous because I didn't understand, like what is gestational diabetes- It was something I had never heard of (\#25 - gdm).p106

Finding 2 Causes of GDM (Credibility - Unequivocal)

The lack of exercise and you know, putting on weight, eating, being pregnant Illustration in general, and not having that, that activity and kind of function to fall back on may have contributed to it. Because you, you're not burning off the calories, your body is storing a lot more fat. (\#14 - gdm) p107-8

Finding 3 Sources of GDM Knowledge (Credibility - Unequivocal)

The dietician, she really taught me a lot you know. I talked to her - she told me Illustration how to break down everything and all that. So, they really do a good job (\#3 gdm).p109

Finding $4 \quad$ Effects of GDM later in life (Credibility - Unequivocal)

I will be used to it - all that stuff they make me do. I'll probably do that for the Illustration rest of my life - watching my weight and doing more exercising. Cuz there's a chance that it will come back (\#3 - gdm). p111 


\section{Paper 5: Perceived barriers to treatment adherence among pregnant African American women}

with diabetes. ${ }^{32}$

This thesis by Brooks $2002^{32}$ aimed to investigate aspects of the diabetes treatment regimen that are most difficult to adhere to among pregnant African-American women with diabetes. The information was gathered by questionnaires and qualitative open ended questioning with no specific philosophy mentioned and analysed by content analysis utilising NUD*IST 4.0 software. Participants were 32 African American women aged 18 to 49 with pregnancies complicated by Type 2 or GDM. Only data from direct questioning has been included in this review. This paper scored seven out of ten in the QARI critical appraisal tool.

Finding $1 \quad$ Exercise: Difficulty with exercise therapy (Credibility - Unequivocal)

Illustration

The hardest thing for me is exercising because most of the time I'm tired Type 2 diabetes or GDM using insulin p73

Finding 2

Negative feelings: depression, anxiety, anger or fear of diabetes or taking insulin (Credibility - Unequivocal)

It's a depressing thing, it is very depressing to me 'cause they tell you all the

Illustration things that could happen if you don't take the insulin and you be worried already, stressed out its not fun. Make you want to hurry up and have the baby - Type 2 diabetes or GDM using insulin - p73

Finding 3 Side effects: Negative side effects associated with pregnancy and insulin (Credibility - Unequivocal)

I don't know if it's because of the diabetes that I'm so tired. I just know I don't

Illustration even feel like moving to even check my numbers or anything - Type 2 diabetes or GDM using insulin - p72 
Finding 4

Glucose monitoring: Difficulty with finger pricks to monitor glucose level (Credibility - Unequivocal)

I don't like pricking my finger either. The excessive holes in my fingers, not

Illustration having a chance to let them heal, trying to let them and stuff and don't have time to - Type 2 diabetes or GDM using insulin - p72

Finding 5

Diet: Difficulty with diet therapy (Credibility - Unequivocal)

What I find most difficult is the diet because you are on such a small amount of carbohydrates and then after you finish eating them you are still hungry. Then

Illustration

Finding 6

Insulin injections: Difficulty with giving self insulin injections (Credibility Unequivocal)

The amount of insulin, how many shots I take is tiresome over a long period of Illustration you can't eat anything until your snack ....and when your snack is only like two carbohydrates so you only get two crackers or something like that you're still hungry until lunch - Type 2 diabetes or GDM using insulin - p70 time. It gets real tiresome. They are always increasing it no matter what you

eat it's more and more, more - Type 2 diabetes or GDM using insulin - p70

\section{Paper 6 - Women's experiences of gestational diabetes self-management: A qualitative study. ${ }^{41}$}

This paper by Carolan $2013^{41}$ aimed to investigate women's experiences of self-managing their GDM. The information was gathered through semi-structured interviews and one focus group and analysed with content analysis informed by van Manen. This is article scored ten out of ten in the QARI critical appraisal tool. Participants were 15 women being treated at a diabetes clinic in a metropolitan maternity unit in Australia and representative of population demographics in the area and included 
women from Caucasian, Asian, South-Asian, Indian and Arabic backgrounds, with a diagnosis of GDM and who had experienced self-management of their condition.

Finding 1

Finding 2

Illustration

Finding 3

Illustration

Finding 4

Illustration
The shock of diagnosis (Credibility - Unequivocal)

I was very surprised and very upset to be diagnosed. I felt a little bit of a failure. I knew that I had brought it on myself because of being overweight ... (Lili - gdm) p3

Coming to terms with GDM (Credibility - Unequivocal)

(I just thought), this is what l've got to do and it's for the baby and whatever. So just do it ... so just get on with it and just do it ... (Leanne - gdm) p4

Working it out and learning new strategies (Credibility - Unequivocal)

As the pregnancy went on I would have to eat less and less carbs to get the same results, and also in the day at different times I would get different results for the same meals. So it wasn't exactly just stick to your diet and then you're fine. By measuring your blood you could see exactly what was going on, if something was going wrong and then change it. So it was a good system ... you were in control. Also... like, I could have two slices of bread for breakfast if I wanted, but I could definitely not have two slices of bread in the evening (that) would send my blood sugar over the limit. (Lili - gdm) p5

Feeling better: looking to a healthier future (Credibility - Unequivocal)

And it's just, health-wise you're definitely, you get your own diet working a little bit better because I never thought that I was in the category for getting adult diabetes, never occurred to me. So the information that that's something that I need to be careful about I think is very helpful. (Lili - gdm) p6 
Finding 5

Illustration
Having a supportive environment (Credibility - Unequivocal)

Now actually my husband comes for a walk with me as well -...he's kind of like me: he doesn't eat vegetables and ...he still doesn't eat vegetables but he's now cooking more for me and he's healthier because he doesn't, because if he's going to eat junk food that's just going to make me jealous. So he's kind of trying to eat healthy as well for me. (Flora - gdm) p6

Paper 7: Women's experiences of factors that facilitate or inhibit gestational diabetes selfmanagement. ${ }^{42}$

This paper by Carolan et al. $2012^{42}$ aimed to investigate the factors that facilitated or inhibited GDM self-management among women in a socially deprived area. An Interpretative phenomenology design was used and information gathered through semi-structured interviews and a focus group and analysed with thematic analysis. Participants were 15 pregnant women, with a diagnosis of GDM, at 28--38 weeks gestation from an Australian multi-ethnic population in the Western region of Melbourne, Australia.

This article scored nine out of ten in the QARI critical appraisal tool.

Finding 1

Barriers to GDM self-management: Social constraints: Festivities and social functions (Credibility - Unequivocal)

I'm myself Indian and we have lot of Indian sweets and that sort of thing. When I didn't know that I was diabetic I was eating sweets as well, like Indian

Illustration proper sweets. And just the religious festivals and eating certain foods, but now l've stopped that as well. Actually it's not compulsory. It's up to you if you want to eat it or not. You just feel a bit out of things - Leni (GDM) - p9 
Finding 2

Illustration

Finding 3

Finding 4

Illustration

Finding 5

Illustration

Finding 6
Barriers to GDM self-management: Social constraints: Finding the balance (Credibility - Unequivocal)

I don't cook the food - it is bad to say I won't eat (the food that her mother-inlaw cooks) - rice - she says it is healthy for the baby - Suji (GDM) - p8

Barriers to GDM self-management: Social constraints: Disruption to the family (Credibility - Unequivocal)

We had three different dinners every night- I could have eaten the same thing without the carbs - but so boring - made the choice - and you may not have the budget to buy crazy expensive things - but you have to expect a little bit more - maybe buying organic, interesting vegetables. Do something nice with it, you know, just make mealtimes feel nice - Lili (GDM) - p8

Barriers to GDM self-management: Time pressures: Finding time for everything (Credibility - Unequivocal)

The doctor said to walk for an hour after meals. I mean, I start (work) at seven and finish at three and then I've got to pick my daughter up from school. Trying to fit that in, it's just - I think, well, God, I'll be dead by the time I get back, you know Leanne (GDM) - p7

Barriers to GDM self-management: Physical constraints (Credibility Unequivocal)

Because I have had pelvic pain, I haven't been able to move a lot. And I have been quite ill - Tran (GDM) - p8

Barriers to GDM self-management: Time pressures: The urgency of immediate change (Credibility - Unequivocal) 
First week, I mean they told me which foods to avoid and so forth, but again that was very limited. I wasn't eating very much anyway during my pregnancy quite a few scores [BGL values] were over what they suggested. I hadn't really Illustration looked after what I had been eating -I really wasn't trying that first week I guess - I didn't think it would affect the sugar levels so much. She (diabetes educator) thought it was very bad - They suggested insulin after that first week and I didn't want that at all. I did try to explain, ... I understand why they are high. I need another chance - Tran (GDM) - p6

Finding 7

Barriers to GDM self-management: Limited comprehension: Limited understanding of GDM (Credibility - Unequivocal)

They didn't tell me what's the side effects for the baby. They just told me, You've got diabetes, you'd better control with this and that. But they didn't tell Illustration me, like, what are the side effects for having sugar levels up like why it's really important to monitor your sugar levels - Prani (GDM) - p9

Barriers to GDM self-management: Limited comprehension: Limited Finding 8 understanding of GDM self-management requirements (Credibility Unequivocal)

I did get appointments where I got some information. But I found it more outside of those appointments. I mean it was helpful, but it wasn't really in Illustration depth. Well like the food for instance, it wasn't a very extensive list of what you could eat, it was very limited and most of the food I eat wasn't on it - Tran (GDM) - p10

Finding 9

Barriers to GDM self-management: Insulin as an easier option (Credibility Unequivocal)

Illustration Yeah, it's painful, I have to say, but it really works. I have to say that is a good 
thing. Because it's easier to help me manage my diet and control my sugar level... Yeah, the drugs (insulin) can help my condition it was so hard to deal with cravings - Xioquan (GDM) - p10

Finding 10

Illustration

Finding 11

Finding 12

Illustration

Finding 13

Illustration
Facilitators for GDM self-management - the baby (Credibility - Unequivocal)

I was very determined to make sure I could do absolutely anything within my power to not allow any, something to happen to the baby. I knew I had brought it on myself by being overweight...I felt very responsible....- Lili (GDM) - p11

Facilitators for GDM self-management - support (Credibility - Unequivocal)

Well I think I could, I probably could do it on my own but having that support base, having someone kind of do it with you ... makes you feel you're not alone doing it...- Margaret (GDM) - p11

Facilitators for GDM self-management: realisation: Realising I had to do it myself (Credibility - Unequivocal)

I realised it was up to me - no one else - there was no point in cheating - I would be just cheating myself - Lili (GDM) - p12

Facilitators for GDM self-management: realisation: An opportunity to prevent Type 2 diabetes (Credibility - Unequivocal)

It's good to learn about it, otherwise the way I was going; definitely I would have diabetes 2. I didn't know about it but now I can control myself and...Yeah, because the way I'm not having anything, I was having heaps of sugars every day - Leanne (GDM) - p13

Paper 8: Gestational Diabetes: The Meaning of an At-Risk Pregnancy. ${ }^{43}$ 
This Heideggerian-Gadamerian hermeneutic phenomenological paper by Evans \& O'Brien $2005^{43}$ aimed to investigate are the meanings that pregnant women attach to their experience of a pregnancy that is judged at risk as a consequence of GDM. The information was gathered through conversational interviews and analysed by a reflective process, consistent with the guidelines of thematic analysis. Participants were 12 pregnant Canadian women from varying cultural, social, and educational backgrounds who were diagnosed with and being treated for diabetes at an outpatient diabetic clinic in a large urban teaching hospital. One woman had Type 1 diabetes - others with GDM, and distinction between them was not made. This study scored eight out of ten in the QARI critical appraisal tool.

Finding $1 \quad$ Balancing (Credibility - Unequivocal)

Illustration

I found that in the beginning it was hard, but once you get used to it it's not hard anymore. It's really routine - Francine - GDM - p72

Finding $2 \quad$ Being a Responsible Mother (Credibility - Unequivocal)

It's not just yourself. I might be feeling fine and it is affecting the baby. It's not Illustration just yourself you're thinking about. You have one that is totally dependent on you to keep it safe - Audrey - GDM - p73

Finding 3 Living a Controlled Pregnancy (Credibility - Unequivocal)

Everything changes when you become diabetic because if you are not in Illustration control, you can't go on that hike. You can't do things spontaneously. You can't go for wings after work because you've got to think, Well, what'd you eat for lunch? - Lynne - GDM - p72

Finding 4 Being Transformed (Credibility - Unequivocal) 
I feel empowered and stuff after this. Like in the past few years I haven't

Illustration looked after my body as well as I should. I've always struggled with my weight. So I feel like after the baby is born I will get straightened out. So it's been positive. - Helen - GDM - p74

\section{Paper 9: Planning for a healthier birth and beyond: Strategies women use to manage gestational diabetes. ${ }^{47}$}

This grounded theory thesis by Hamel $2003^{47}$ aimed to investigate the experience of being a woman diagnosed with GDM. The information was gathered by open-ended, semi-structured interviews and analysed by constant comparative analysis developed by Glaser and Strauss. There were seven participants residing in Northern New England having a diagnosis of GDM. This thesis scored ten out of ten in the QARI critical appraisal tool.

Finding $1 \quad$ Getting diagnosed with Gestational Diabetes (Credibility - Unequivocal)

Illustration

I have not had any friends or family that have been diagnosed, so I think that I freaked out a little bit more than a lot of people ... I was pretty panic-stricken. Omigosh! What does this mean for the baby? What does this mean for me?

Will the baby be healthy, or be okay? - Emily - GDM - p81

Finding 2

Regaining a sense of control - Stress (Credibility - Unequivocal)

These are all fears of the unknown, particularly if you are like me and did not know someone who had had it before ... I didn't know how my baby would Illustration be, I didn't know if I would be okay, and I didn't know what I would need to do to cope ... That's where the emotion came out with the whole gestational diabetes diagnosis and treatment, because I could potentially be jeopardising 
my new baby. My own body might not be the safest place for my child. - Emily - GDM - p89

Finding 3

Illustration

Finding 4

Illustration

Finding 5

Illustration

Finding 6
Regaining a sense of control: health of both (Credibility - Unequivocal)

At least it's something to work towards, that if I do this, and I work hard, then I might be able to get this, too, but at the same time not set myself up. Even if I work very hard and it doesn't end up that way, it's not my fault, at least I was working towards it, you know. That's my ultimate goal. - Emily - GDM - p96

Regaining a sense of control: Perceived threat (Credibility - Unequivocal)

My body frustrates me when I can do the exact same thing for diet, get my walk in, and, after, my blood sugar is down - and then it all of a sudden is up again; - Sara - GDM - p97

Regaining a sense of control: Need for information (Credibility - Unequivocal)

I was looking back at my original interview, and, you know, at first it's the fear of the absolute unknown, because I had no idea what to expect with this. Then it was fear: ...Omigosh! So many things I need to be aware of...; I don't think that people are aware that testing your blood sugars is one piece and testing your ketone levels and your urine are another piece, because the decreased ketones can lead to indications of brain development abnormalities in the fetus if your ketones are too high. And so it was scary, even though I still had information, but not having the education to know what levels would still be acceptable, and that the fetus's - the baby's -chances would still be okay ... [getting that information] was what was the most helpful for me. - Emily - GDM $-\mathrm{p} 100$

Regaining a sense of control: Need for Social Support (Credibility - 
Unequivocal)

My husband is available and is very supportive. He reminds me to have my snacks and to make sure I am eating, and he also supports [me] to make sure I am getting out for some exercise. We have a treadmill at home ... I have someone who will come and will sit with me and talk about different things ... She is just another support person, actually ... If there was some kind of a support group available, too [it would be helpful]. I mean, gestational diabetes

Illustration would be very interesting. Either people that have had it or people that are going through it would be great. I know that was one thing that I would have really appreciated. Having somebody to talk to ... or to phone ... Now that I've experienced it, if somebody had a question for different snack ideas, I ate a lot of cheese and crackers. Or - you know what I mean. Just something to let them know how I did. What I did to manage it, would be [helpful]. - Sarah GDM - p99

Finding 7 Planning for a Healthier Birth and Beyond (Credibility - Unequivocal)

For me I think it is . . . the pregnancy. I am hoping - I mean, I know there is always a chance that after I have the baby I will have to continue this, but I think now that I have been though it I will be eating different anyway. I think it

Illustration really made me take a look at what a serving is. I was heavy before I got pregnant, and I haven't gone back to my prepregnancy weight yet, so in the 9 months that I have been pregnant I haven't gained anything, which has kind of freaked me out. But with the gestational diabetes I am eating differently than I would have before I was pregnant anyway. - Sara - GDM -p114

Finding 8

Planning for a Healthier Birth and Beyond: Commitment to the Fetus's WellBeing (Credibility - Unequivocal) 
I test my blood four times a day. I check for ketones each morning and then I

Illustration do my fasting blood, and then 2 hours after breakfast, lunch and dinner. I

Finding 9 administer ... the insulin . . . This isn't about me, it's about the baby, and that makes a load of difference. - Emily - GDM - p115

Planning for a Healthier Birth and Beyond: Concern for Health of Self (Credibility - Unequivocal)

I think it is definitely a fair warning for me, to watch what I do. I've always had a weight problem growing up, so it's one of those deals where I know it's all Illustration related, what you're eating, what you're not eating, whether you're exercising or you're not ... It's been a learning experience. - Sarah - GDM - p127

Finding 10 Planning for a Healthier Birth and Beyond: Support and Information (Credibility - Unequivocal)

[The members of the health care team need to] reinforce each other, definitely ... I've asked the same questions of three different people at three different times, none of them sitting in the room together, and received the same Illustration answer, and I cannot even tell you how much that's meant to me . . I I have so many doctors' appointments in a week, you know, I usually have about three appointments in a week, one with the nurse, one with the nutritionist, and one with my OB-GYN. - Emily - GDM - p133

Paper 10: Women with gestational diabetes in Vietnam: a qualitative study to determine attitudes and health behaviours. ${ }^{33}$

This study by Hirst et al. $2012^{33}$ aimed to investigate attitudes and health behaviours of pregnant women with GDM in Vietnam. The information was gathered by focus group interviews and analysed 
with thematic analysis. Participants were 34 pregnant women with GDM aged over 18 years and treated at Hung Vuong Hospital, Ho Chi Minh City, Vietnam. There were four focus groups. This study scored eight out of ten in the QARI critical appraisal tool.

Finding 1

Illustration

Finding 2

Illustration

Finding 3

Illustration

Finding 4

Illustration

Finding 5

Illustration
Confusion and concern about the diagnosis of GDM (Credibility Unequivocal)

My doctor did not explain much about this condition. She only noted this condition was resulted partly from gene and partly the food we consume nowadays. Our food contains many kinds of chemicals that may cause diabetes. I could not understand the disease - GDM - p3

Fear of adverse effects from GDM (Credibility - Unequivocal)

It may slow baby's growth, sudden death. . .babies easily have low blood sugar levels or more likely be born with abnormalities - GDM - p4

Dietary changes - I think it's so tough for us (Credibility - Unequivocal)

No sugar milk seems not to make me full. Rice makes me full, but starch is prohibited. It's really hard for us. - GDM - p5

Blood glucose monitoring: access and understanding barriers (Credibility Unequivocal)

I guess ... I would be fatigued because of blood loss if I keep getting blood for checking every day until delivery - GDM - p5

Breast-feeding: balancing conflicting information about benefits for baby (Credibility - Unequivocal)

I'm concerned about that (transmission of diabetes to the infant) of course. However to my understanding breast milk has antibodies which might be good 
for my baby because they would protect it from infection - GDM - p5

Finding 6

The desire for more information about GDM (Credibility - Unequivocal)

There is just a small sheet concerning the risk of GDM distributed by the

Illustration

hospital staff at the antenatal care department. No other information on GDM

is available - GDM - p6

\section{Paper 11: Beliefs about health and illness is Swedish and African-born women with gestational diabetes living in Sweden. ${ }^{34}$}

This paper by Hjelm $\mathrm{K}$ et al. $2012^{34}$ aimed to investigate beliefs about health and illness in women with GDM born in Sweden and Africa living in Sweden and the influence of beliefs on self-care and care seeking. The information was gathered through semi-structured interviews and analysed with qualitative content analysis. Participants were a consecutive sample of women diagnosed with GDM, 13 born in Sweden and 10 born in Africa, from a diabetes clinic in Sweden.

This study scored eight out of ten in the QARI critical appraisal tool.

Finding $1 \quad$ IIIness (Credibility - Unequivocal)

Worried for the child - that the child will be too big - if you get type 2 diabetes -

Illustration followed by coronary heart disease, stroke- that worries me. (Swedish woman - gdm) p1379

Finding $2 \quad$ Health (Credibility - Unequivocal)

I need to follow all the rules, all this advice I have got from the doctor and Illustration health care - I need to take my insulin at the right time, I need to eat at the right time, I need to rest at the right time...(African woman - gdm) p1379 
Finding 3

Illustration
Self-care and care seeking (Credibility - Unsupported)

Most respondents practised only self-care and measures related to the individual ... when health care was needed, it was mainly sought from midwives or physicians in the professional sector

\section{Paper 12: Swedish and Middle-Eastern-born women's beliefs about gestational diabetes. ${ }^{35}$}

This paper by Hjelm et al $2005^{35}$ aimed to compare beliefs about health and illness between women born in Sweden and the Middle East who developed GDM. The information was gathered by semistructured interviews and analysed by thematic analysis. The participants were a consecutive sample of women attending an in-hospital specialist diabetes clinic in Sweden with GDM; 13 born in Sweden and 14 born in the Middle East.

This study scored six out of ten in the QARI critical appraisal tool

Finding $1 \quad$ Beliefs about illness (Credibility - Unequivocal)

Illustration

I panicked....., and.... she said yes ... you have diabetes and you have to live like this and the baby can become too big and complications at birth..... was the only thing I heard....I was terribly frightened..... (Respondent 9 - GDM) p48

Finding $2 \quad$ Beliefs about health (Credibility - Unequivocal)

Health is everything......It is good to keep in health for one's work, for one's Illustration home, for one's husband.....the whole responsibility we [women] have for our children. (Respondent 17 - middle eastern woman - GDM) - p52

Finding $3 \quad$ Self-care and care-seeking pattern (Credibility - Unequivocal) 
Fear of the delivery is something natural which I think all women have... but for

Illustration this I am more worried about how diabetes can affect the baby.... (Respondent 7 - GDM) p53

\section{Paper 13: Management of gestational diabetes from the patient's perspective - a comparison of Swedish and Middle-Eastern born women. ${ }^{36}$}

This paper by Hjelm et al $2007^{36}$ aimed to investigate and compare Swedish and Middle-Eastern born women's evaluation of a Swedish specialised diabetes clinic for management of women with GDM and its contribution to a decreased level of stress and improved coping capability to promote health in patients receiving care. Participants were women with GDM, 13 born in Sweden and 14 born in the Middle East. The information was gathered by semi-structured interview and analysed by content analysis.

This study scored five out of ten in the QARI critical appraisal tool.

Finding 1

Illustration

Finding 2

Illustration
Patients' perspectives on the process or content of care competence (Credibility - Unequivocal)

The midwife does not know all about diabetes and those who work with diabetes don't know all about the baby (GDM) p172

Patients' perspectives on the organisation or structure of care (Credibility Unequivocal)

It would have been good if the midwife had been able to tell me more when I was there - you should not need to wait for two weeks before you can meet a dietician - I don't understand why I met a dietician first and then the physician (GDM) p173 
Finding 3 Patients' emotions and attitudes to the clinic (Credibility - Unequivocal)

Illustration

at the clinic I was informed about having gestational diabetes but not about the glucose tolerance test - there were further check-ups at the diabetes clinic - a lot of questions arose and that information is not focused on patients but on physicians - and then you ask even more questions - and when you are told that you have to ask your doctor - I think this is very bad - here are no information leaflets about gestational diabetes...First I met the diabetes specialist nurse [at the diabetes clinic] and she couldn't answer the questions. She was very good on diabetes but not on gestational diabetes...I had to wait until two weeks later when I met the doctor with questions that I wondered about rather general and basic questions. It took nearly four weeks, yes it did and $\mathrm{X}$ [the diabetologist] explained to me and since then there has been nothing. (GDM) - p173

\section{Paper 14: Beliefs about health and illness in women managed for gestational diabetes in two} organisations. ${ }^{37}$

This paper by Hjelm et al $2008^{37}$ aimed to explore the beliefs about health, illness and health care in women with GDM managed in two different organisations based on diabetology or obstetrics. Information was gathered by semi-structured interviews and analysed by content analysis. Participants were a consecutive sample of Swedish women diagnosed with GDM; 13 managed in a Swedish university hospital specialist diabetes clinic with regular contact with a diabetologist and antenatal care provided by a midwife and 10 managed in a Swedish university hospital specialist maternity clinic providing regular contact with a midwife, a structured programme for self-monitoring of blood glucose and insulin treatment, and a 1-day diabetes class by an obstetrician, a diabetologist, a midwife and a dietician.

This study scored seven out of ten in the QARI critical appraisal tool. 
Finding $1 \quad$ Beliefs about health (Credibility - Unequivocal)

Illustration

For me health is feeling well mentally and physically...I would say being free from any disease. (10 - GDM)...p172

Finding $2 \quad$ Beliefs about illness (Credibility - Unequivocal)

I was informed about it after the glucose tolerance test in week $28 \ldots .$. and then I didn't react so much but then when I was on my way home....started to cry Illustration violently ....I was horribly sad because I was afraid I had done something wrong to my child, that I had not looked after myself...I got a reminder, so I was horribly sad. (2 - GDM) p175

Finding $3 \quad$ Beliefs about health care (Credibility - Unequivocal)

Illustration .....that both the pregnancy and diabetes are in focus, so that it isn't just diabetes when you come here and not only the pregnancy at the midwife....I felt it like that....it could be combined more....that it feels like co-operation. (4 GDM) p178

\section{Paper 15: A qualitative analysis of the psychological impact of pregnancy for first time mothers with Type 1 diabetes. ${ }^{48}$}

This grounded theory thesis by Horrocks $2009^{48}$ aimed to assess the psychological and emotional impact of pregnancy in the context of Type 1 diabetes for first time mothers. Information was obtained from semi-structured interviews and analysed by content analysis, based on a social constructionist form of grounded theory. Participants were nine white British women who were first-time mothers and currently pregnant and receiving specialist support from a diabetes antenatal clinic in East Anglia, England.

This study scored ten out of ten in the QARI critical appraisal tool. 
Finding 1

1 Diabetes - Striving for the Sake of the Baby (Credibility - Unequivocal)

If most people realised some of the anguish.... am a very rigid person with my

Illustration

diabetes anyway, but I have given everything to this (Laura.- Type 1 diabetes line 53).p79

Understanding the Experiences of Pregnancy for First Time Mothers with Type

Finding 2

Illustration

Finding 3

Illustration

Finding 4

Illustration

Finding 5
1 Diabetes - Striving for the Sake of the Baby - Process of Acceptance and Adjustment (Credibility - Unequivocal)

It's like reprogramming yourself ... but you do adapt to it (Layla - Type 1 diabetic, line 92). p81

Understanding the Experiences of Pregnancy for First Time Mothers with Type

1 Diabetes - Striving for the Sake of the Baby -Process of Acceptance and Adjustment - Factors promoting acceptance and adjustment: engagement (Credibility - Unequivocal)

I look forward to it now ... she's on her way now ... she's become a lot realer [sic] (Cathy, Type 1 diabetic line 220).p83

Understanding the Experiences of Pregnancy for First Time Mothers with Type

1 Diabetes - Striving for the Sake of the Baby -Process of Acceptance and Adjustment - Factors promoting acceptance and adjustment: responsibility (Credibility - Unequivocal)

It's not just me now, what I am doing, I am affecting baby as well (Eileen Type 1 diabetic, line 64-65).p84

Understanding the Experiences of Pregnancy for First Time Mothers with Type 
1 Diabetes - Striving for the Sake of the Baby -Process of Acceptance and Adjustment - Factors inhibiting acceptance and adjustment: fear (Credibility Unequivocal)

Illustration

Have I looked after myself well enough for it to be alright? (Diana - Type 1 diabetic, line 18). p86

Understanding the Experiences of Pregnancy for First Time Mothers with Type

Finding 6

1 Diabetes - Striving for the Sake of the Baby -Process of Acceptance and Adjustment - Factors inhibiting acceptance and adjustment: negative beliefs about diabetes (Credibility - Unequivocal)

Illustration

I never actually thought I was going to fall pregnant because of this un-luck thing (Laura - Type 1 diabetes, line 72). p88

Finding 7

Balancing: Issues of Control (Credibility - Unequivocal)

The pregnancy wasn't planned, so my levels before that were quite terrible,

Illustration my HbA1c was 10.4, it's now 8.1 so it has come down. My sugar levels have always been uncontrollable; trying to find a balance has been quite hard (Cathy,- Type 1 diabetic - line 47-50).p89

Finding 8

Balancing: Issues of Control - Losing control. (Credibility - Unequivocal)

Illustration

It is constant changing; things can be different every two to three days (Eileen - Type 1 diabetic, line 55). p90

Finding 9 Balancing: Issues of Control - Gaining control (Credibility - Unequivocal)

It is just constant testing and checking and not really knowing how you are Illustration feeling because you don't really have all the obvious signs that you used to (Eileen - Type 1 diabetic, line 47). p91 
Finding 10

Illustration

Finding 11

Illustration

Finding 12

Illustration

Finding 13

Illustration

Finding 14

Illustration

Finding 15
Getting On With It vs. One Step At a Time - Getting On With It (Credibility Unequivocal)

I haven't really sat back and thought about it, I have just got on with it more. I think that I will probably sit back when the baby is here and think, "Well how did that happen"; You know it all came together somehow (Layla - Type 1 diabetic, line 238-240).p 94

Getting on with it vs. One Step At a Time - One Step At a Time (Credibility Unequivocal)

It's like just taking one step at a time, you can't do everything in big massive leaps, you have just got to, excuse the pun, but take baby steps (Jenny - Type 1 diabetic, line 400).p94

Learning / relearning (Credibility - Unequivocal)

I've never been pregnant before and I've never taken much notice of my diabetes before so it's all new to me really (Cathy - Type 1 diabetic, line 254). p95

Coping with negative emotion (Credibility - Unequivocal) $\mathrm{s}$

I really, really doubted myself (Sophie - Type 1 diabetic, from line 119). p98

How Do Women With Type 1 Diabetes View Themselves During Pregnancy Risky vs. Nurturing Body (Credibility - Unequivocal)

Babies don't like ketones (Diana - Type 1 diabetic, line 47). p100

How Do Women With Type 1 Diabetes View Themselves During Pregnancy Risky vs. Nurturing Body - empowered (Credibility - Unequivocal) 
Illustration

Finding 16

Illustration

Finding 17

Illustration

Finding 18

Illustration

Illustration

Finding 20 Finding 19
I am proud of myself because I was so frightened of it (Laura - Type 1 diabetic, line 49). p103

How Do Women With Type 1 Diabetes View Themselves During Pregnancy Risky vs. Nurturing Body - Different From Normal (Credibility - Unequivocal)

You are just constantly worried; obviously the doctors have to tell you all the effects that your high blood sugars have, and when you've constantly got it in your mind, you just think well, why can't I be normal, and have a normal baby? (Diana - Type 1 diabetic, line 48-51). p105

How Do Women With Type 1 Diabetes View Themselves During Pregnancy Risky vs. Nurturing Body - Objectified (Credibility - Unequivocal)

We're human and it is not just a case of numbers on a page (Jenny - Type 1 diabetic, line 176). p106

What Are the Participants Views on the Support They Receive From Others Supportive Network (Credibility - Unequivocal)

We know we can't do this on our own (Cathy - Type 1 diabetic, line 341).p109

What Are the Participants Views on the Support They Receive From Others Supportive Networks -Professional Support How to Promote Self Care? Specialist care (Credibility - Unequivocal)

There is always someone you can ring up if you are really worried and talk it over, sort it out (Eileen - Type 1 diabetic, line 75). p109

What Are the Participants Views on the Support They Receive From Others Supportive Networks -Professional Support How to Promote Self Care? Holistic care (Credibility - Unequivocal) 
[Specialist diabetes midwife], she is always there for me, I just phone her up,

Illustration

Finding 21

Finding 22

Illustration

Illustration

Finding 23 even if it's like silly little things, she don't care, she's always there (Diana Type 1 diabetic, line 173-174). p111

What Are the Participants Views on the Support They Receive From Others Supportive Networks -Professional Support How to Promote Self Care? Collaborative care (Credibility - Unequivocal)

You need help with your own care, it's not people looking after you, it's you looking after yourself as well, that's what I need, I need to have input in it as well (Cathy - Type 1 diabetes, line 265-267). p113

What Are the Participants Views on the Support They Receive From Others Supportive Networks - Family and Friends: Do They Understand? (Credibility Unequivocal)

Everyone's been really supportive, it's difficult because most people don't really understand diabetes, they kind of understand it to a point but then don't really understand it past that point (Jenny - Type 1 diabetes, line 223-225) p114

What Are the Participants Views on the Support They Receive From Others Supportive Networks - Partners: A Shared Responsibility? (Credibility Unequivocal)

I have a very supportive partner who knows all about it. .. so we have sort of done it together. (Eileen - Type 1 diabetes, line 92-93) p115

Paper 16: Women's perceptions of being pregnant and having pregestational diabetes. ${ }^{44}$ 
This study by Lavender et al. $2010^{44}$ followed a hermeneutic phenomenological approach based on Heidegger and aimed to explore the experiences of White British and South East Asian women with Type 1 and Type 2 diabetes, and the perceived impact of diabetes on their reproductive health. Information was gathered by focus groups and one-to-one interviews and analysed by content analysis described by van Manen. Participants were 22 women with Type 1 or Type 2 diabetes of different parity and ethnicity managed at obstetric and diabetes clinics in three hospital sites in the North West of England; only 14 participants were pregnant at interview and information from these women only was included in this review.

This article scored nine out of ten in the QARI critical appraisal tool.

Finding 1

Relinquishing personal control - Disruption to everyday lives (Credibility Unequivocal)

I would say it's more stressful because you're more in hospital. You're coming at least twice a week ...it's another head-ache ...And it's so hard to squash everything in. Like this morning I had to drop my kids at eight o'clock in school

Illustration

Finding 2 Unequivocal)

I suppose the only thing with coming in so often, like now with the pregnancy, you know its right for the baby and yourself but you do feel quite vulnerable as Illustration - they have breakfast club, so I'm lucky that way, so I could drop them off early to get here for nine o'clock....It's too much. And then I think, - Oh, my God, is this all necessary.... and the waiting times are just a laugh. (Fatima - preexisting diabetes) - p591

Relinquishing Personal control - surrendering control to others (Credibility -

well - cause you think suddenly something that you can control is something that you can't control really. And always having to accept that other people will want to know what the blood is doing ...so l've got to come in after 23 years of 
managing this to have someone else tell me, you know what to do with it.....(Heather - pre-existing diabetes) - p592

Finding 3

Illustration

Finding 4

Illustration
Pregnancy overshadowed by diabetes (Credibility - Unequivocal)

l've had nobody to speak to because it's just so medical which is absolutely understandable because you want your sugars to be absolutely perfect and that's the main objective. But you've gotta remember I'm having a baby and it's my first baby, I don't know what's going on with my body... .(Rachael - preexisting diabetes) - p593

Haphazard preconception care (Credibility - Unequivocal)

When I came, we just had vague chats about it to be honest...(Lisa - preexisting diabetes) - p593

\section{Paper 17: A transformed pregnancy: the psychosocial consequences of gestational} diabetes. ${ }^{51}$

This ethnographic paper by Lawson \& Rajaram $1994^{51}$ aimed to assess the meaning pregnant women attach to GDM. Information was gathered by semi-structured interviews and analysed by content analysis (using method developed by Glaser and Strauss). Participants were 17 pregnant women between the ages of 24 and 36, with no previous history of GDM being treated at a high-risk maternity clinic at a large university medical centre located in Kentucky, USA.

This article scored six out of ten in the QARI critical appraisal tool.

Finding $1 \quad$ Reactions to the diagnosis (Credibility - Unequivocal)

Illustration

I felt like it was the end of the world for me and I just thought of the worse.

Even though they told me that nothing was wrong with baby, I had an 
ultrasound and was relieved that the baby was ok. But, I was really depressed 'cause I knew that the diabetes could affect the baby. With sugar [diabetes], they said the baby will be large and then they will take it. I worry about the effects of a C-section on the baby. So, the main concern right now is the baby. (Kathy - GDM diet controlled, family history of diabetes) - p543

Finding 2

Finding 3

Illustration

Finding 4

Illustration
Coping with the diagnosis (Credibility - Unequivocal)

'I believe in not giving in to diabetes. I will take care of myself and control the diabetes. I know that I will have to lose this weight after I have the baby'. (Susan GDM - diet controlled) p549

Experiencing a transformed pregnancy - dietary management (Credibility Unequivocal)

I have always been a sweet addict. I love sugar. It is really hard for me not to eat ice cream. Friends come in and have ice cream and eat it in front of me, but I know I can't have it. . . I cried when I saw my husband eat ice cream. I really knew that my pregnancy was different when I could not eat ice cream. It is really hard to suddenly change my eating and cooking patterns... If it had happened earlier in my pregnancy, then I would have been more prepared than I am now. But to suddenly change how I eat and cook is hard. (Robin DGM - diet controlled) - p549-50

Experiencing a transformed pregnancy - Insulin injections (Credibility Unequivocal)

I give myself two shots everyday. Even though I had two other pregnancies, this is the worst pregnancy I had. With the insulin, I cry a lot, I feel lonely and have severe mood swings. I watch news stories or commercials on TV and cry. I wake-up at night and wonder if I will die and if I will live to see my 
children grow-up, or if I will see my grandchildren. - (Beth - GDM - insulin dependent) - p552

Finding 5

Experiencing a transformed pregnancy - Blood glucose monitoring (Credibility - Unequivocal)

I took my blood at Lamaze classes, and it was interesting because I wanted to hide it, even though other gestational diabetics could have been in the class. I have never known anybody who had gestational diabetes 'cause they never Illustration talked about it. I could not reveal to others that I was having an abnormal pregnancy by testing my blood. I tested my blood in a bath room stall where no one could see what I was doing. In concealing my testing, I was perpetuating the myth that all pregnancies are normal. I was trying to conform to the myth of a 'perfect' pregnancy - (Michele - GDM - diet controlled) - p551

Finding 6 Experiencing a transformed pregnancy - patient-provider interactions (Credibility - Unequivocal)

'Most gestational diabetics do not get enough information about nutrition, such Illustration as the importance of reading food labels and meal planning.' - (Sharon - diet controlled) - p555

\section{Paper 18: Food Perceptions and Concerns of Aboriginal Women Coping with Gestational Diabetes in Winnipeg, Manitoba. ${ }^{38}$}

This paper by Neufeld $2011^{38}$ aimed to assess how Aboriginal women in an urban setting perceive dietary treatment recommendations associated with GDM. Data was collected by semi-structured explanatory model interviews and analysed by thematic analysis. Participants were 29 self-declared Aboriginal women from an urban centre of Winnipeg, Manitoba who had received a diagnosis of GDM 
within the last five years - 16 were pregnant at time of interview (two of these without current diagnosis of diabetes). For this review data was collected only from those pregnant at the time of interview. Of the 14 pregnant and diagnosed with diabetes four were diagnosed with Type 2 diabetes and ten with a current diagnosis of GDM.

This article scored seven out of ten in the QARI critical appraisal tool.

Finding $1 \quad$ Food and Gestational Diabetes - instability (Credibility - Unequivocal)

It's such a struggle to sit here and have to eat..., (She would also tend to eat a meal only once a day, consuming larger serving sizes than recommended)

Illustration $\quad$...I'm not a big eater but I eat more than 1 cup. I mean ...hello, that's my only meal I eat a day! Diane - GDM with current and last pregnancy, 3 y ago; second trimester - p485-6

Finding 2 Treatment Experiences (Credibility - Unequivocal)

Trying to keep it under control, it's getting aggravating sometimes because it Illustration

Finding 3 doesn't always work....Pretty much a lot of things bring it (blood glucose) up. I found you pretty much got to eat like a mouse to keep it down. - Terri - GDM with previous pregnancies and currently; second trimester - p485

Food and Gestational Diabetes - Food, Fear and Anxiety (Credibility Unequivocal)

Illustration

Somebody says something or things aren't going right, you go eat! - Doris GDM currently; third trimester - p486

Finding 4

Food and Gestational Diabetes - Misinterpretation and Frustration (Credibility - Unequivocal)

Illustration When you think of healthy, you think of fruit and vegetables, but tomatoes and 
apples and oranges and whatever aren't good for you, they're high in sugar... At the same time, she explained that for women with GDM, chocolate bars aren't bad for you, because chocolate doesn't release its sugars all at once like Pepsi. - Diane - GDM with current and last pregnancy, 3 y ago; second trimester - p487

\section{Paper 19: 'From stun to gradual balance'--women's experiences of living with gestational diabetes mellitus. ${ }^{49}$}

This grounded theory article by Persson et al $2010^{49}$ aimed to assess the experiences of pregnant women being diagnosed with GDM and its impact on their daily life. Information was gathered by semi-structured interviews and analysed by content analysis. Participants included ten women - all except one of Swedish origin - with one immigrant who had lived in Sweden since her teens, was well established within Swedish society and was fluent in Swedish attending antenatal clinics in a county in Northern Sweden.

This study scored nine out of ten in the QARI critical appraisal tool.

Finding 1 From stun to gradual balance - Struck by lightning (Credibility - Unequivocal)

To initially have felt so good and well, not had any nausea and the baby was Illustration kicking and everything was so fine, the checkups at the midwife and so on, and then this slap in the face? UGH!? - gdm p457

Finding 2

From stun to gradual balance - having a personal responsibility (Credibility Unequivocal)

Illustration

You would do anything for the wellbeing of the baby, to have a healthy baby gdm p457 
Finding 3

Illustration

Finding 4

Illustration

Finding 6

Finding 7

Illustration
From stun to gradual balance - Being under surveillance (Credibility Unequivocal)

He [the spouse] becomes a little like this - Are you really going to eat that? Then it rather gives you an even more guilty conscience. - gdm p457

From stun to gradual balance - Feeling socially apart (Credibility Unequivocal)

You have to say all the time, No thank you, I can't. I'm diabetic - to have to acknowledge this disease all the time. It [the disease] is hidden in one sense, but still gets very obvious in some situations - gdm p458

From stun to gradual balance - Being sufficiently supported (Credibility Unequivocal)

My dad's wife bakes bread and she's very eager to make sure that there is whole grain and no sugar ... so she is almost more into this than I am.? - gdm p458

From stun to gradual balance - Struggling for protection (Credibility Unequivocal)

Well, a bit of a guilty conscience, I think. - Not so much for my own sake, but for the baby. - Oh, poor thing, now he's lying there in a bath of sugar ... and feels bad. - gdm p457

From stun to gradual balance - Changing the self-image (Credibility Unequivocal)

Unless there is a miracle somehow I will probably be struck with diabetes mellitus, type 2, and that is so sad because... diabetes mellitus brings so many 
other diseases if you don' take care of yourself properly. - gdm p458

Finding 8

From stun to gradual balance - Adapting to a new situation (Credibility Unequivocal)

It takes time to find your routines, to get all these pieces of the puzzle to fit into

Illustration your life. My God, it does! You do not change from one day to the next. It is not possible. - gdm p458

Finding 9

From stun to gradual balance - Waiting for the 'Moment of truth' (Credibility Unequivocal)

Illustration

When the birth approaches and you're so awfully worried that the baby will be affected. - gdm p459

\section{Paper 20: Coping with diabetes through pregnancy. ${ }^{45}$}

This study by Richmond $2009^{45}$ was designed with a qualitative phenomenological methodology following Husserl's philosophy and aimed to investigate how identity was linked to the improvement, and deterioration, of blood glucose control in pregnant women with Type 1 diabetes. Information was gathered by interviews and analysed by qualitative thematic analysis. Participants included 11 women with Type 1 diabetes attending the joint obstetric/diabetic clinic in a district general hospital between October 2001 and April 2004 in Stockport, UK.

This article scored seven out of ten in the QARI critical appraisal tool.

Finding $1 \quad$ Hypoglycaemia (Credibility - Unequivocal)

Owen (four-year-old son) went to tell a neighbour ...I must have flaked out on Illustration the kitchen table and Owen went to tell a neighbour and just as I ... people came in. I then kind of came to ... when I mention it to people they say Oh my 
God how dangerous is that?? But I mean it could have been much worse. (D) pre-existing Type 1 diabetes p90

Finding 2 Concern for their unborn child (Credibility - Unequivocal)

I know because I'm pregnant l've got to look after myself more because I don't Illustration want anything to happen to the baby because of it ... because of me not looking after meself ... (K) - pre-existing Type 1 diabetes p89

Finding $3 \quad$ Concerns for existing children (Credibility - Unequivocal)

If I turn away from my child (two-year-old daughter) while it's stood next to you at the side of the road, anything could happen you know, but you might not Illustration recognise that you're having a hypo or you might not have anything in the house for a hypo. It's just too much of a risk for me. (E) - pre-existing Type 1 diabetes $\mathrm{p} 90$

\section{Paper 21: The lived experience of pregnancy for women with pre-existing insulin-dependent diabetes. $^{46}$}

This interpretive phenomenology thesis by Sheffer $2000^{46}$ aimed to explore the lived experience of pregnancy for women with pre-existing IDDM. Information was gathered by audio-taped semi-focused one-on-one interviews and analysed by thematic analysis following a framework of interpretive phenomenology outlined by Benner. There were eight participants, who had lived with pre-existing insulin dependent diabetes mellitus from four to twenty years and had treatment in a clinic in a tertiary level health care centre in Dalhousie, Canada.

This thesis scored eight out of ten in the QARI critical appraisal tool. 
Finding 1

Illustration

Finding 2

Illustration

Finding 3

Illustration

Finding 4

Illustration
Uncertainty About Having a Healthy Baby (Credibility - Unequivocal)

Like it, it, I'm sticking to it basically for the sake of my baby ...So, everything, everything for this little baby, that's how we're looking at it. Yeah. (Anne - Preexisting Type 1 diabetes) p54

Yes. I am a Diabetic - Diabetes as a background (Credibility - Unequivocal)

...[But] I don't think about it too much now and it seems to go along pretty well and I'm very comfortable regulating my insulin myself. I don't mind doing that at all. So, I guess I don't, only way if it's bad and getting a little high, I guess I might think about it then. I mean I'm just thinking about what I've got to do, but nothing that upsets me by any stretch of the means. Just whatever measures I have to take to make it good again. (Gloria - pre-existing Type 1 diabetic) p578

Yes. I am a Diabetic - The meaning of high risk as a diabetic woman (Credibility - Unequivocal)

Like once you get used to it, it's not bad And you don 't think anything of it, and ah, what really annoyed me when I first was pregnant, I was, everybody told me I was at such high risk and I thought, you idiot, I'm not at high risk. But you know, seeing the information, well, yes, I guess I am at that high risk, but you know, I don't feel I'm at high risk, I'm just normal. I could see if my blood sugars were really high, yes, but they're not. (Debbie - Type 1 diabetic) p61

Yes. I am a Diabetic - Diabetes as background and foreground (Credibility Unequivocal)

Because you have to, you've got no choice. You have to have that good extra bit of excellent control. The sugars have to be tested four times a day. I started 
that as soon as I took the pregnancy test and it came back positive. My sugars are four times a day. I really started watching what I ate and making sure that there was no extra sugars here or little treats here and there that shouldn't have been there and it's paid off. I switched to low-fat everything and I've only put on ten pounds, but the baby's growing good, so, as a matter of fact, I'm measuring bigger than what I should be right now, but I was big to start with. (Betty - Type 1 diabetic) p63

Finding 5 My Baby Comes First (Credibility - Unequivocal)

I thought, okay, I'm not doing this for me anymore, I'm doing this for somebody else and, I was diagnosed with diabetes and I was on my own for a few years. I had no educator. I didn't have anybody to tell me the rights and the wrongs about it. My family doctor had recommended somebody, but that was as far as

Illustration it had gone. I had never got a referral. I hadn't had anything like that so, up until I got pregnant and went back to my doctor and he says, "Okay, I'm sending you straight to the [hospital";. That's when it hit me like, this is reality. And ah, we took \{the] reins and here we are. It was a wake up call. (Elaine Type 1 diabetic) p66-7

Finding 6 This is Hard Work (Credibility - Unequivocal)

I think being pregnant and having Type 1 diabetes just means that whatever a woman who doesn't have Type 1 diabetes would do to take of herself during Illustration pregnancy, I have to do twice as good. I have to, I, you know what I mean, I have to be twice as careful with, with what I eat and my exercise and my rest and everything -1 just have to be better than, than the average woman, really. (Anne - Type 1 diabetic) p68

Finding $7 \quad$ But, Do You Know ME? (Credibility - Unequivocal) 
The other doctors were sort of residents and they weren't, I have given up and so I just go along with whatever they say and I go home and I do what I know. I take in what they tell me and then I'll go home and I'll do what I think is going to work and it usually does. I mean I always take into consideration what they say and I'Il try what they say, but I still tend to do what I want to do. And, but today, [the nurse] actually heard me and [the nurse] agreed with me. That was

Illustration

Finding 8

Illustration

Finding 9

Illustration actually a big sense of relief....I'm sure sometimes they've got to think well, she's just being resistant or she's just, she's not listening to us, she's doing this wrong. She's probably doing that. She's probably not telling us or whatever. I know this must be going through their heads, but, and so then, I'm sure they're exasperated and I'm exasperated and so then they just sort of humour me and when I go home and do whatever. But today was a good day. (Gloria - Type 1 diabetic) p71

Feeling Afraid (Credibility - Unequivocal)

I'm more petrified with this one than I was before. I'm anxious all the time about it. I can't wait for it to get here. With [my daughter] I wanted it to stay in; I always knew it would be protected. This one I want completely out, so I know that it's okay. I just don't know what's happening to it inside, you know, I want it out now, I want to make sure that its okay. (Elaine - Type 1 diabetic) p73

Feeling Guilty: The Weight of Responsibility (Credibility - Unequivocal)

This is our first child and, like, probably our, our only child so ...we're not planning any more ...it's not engraved in stone or anything like that, but at the present time, under the circumstances as far as, it's been very stressful, as far as the diabetes. As far as the diabetes, like the strict control, like the, food and, uh, like, you know, the complications that could arise, now mind you, I've been very fortunate and I haven't had any problems, but just, uh, like, the 
problems that could- a bigger baby, a deformed baby, like, it, it's very stressful to even think, well, oh my soul, my baby could be deformed because of me and my blood sugars, so, it, uh, it's been kind of stressful that way. (Debbie Type 1 diabetic) p75

Finding 10 Integrating Past Experience (Credibility - Unequivocal)

I, um, had a miscarriage when I was nineteen and my sugars were way out of control at that time and I kind of always think that that you know that probably was the reason why. So when I found I was pregnant this time, I was so strict with myself in the first three months. I kind of eased up a little but not really usual like after that but I was like really strict the first three months because I

Illustration just didn't want a repeat of that or anything like that ...but that was like totally unplanned and I wanted it that time too so in a way you know I guess that was probably the best thing that could've happened at the time but I always kind of kept in the back of my mind just knowing that I wasn't taking care of myself at all and that's probably why I ended up miscarrying. (Anne - Type 1 diabetes) p77

\section{Paper 22: Women with pre-existing diabetes and their experiences of maternity care services. ${ }^{50}$}

This grounded theory paper by Stenhouse et al. $2012^{50}$ aimed to explore the experience of maternity care services used by women whose pregnancy is complicated by pre-existing diabetes. Information was gathered via in-depth interviews utilising one-to-one, dyad and group interviews with 12 pregnant women with Type 1 and Type 2 diabetes mellitus and eight of their significant others attending an antenatal clinic of a large district general hospital in South West England. Thematic analysis was undertaken.

This study scored eight out of ten in the QARI critical appraisal tool. 
Finding $1 \quad$ Empathetic care (Credibility - Unequivocal)

Illustration

I don't think they really understand how hard it is, or they certainly don't demonstrate that they understand how hard it is, when all these things happen to a person all in one go..... (Oral medication changed to insulin)... it is a big; to me it is a huge thing. The shock of being pregnant so quickly, the shock of having to inject myself, the shock of living with having to inject and having hypos and understanding diabetes - Soebia - Type 2 diabetes - p3

Finding 2

Feeling judged by health-care professionals (Credibility - Unequivocal)

Um...it's been quite...I have found the going into the room with lots of people in Illustration there is quite difficult to err ...to handle. It's almost like, I find like ,you're being judged really rather than going into see a panel.- Regina - Type 1 diabetes p4

Finding 3

The notion of Expertise (Credibility - Unequivocal)

I can see why we have to go [to hospital]; obviously because if it was uncontrolled then they'd catch it and then make sure there was nothing to Illustration harm the baby.... I think we're not stupid we know what we're doing but, yah obviously you go to make sure the baby is okay, but it can be frustrating.Emily- Type 1 diabetes - p4 


\section{Categorisation and synthesis of qualitative research findings}

Of the 153 reported findings, four findings were not supported by the data and were not included in the categorisation and synthesis of findings. The remaining 149 findings were extracted from the included studies and were collated to form categories based on identified similarities. Some findings were included in several categories, so a total of 174 study findings were included in the categories. This moves from a focus on individual studies to consideration of all findings for all the studies included in the review. A total of six categories were created on the basis of similarities of meaning, and from these, two synthesised findings (meta-synthesis) were produced as is illustrated in Appendix IV - QARI graph.

\section{Meta-synthesis}

Synthesised finding 1 - Health professionals should be aware that their attitudes and practices in the care of women with diabetes during pregnancy needs to be empathetic and based upon a collaborative model of care.

Figure 1 is a diagrammatic representation of Synthesised finding 1 


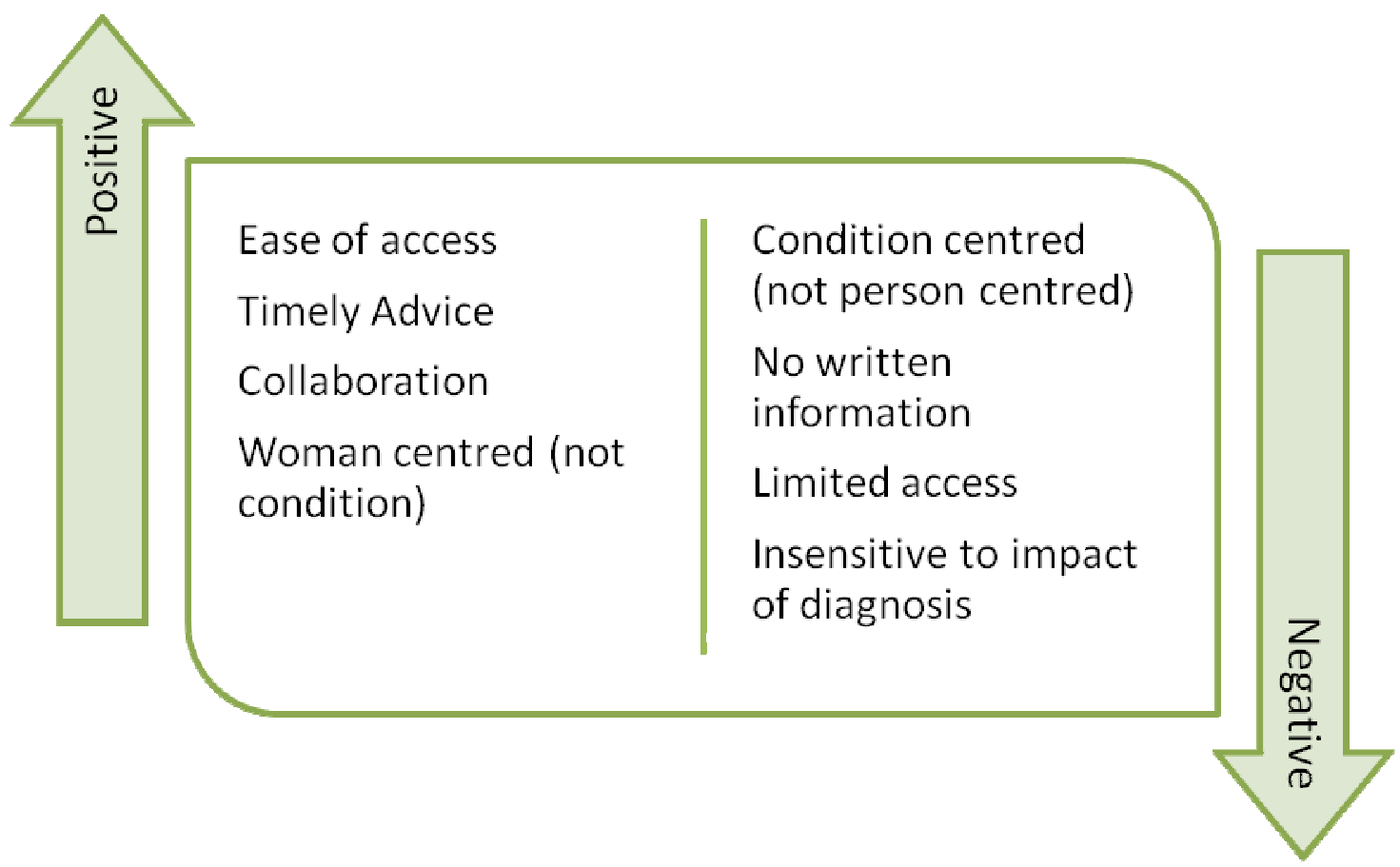

Figure 1 Synthesised finding 1

Health professionals were seen to be supportive and accessible or unsupportive for a variety of reasons: being judgmental, not having relevant information, time-wasting, not acknowledging women's knowledge of diabetes.

Health professionals concentrated on their individual area of expertise rather than treating the woman as a complete individual i.e. diabetes nurse concentrated on diabetes only and midwife on pregnancy only, which was seen to be negative. Health professionals did not always provide enough information in a timely or appropriate fashion to address women's concerns.

This metasynthesis was created from two categories with 29 findings.

\section{Category 1 - Positive effect of health professionals}

This category was informed by ten findings from seven studies. The findings all focused on particular positive effects of health professional interactions on pregnant women with diabetes, including knowing the person not just a diagnosis, positive advice for the future, health professional recognising women's knowledge and expertise in managing their condition and working in a collaborative manner and health professionals being easily accessible (e.g. by phone) and supportive. The category 
conveys that health professionals can have a positive effect on each woman.

\section{Category 2 - Negative effect of health professionals}

This category was informed by 19 findings from 11 studies. The findings all focused on particular negative effects of health professional interactions on pregnant women with diabetes, including lack of relevant information being provided to women regarding the effects of GDM on the child. Culturally appropriate dietary advice was not provided and health professionals concentrated on their own areas of expertise rather than holistic care. Multiple appointments with different health professionals were seen as inconvenient and waiting times both for appointments and referral to specialists were seen as an annoyance and disrespectful to the woman. Health professionals did not provide appropriate written information and were not sensitive to the impact of the diagnosis and required lifestyle modification and treatment to the women. The category conveys that health professionals can have a negative effect on each woman.

\section{Synthesised finding 2 - Women with perceived low adherence need time to adjust and} education, these are major factors positively affecting women's motivation for adherence to treatment for diabetes in pregnancy.

Figure 2 is a diagrammatic representation of synthesised finding 2 


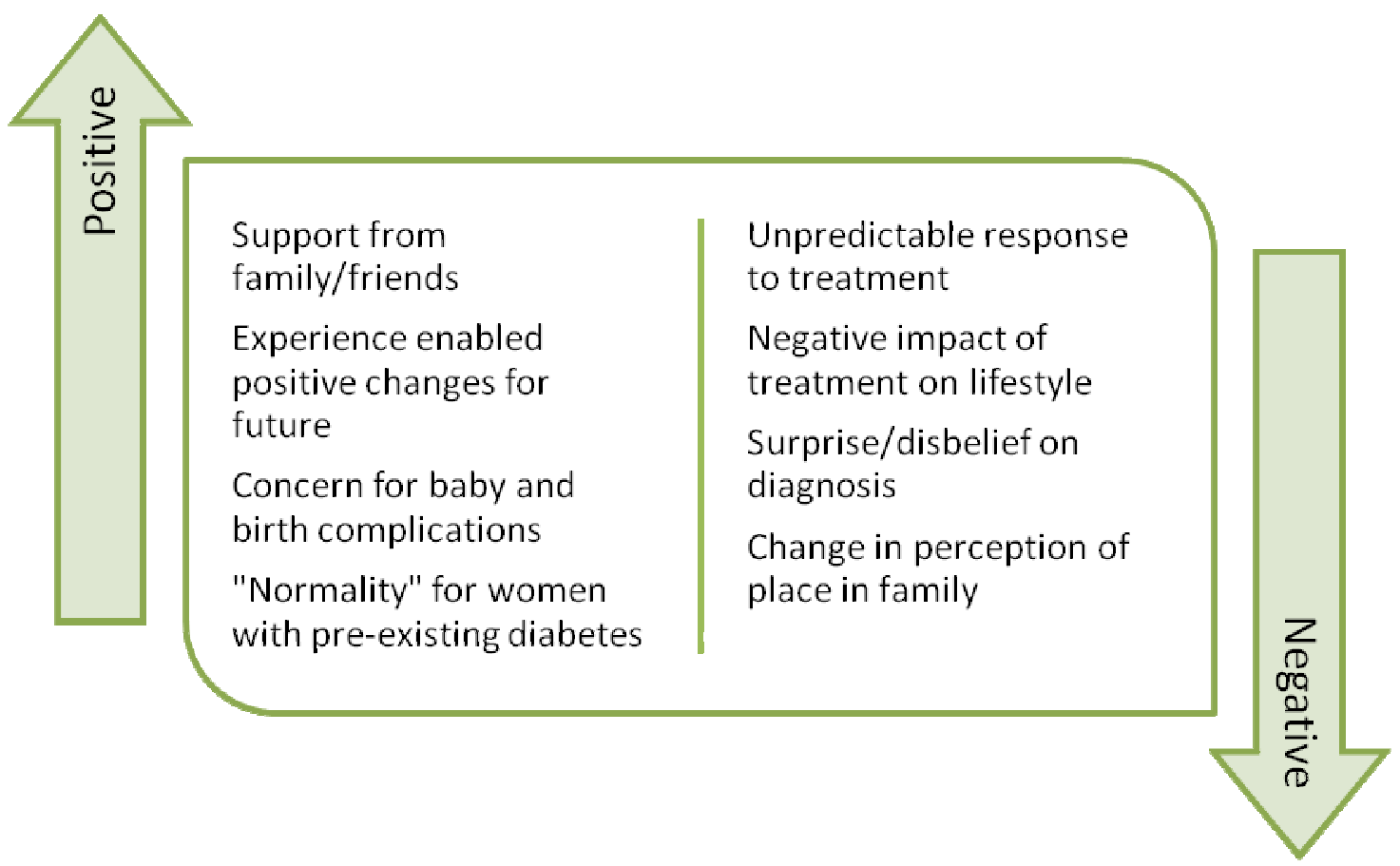

Figure 2 Synthesised finding 2

Women worked out routines and strategies to control their blood glucose with time. They expressed concern and anxiety for the wellbeing of their unborn baby and this often motivated them to control their blood glucose levels. Women with GDM expressed various emotions at the diagnosis including surprise and disbelief and women with pre-existing diabetes were concerned about their loss of diabetic control with pregnancy, their ability to care for existing children and their perception of their place in the family was challenged.

Barriers to adherence to treatment regimes included: the time spent managing their condition, frustration that blood glucose levels seemed unpredictable even though they complied to treatment regimes, concerns with blood glucose monitoring including concerns about blood loss, social isolation and pain associated with finger pricking, concern with the restrictive nature of the prescribed diet and exercise with difficulty with competing priorities with family and social obligations, difficulties with insulin. Some acknowledged however that it made control of their diabetes easier. 
Enablers to good adherence to treatment regimes included support by family members and friends, concern about the wellbeing of their unborn child and the effect of their diabetes on the child and delivery of the child. Women with pre-existing diabetes felt that pregnancy conferred 'normality' on them. Women were informed of the causes of diabetes and concerned about their future with diabetes.

This metasynthesis was created from four categories with 145 findings.

\section{Category 3 - Adherence to treatment improves with time, experience and support}

This category was informed by 38 findings from 13 studies. The findings all focused on aspects of women's adherence to treatment regimes and the improvement of their adherence with time, experience and support. Factors included women placing more importance of preconception advice depending on their previous pregnancy experiences and being concerned about their future with diabetes. Some women felt that the experience of treatment and monitoring of diabetes in pregnancy meant that they could make lifestyle changes to benefit both themselves and their families in the future and felt empowered to make positive steps toward this goal. With time women gained the skills and knowledge to manage their condition and realised that it was up to them to control their diabetes and worked out strategies to do this. Women were more likely to make positive changes when family members and friends supported them in adhering to their treatment regimes. The category conveys that adherence to treatment regimes improves with time, experience and support.

\section{Category 4 - The restrictions of diabetes impact a woman's lived experience}

This category was informed by 35 findings from 13 studies. The findings all focused on aspects of the diagnosis and treatment of pregnant women with diabetes that were perceived to the women as being restrictive in their daily lives. Women felt that diabetes impacted on their social and religious lives due to having to be concerned about the effects of fasting, different foods and exercise regimes on blood glucose levels and having to frequently monitor blood glucose levels made them conspicuous and feel socially isolated. Some women felt that frequent blood glucose monitoring might lead to blood loss and had concerns about the pain associated with frequent finger pricking. Some women had difficulties with insulin including pain with injections and some felt it was associated with mood swings 
and that blood glucose levels seemed unpredictable even with good adherence to treatment regimes. Exercise regimes were seen as problematic because of time constraints, tiredness and other physical concerns. The prescribed diet was seen to be restrictive and difficult to fit around competing priorities with family and social obligations and the change from previous eating patterns. The time spent managing their condition was seen as restrictive and of concern to many pregnant women with diabetes. The category conveys that diabetes and its treatment negatively impact the lived experience of pregnant women with diabetes.

\section{Category 5 - Being informed of the risks and causes of diabetes in pregnancy increases both anxiety and motivation}

This category was informed by 51 findings from 18 studies. The findings all focused on the anxietyinducing and motivating effects when pregnant women with diabetes were informed of the risks and causes of diabetes in pregnancy. Women were informed and concerned that their diabetes put their unborn child at greater risk of abnormality or birth complications than the general population and that caesarean section was a likely delivery option. This motivated them to control their blood glucose levels. Women with pre-existing diabetes were motivated to work harder to control their diabetes than before pregnancy to minimise these risks. Women were aware of the association with genes and obesity but some were misinformed and anxious about a perceived infectious nature of transmission of diabetes through breast milk. The category conveys that pregnant women with diabetes being informed of the risk and causes of their diabetes can increase their anxiety but also motivation for good treatment outcomes.

\section{Category 6 - Diabetes causes a change in women's perception of self and their place in the family and of control of self}

This category was informed by 21 findings from 12 studies. The findings all focused on the change in the woman's perception of self: her perception of herself within the family unit and her perception of 
being in control of herself, brought about by being pregnant with diabetes. Women expressed various emotions, such as surprise and disbelief, with the diagnosis of GDM and also of pregnancy for some women with pre-existing diabetes. Women's underlying health beliefs suggested that they felt that the health of the mother was important for family functioning and that diabetes compromised that role. Women with pre-existing diabetes expressed concern for their existing children and their ability to care for them in the event of hypoglycaemia. Women with pre-existing diabetes felt that pregnancy provided them with a sense of proof of normality. Many women conveyed a sense that they were inherently unlucky. The category conveys that the diagnosis of pregnancy in a diabetic woman or the diagnosis of gestational diabetes in a pregnant woman can have an effect on her self-perception and of her role in her family and society. 


\section{Chapter 4}

\section{Discussion}

This systematic review of the qualitative evidence was undertaken to gain insight and understanding of women's experience of diabetes and diabetes management in pregnancy with the objective of ascertaining how these experiences relate to their understanding of their condition and adherence to treatment regimes.

The 22 papers included in the meta-synthesis resulted in 174 findings, which were developed into 6 categories and two synthesised findings. These were:

- "Health professionals should be aware that their attitudes and practices in the care of women with diabetes during pregnancy needs to be empathetic and based upon a collaborative model of care" and

- "Women with perceived low adherence need time to adjust and education; these are major factors positively affecting women's motivation for adherence to treatment for diabetes in pregnancy"

These synthesized findings provide insight into factors affecting pregnant women's adherence to treatment regimes for diabetes.

A 2008 Cochrane review ${ }^{13}$ was conducted to ascertain the evidence for interventions to enhance adherence to medication regimes. For short-term drug treatments, counselling, written information and personal phone calls were beneficial. For long-term treatments, no simple intervention led to improvements in health outcomes. More complex interventions including combinations of more convenient care, information, counselling, reminders, self-monitoring, reinforcement, family therapy, psychological therapy, mailed communications, crisis intervention, manual telephone follow-up, and 
other forms of additional supervision or attention were beneficial. However, even with the most effective methods for long-term treatments, improvements in drug usage or health were small.

The first synthesised finding - Health professionals should be aware that their attitudes and practices in the care of women with diabetes during pregnancy needs to be empathetic and based upon a collaborative model of care - identified that women perceived health professionals to be both positive and negative influences on the management of their diabetes in pregnancy.

Health professionals were seen to be a positive influence when they provided timely, appropriate advice that encompassed both the diabetes and the pregnancy, and when different health professionals reinforced each other. The research indicated that health care settings should facilitate patient-centred practice where appropriate healthcare professionals are easily accessible to patients in a timely fashion and health care professionals should work collaboratively to reinforce each other within their respective specialties, and provide information to women in a timely and culturally appropriate manner.

Health professionals were seen to be a negative influence where there was little cooperation between specialties and where women perceived their condition was being managed rather than them being treated as a whole person. Central to this was being given accurate, appropriate information about their condition and treatment in a timely and culturally appropriate fashion. A recurring theme was that insufficient or culturally inappropriate information was provided about diet and lifestyle factors related to treatment, and that consultations with various specialist health professionals often took some time to arrange and this created both anxiety and frustration. The disjointed nature of many of these appointments also frustrated women who found difficulty with the additional time demand in their already busy lives. Some health professionals were seen to be judgmental and dismissive of women's prior knowledge of diabetes. A number of women identified a lack of appropriate written information and several identified that peer support would be valuable. These findings are consistent with findings from Kardas' recent review of systematic reviews of determinants of patient adherence, ${ }^{52}$ where healthcare team and system-related factors affecting adherence having a negative effect on adherence included lack of providers/caregiver availability and poor access to a healthcare facility 
(e.g. long waiting times, queues, lack of privacy, inconvenient appointment times, inconvenient opening hours, seeing a different language speaking therapist, difficulty in obtaining sick leave for treatment, and having no time to refill prescriptions, or other pharmacy-related problems). Drug related matters having a negative effect on adherence include unclear information about proper drug administration, greater number of prescribing physicians, conflicting messages between GPs and specialists on medication, discrepancies between treatment guidelines and common clinical practice (as patients try to ask several specialists) and use of multiple pharmacies. Health care provider-client communication and relationship issues having a negative effect on adherence included poor healthcare provider-patient relationship, poor patient-physician communication, lack of trust in doctors and healthcare, lack of patient satisfaction with their healthcare and limited caregiver adherence strategies. Positive effects on adherence included quality, duration and frequency of interaction between the patient and doctor, offering enough time to the patient, leaving space to talk about problems concerning medication or side effects, patient involvement in decision making, encouraging self-management, Doctor responsiveness, Doctor's ability to demonstrate empathy, Doctor's ability to elicit and respect the patient's concerns, and perceived healthcare provider support. Drug related matters having a positive effect on adherence included Doctor's ability to provide appropriate information as to the drug administration and being given information about the action of the drugs and prescription by a specialist. ${ }^{52}$ There is increasing emphasis on 'teaching' empathy in medical and other health professional undergraduate programs. ${ }^{53}$ The findings of this review suggest that continued development and promotion of such programs would benefit patient's adherence to treatment regimes.

The second synthesised finding - Women with perceived low adherence need time to adjust and education; these are major factors positively affecting women's motivation for adherence to treatment for diabetes in pregnancy - identified a number of factors that positively and negatively affected women's attitudes to diabetes and their adherence to treatment regimes.

Women were generally informed that there were risks to the foetus, delivery and their future health risks. These were major motivating factors to adhere to medical advice, although they also produced some angst and self-blame. Some women expressed gratitude for the advice given and felt 
empowered to alter lifestyle and diet to positively influence the future health of themselves and their families. Other enablers of adherence to treatment recommendations included support from partners and family.

Barriers to adherence to treatment included difficulties with advice given and the treatment itself. Some women found dietary advice difficult to adhere to, as the foods recommended were not culturally familiar to them, time consuming to prepare and often seen to be expensive. Some women had concerns with customs around various religious festivals. The acts of finger pricking for blood glucose measurements and administration of insulin were said to be painful and time-consuming. Exercise was mentioned as being time consuming and difficult due to the physical constraints of pregnancy. For those women using insulin, hypoglycaemia was seen as a major difficulty, especially if they had responsibility for other children. Again these concerns are similar to those in Kardas' review $^{52}$ - where therapy related factors affecting negative adherence included complexity of the regimen (e.g. complex/frequent dosing schedule/number of tablets), number of prescribed medications (polymedication), doses during the day (particularly the middle-of-day or early-morning doses), instability of the regimen, need to adjust dietary habits for taking medication, and disliking aspects of the medication. Positive factors included simple regimen, fewer drugs prescribed, long acting formulation, unit-of-use packaging, and flexibility/patient choice in treatment regular medication schedule (vs. irregular dose interval).

For some women with Type 2 or GDM, treatment with oral hypoglycaemics may be a clinically suitable alternative to insulin if diet and exercise therapy is insufficient and this would address concerns with the frequent blood glucose monitoring associated with insulin, the insulin itself and in part, the concern some women had with hypoglycaemia. Additionally it has been shown that complex medication regimes are more likely to result in poor adherence to medication, ${ }^{52}$ so simpler oral regimes may be preferable to injectable, where they are clinically appropriate.

There was little mention of the use of oral hypoglycaemics in this review. Metformin particularly is increasingly being used for diabetes in pregnancy, although many guidelines used for diabetes in 
pregnancy imply that insulin should be instituted when diet and exercise are not sufficient. With its lesser propensity to cause hypoglycaemia (which was a concern of women using insulin), consideration should be given to using metformin or glibenclamide, which have not been shown to be teratogenic, where clinically appropriate.

This was highlighted in some of the findings of the review, for example: "I don't think they really understand how hard it is, or they certainly don't demonstrate that they understand how hard it is, when all these things happen to a person all in one go..... (oral medication changed to insulin)... it is a big; to me it is a huge thing. The shock of being pregnant so quickly, the shock of having to inject myself, the shock of living with having to inject and having hypos and understanding diabetes" Soebia - Pre-existing Type 2 diabetes - p 3 - Stenhouse et al 2012. ${ }^{50}$ This statement encompasses a number of concerns that women expressed. Hypoglycaemia is one of these concerns. For women with Type 1 diabetes and Type 2 diabetes treated with insulin the loss of the normal hormonal responses to hypoglycaemia results in loss of the ability to recover spontaneously from insulininduced hypoglycaemia. Also there is a syndrome of 'hypoglycaemia unawareness', or the lack of recognisable autonomic responses to hypoglycaemia (palpitations, tremor, sweating) due to defective adrenaline secretion in response to hypoglycaemia in these women. ${ }^{54}$ For women with pre-existing Type 2 diabetes or GDM hypoglycaemia is more common with insulin therapy than oral hypoglycaemics $^{55,56}$ and consideration should be made to continue their use where clinically appropriate. Safety of both glibenclamide and metformin in pregnancy has been established, ${ }^{56-58}$ although it is acknowledged that no long term neonatal follow-up studies have been performed. An Australian study - Metformin in Gestational diabetes - $\mathrm{MiG}^{59}$ - gathered information on the acceptability to women of metformin treatment in GDM via questionnaire. They showed that $76.6 \%$ of women treated with metformin would choose metformin in a subsequent pregnancy whereas only $27.2 \%$ of women treated with insulin would choose insulin again. Also more women treated with metformin than insulin said that taking medication was the easiest part of treatment and fewer women taking metformin than insulin said that taking medication was the hardest part of treatment. 
Separately from pregnancy the risk of hypoglycaemia in patients with Type 2 diabetes is particularly elevated in those receiving insulin therapy. Patients with type 2 diabetes mellitus treated with sulfonylureas such as glibenclamide are also at increased risk of experiencing hypoglycaemic symptoms. Metformin monotherapy is not associated with hypoglycaemia. ${ }^{60,61}$ It has been demonstrated that hypoglycaemia is inversely related to quality of life and well-being in patients with $\mathrm{T}^{2} \mathrm{DM}^{60}$.Guidelines in few countries include metformin or glibenclamide for antenatal management of GDM with a survey study of GDM health workers reporting $17 \%$ of countries surveyed reporting use of metformin and $10.6 \%$ glibenclamide. ${ }^{62}$ Additional attractions for using these drugs are decreased cost and easier administration than insulin if diet therapy is insufficient.

\section{Limitations of the review}

There are a number of potential limitations with this review. While a systematic search was carried out and every effort made to identify relevant studies it is possible that some studies may have been missed. Qualitative studies can be hard to find and indexing is poorer than for quantitative studies, as they are often not referenced in the usually indexed search engines. ${ }^{63,64}$ Also studies that have been conducted and indexed since the search have not been included in this review, and it may be necessary to perform and update as other studies are conducted. Only English language studies were included and this presents another limitation.

This review pooled the data from participants with pre-existing and GDM and also women from ethnic minority groups, at-risk groups and from across socioeconomic groups where subgroup analysis may reveal different findings.

\section{Conclusion}

This review identified a number of studies addressing the pregnant women's experience of adherence to treatment for diabetes during the course of pregnancy. Findings were extracted from these studies and then synthesised. These synthesised findings stressed that health professionals should recognise 
that pregnant women's experiences of their medical conditions and treatments can affect their adherence to treatment regimes and therefore their continued health and benefit perinatal outcomes. Health professionals also need to acknowledge that both the medical condition and pregnancy are only part of women's complex lives and that treatment regimes should accommodate this as far as possible. Treatment of the pregnant diabetic involves a number of different health professionals and it is important that these professions works in synchrony and appointments are made in a timely and appropriate time frame. The 2008 Cochrane review ${ }^{13}$ conducted to ascertain the evidence for interventions to enhance adherence to medication regimes showed that for short-term drug treatments, counselling, written information and personal phone calls were beneficial. This is particularly relevant for the treatment of GDM as the condition is likely to be relatively short-term (albeit with longer-term consequences and risks), and indeed many of the women in this review cited the need for timely delivery of information, both written and verbal, to be advantageous to improving their understanding of and adherence to treatment regimes.

The findings of this review suggest that the simplest clinically appropriate treatment should be offered to women with diabetes in pregnancy and that education needs to be offered, both orally and written, to support them to adjust to their condition, which for many of them was a life-changing circumstance.

\section{Implications for practice}

Health professionals should be aware of the implications of the two synthesised findings of this review, namely that:

- Health professionals should be aware that their attitudes and practices in the care of women with diabetes during pregnancy needs to be empathetic and based upon a collaborative model of care

- Continued development and promotion of educational programs with an emphasis on 'teaching' empathy in medical and other health professional undergraduate programs would benefit patient's adherence to treatment regimes.

- Women with perceived low adherence need time to adjust and education. These are major 
factors positively affecting women's motivation for adherence to treatment for diabetes in pregnancy.

\section{Implications for research}

Metformin is increasingly being used for the treatment of diabetes in pregnancy. There is also evidence that glibenclamide is used in pregnancy and both show no indication of teratogenic effects. ${ }^{56-58}$ There is some information that women with GDM prefer to use metformin rather than insulin where it is clinically appropriate ${ }^{59}$ but little other information regarding women's experience or perceptions of taking these medications whilst pregnant. It would be interesting to ascertain women's experience and attitudes to taking these medications via qualitative enquiry, and to determine if interventions for improvement of adherence differ between women who are pregnant and the general population as detailed in the Cochrane review ${ }^{13}$, although evidence provided from this review suggests, that at least for short-term treatment successful interventions for pregnant women with diabetes might be similar as for the general population.

\section{Conflict of Interest}

None noted 


\section{References}

1 South Australian Perinatal Practice Guidelines. Diabetes mellitus and abnormal glucose tolerance. Department of Health, Government of South Australia site. Available at http://www.sahealth.sa.gov.au/wps/wcm/connect/146238004ee2144cb404bdd150ce4f37/Diabetesmellitus-WCHN-PPG-

06082012.pdf?MOD=AJPERES\&CACHEID=146238004ee2144cb404bdd150ce4f37. Accessed Oct 4, 2012

2 South Australian Perinatal Practice Guidelines. Preconception advice. Department of Health, Government of South Australia site. Available at http://www.sahealth.sa.gov.au/wps/wcm/connect/1f11de804eed8cb5afbeaf6a7ac0d6e4/Preconceptio n-advice-WCHN-PPG-

22112011.pdf?MOD=AJPERES\&CACHEID=1f11de804eed8cb5afbeaf6a7ac0d6e4. Accessed Oct 4, 2012

3 American Diabetes Association. Diagnosis and Classification of Diabetes Mellitus. Diabetes Care. 2013;36(Supplement 1):S67-S74.

4 Colom C, Corcoy R. Maturity onset diabetes of the young and pregnancy. Best Practice \& Research Clinical Endocrinology \& Metabolism. 2010;24(4):605-15.

5 Nelson-Piercy C. Diabetes mellitus. Handbook of Obstetric Medicine. Fourth ed. London: informa healthcare 2010:79-95.

6 U.S. Department of Health and Human Services. Womens Health USA 2010.: U.S. Department of Health and Human Services,. Health Resources and Services Administration. Rockville, Maryland: U.S. Department of Health and Human Services, 2010.;

7 Australian Government, Australian Institute of Health and Welfare. Australia's health 2010. Canberra 2010. Available at http://www.aihw.gov.au/publication-detail/?id=6442468376. Accessed August 4, 2013 

conditions by pregnant women attending an Australian maternity hospital. Australian and New Zealand Journal of Obstetrics and Gynaecology. 2011;51(4):333-8.

9 Schwartz R, Teramo KA. Effects of diabetic pregnancy on the fetus and newborn. Seminars in Perinatology. 2000;24(2):120-35.

10 U.S.Food and Drug Administration. Pregnancy and Lactation Labelling. 2012 [cited 27/5/2012]; Available from:

http://www.fda.gov/Drugs/DevelopmentApprovalProcess/DevelopmentResources/Labeling/ucm09330 7.htm.

11 Kennedy D. A to X: the problem of categorisation of drugs in pregnancy - an Australian perspective. MJA. 2011;195(10):572-4.

12 Nordeng H, Ystrøm E, Einarson A. Perception of risk regarding the use of medications and other exposures during pregnancy. European Journal of Clinical Pharmacology. 2010;66(2):207-14.

13 Haynes R, Ackloo E, Sahota N, McDonald H, Yao X. Interventions for enhancing medication adherence. Cochrane Database of Systematic Reviews. 2008(2):CD000011.

14 Persson M, Hörnsten Å, Winkvist A, Mogren I. "Mission Impossible"? Midwives' experiences counseling pregnant women with gestational diabetes mellitus. Patient Education and Counseling. 2011;84(1):78-83.

15 Persson M, Hornsten $\AA$, Winkvist A, Mogren I. 'Dealing with ambiguity'- the role of obstetricians in gestational diabetes mellitus. Acta Obstetricia et Gynecologica Scandinavica. 2012;91(4):439-46.

16 The Kafka Project by Mauro Nervi, (Internet) A Country Doctor. (Translated I Johnston). December 2003; [cited 8/8/2013]; line 82. Available from: http://www.kafka.org/index.php?aid=168

17 Becker MH, Maiman LA. Sociobehavioral Determinants of Compliance with Health and Medical Care Recommendations.Medical Care. 1975;13(1):10-24.

18 Lagan BM, Sinclair M, George Kernohan W. Internet Use in Pregnancy Informs Women's Decision Making: A Web-Based Survey. Birth. 2010;37(2):106-15.

19 Horne R, Weinman J, Barber N, Elliot R, Morgan M. [December 2005]. Concordance, adherence and compliance in medicine taking. Report for the National Coordinating Centre for NHS 
Service Delivery and Organization R \& D (NCCSDO) Available at http://www.netscc.ac.uk/hsdr/files/project/SDO_ES_08-1412-076_V01.pdf, accessed 25 May 2012

20 Vrijens B, De Geest S, Hughes DA et al. A new taxonomy for describing and defining adherence to medications. British Journal of Clinical Pharmacology. 2012;73(5):691-705.

21 McHorney CA, Gadkari AS. Individual patients hold different beliefs to prescription medications to which they persist vs nonpersist and persist vs nonfulfill. Patient Preference and Adherence. 2010;2010(4):187 - 95.

22 Lewis G. The Confidential Enquiry into Maternal and Child Health (CEMACH). Saving Mothers' Lives: reviewing maternal deaths to make motherhood safer - 2003-2005. The Seventh Report on Confidential Enquiries into Maternal Deaths in the United Kingdom. London. CEMACH.; 2007.

23 Black N. Why we need qualitative research. J Epidemiol Community Health 1994;48(5):425-6.

24 Popay J, Williams G. Qualitative research and evidence-based healthcare. J R Soc Med 1998;91(Suppl 35):32-7.

25 Pearson A, Robertson-Malt S, Rittenmeyer L. Synthesizing Qualitative Evidence: LippincottJoanna Briggs Institute 2011.

26 Crotty $M$. The foundations of social research : meaning and perspective in the research process. St Leonards, NSW: Allen \& Unwin 1998

27 Hannes K, Lockwood C. Pragmatism as the philosophical foundation for the Joanna Briggs meta-aggregative approach to qualitative evidence synthesis. Journal of Advanced Nursing. $2011 ; 67(7): 1632-42$.

28 Walsh D, Downe S. Meta-synthesis method for qualitative research: a literature review. Journal of Advanced Nursing. 2005;50(2):204-11.

29 Kelsey JL. Observational Epidemiology. In: Editor-in-Chief: Kris H, ed. International Encyclopedia of Public Health. Oxford: Academic Press 2008:609-20.

30 Bandyopadhyay M, Small R, Davey M-A, Oats JJN, Forster DA, Aylward A. Lived experience of gestational diabetes mellitus among immigrant South Asian women in Australia. The Australian \& New Zealand journal of obstetrics \& gynaecology. 2011;51(4):360-4. 
Bieda J. Perceptions of risk for the development of type 2 diabetes in African-American women with gestational diabetes [Dissertation]. [Michigan - United States]. [University of Michigan]; 2009.

32 Brooks LM. Perceived barriers to treatment adherence among pregnant African American women with diabetes [Dissertation]:[Ohio - United States]: Case Western Reserve University (Health Sciences); 2002.

33 Hirst JE, Tran TS, Do MAT, Rowena F, Morris JM, Jeffery HE. Women with gestational diabetes in Vietnam: a qualitative study to determine attitudes and health behaviours. BMC pregnancy and childbirth. 2012;12(10.1186/1471-2393-12-81):81.

34 Hjelm K, Berntorp K, Apelqvist J. Beliefs about health and illness in Swedish and African - born women with gestational diabetes living in Sweden. Journal of Clinical Nursing. 2012;21(9-10):1374-86.

35 Hjelm K, Bard K, Nyberg DA, Apelqvist J. Swedish and Middle-Eastern-born women's beliefs about gestational diabetes. Midwifery. 2005 Mar;21(1):44-60.

36 Hjelm K, Bard K, Nyberg P, Apelqvist J. Management of gestational diabetes from the patient's perspective - a comparison of Swedish and Middle-Eastern born women. Journal of Clinical Nursing. 2007;16(1):168-78.

37 Hjelm K, Berntorp K, Frid A, Aberg A, Apelqvist J. Beliefs about health and illness in women managed for gestational diabetes in two organisations. Midwifery. 2008;24(2):168-82.

38 Neufeld HT. Food Perceptions and Concerns of Aboriginal Women Coping with Gestational Diabetes in Winnipeg, Manitoba. Journal of Nutrition Education \& Behavior. 2011;43(6):482-91.

39 Berg M. Pregnancy and diabetes: how women handle the challenges. Journal of Perinatal Education. 2005;14(3):23-32.

40 Berg M, Honkasalo ML. Pregnancy and diabetes--a hermeneutic phenomenological study of women's experiences. J Psychosom Obstet Gynaecol. 2000;21(1):39-48.

41 Carolan M. Women's experiences of gestational diabetes self-management: A qualitative study. Midwifery. 2013;29(6):637-45.

42 Carolan MC, Gill G, Steele C. Women's experiences of factors that facilitate or inhibit gestational diabetes self-management. BMC pregnancy and childbirth. 2012;12(1):99. 
43 Evans MK, O'Brien B. Gestational Diabetes: The Meaning of an At-Risk Pregnancy. Qualitative Health Research. 2005;15(1):66-81.

44 Lavender T, Platt MJ, Tsekiri E et al. Women's perceptions of being pregnant and having pregestational diabetes. Midwifery. 2010;26(6):589-95.

45 Richmond J. Coping with diabetes through pregnancy. British Journal of Midwifery. 2009;17(2):84-91 .

46 Sheffer CJ. The lived experience of pregnancy for women with pre-existing insulin-dependent diabetes [Dissertation]. Canada: [Dalhousie University (Canada)]; 2000.

47 Hamel LC. Planning for a healthier birth and beyond: Strategies women use to manage gestational diabetes [Dissertation]. [Maine - United States]. [The University of Maine]; 2003.

48 Horrocks L. A qualitative analysis of the psychological impact of pregnancy for first time mothers with type 1 diabetes. [Dissertation]: [University of East Anglia]; 2009.

49 Persson M, Winkvist A, Mogren I. 'From stun to gradual balance'--women's experiences of living with gestational diabetes mellitus. Scand J Caring Sci. 2010;24(3):454-62.

50 Stenhouse E, Letherby G, Stephen N. Women with pre-existing diabetes and their experiences of maternity care services. Midwifery. 2012(10.1016/j.midw.2011.12.007).

51 Lawson EJ, Rajaram S. A transformed pregnancy : the psychosocial consequences of gestational diabetes. Sociology of Health \& IIIness. 1994;16(4):536-62.

52 Kardas P, Lewek P, Matyjaszczyk M. Determinants of patient adherence: a review of systematic reviews. Frontiers in Pharmacology. 2013;4.

53 Pedersen R. Empathy development in medical education - A critical review. Medical Teacher. 2010;32(7):593-600.

54 Rosenn BM, Miodovnik M. Glycemic control in the diabetic pregnancy: Is tighter always better? Journal of Maternal-Fetal and Neonatal Medicine. 2000;9(1):29-34.

55 Yogev Y, Ben-Haroush A, Chen R, Rosenn B, Hod M, Langer O. Undiagnosed Asymptomatic Hypoglycemia: Diet, Insulin, and Glyburide for Gestational Diabetic Pregnancy. Obstetrics \& Gynecology. 2004;104(1):88-93 10.1097/01.AOG.0000129239.82126.a1. 
56 Nicholson W, Baptiste-Roberts K. Oral hypoglycaemic agents during pregnancy: The evidence for effectiveness and safety. Best Practice \& Research Clinical Obstetrics \& Gynaecology. 2011;25(1):51-63.

57 Gilbert C, Valois M, Koren G. Pregnancy outcome after first-trimester exposure to metformin: a meta-analysis. Fertility and Sterility. 2006;86(3):658-63.

58 Gutzin S, Kozer E, Magee L, Feig D, Koren G. The safety of oral hypoglycemic agents in the first trimester of pregnancy: A meta-analysis. Canadian Journal of Clinical Pharmacology. 2003;10(4):179 - 83.

59 Rowan JA, Hague WM, Gao W, Battin MR, Moore MP. Metformin versus Insulin for the Treatment of Gestational Diabetes. New England Journal of Medicine. 2008;358(19):2003-15.

60 Alvarez-Guisasola F, Yin DD, Nocea G, Qiu Y, Mavros P. Association of hypoglycemic symptoms with patients' rating of their health-related quality of life state: a cross sectional study. Health Qual Life Outcomes. 2010;8:86.

61 Rossi S, ed. Australian Medicines Handbook. 2013 ed 2013.

62 Jiwani A, Marseille E, Lohse N. Gestational diabetes mellitus: results from a survey of country prevalence and practices. Journal of Maternal-Fetal and Neonatal Medicine. 2012;25(6):600-10.

63 Atkins S, Lewin S, Smith H, Engel M, Fretheim A, Volmink J. Conducting a meta-ethnography of qualitative literature: Lessons learnt. BMC Me Res Methodol. 2008;8(1):1-10.

64 The Joanna Briggs Institute. Joanna Briggs Institute Reviewers' Manual: 2011 edition: The Joanna Briggs Institute 2011. 


\section{Appendix I: Search strategy}

\section{Pubmed - search conducted 22 October 2012}

\#4 Add Search ((\#3) AND \#2) AND \#1

\#3 Add Search Experience[tw] OR interviews as topic[mh] OR interview*[tw] OR focus group*[tw] OR anecdotes as topics[mh] OR anecdot*[tw] OR qualitative research[mh] OR qualitative[tw] OR grounded theor*[tw]

\#2 Add Search Diabet*[tw] OR glucose metabolism disorders[mh] OR prediabet* ${ }^{*}[\mathrm{tw}]$ OR blood glucose[mh] OR blood glucose self-monitoring[mh] OR blood glucose[tw] OR blood sugar*[tw] OR glucose tolerance test[mh] OR glucose tolerance[tw] OR hypoglycem*[tw] OR hyperglycem*[tw]

\#1 Add Search Pregnan*[tw] OR pregnancy[mh:noexp] OR prenatal care[mh] OR prenatal[tw] OR pregnancy in diabetes[mh] OR matern*[tw] OR maternal behaviour[mh] OR mother*[tw] OR mothers[mh] OR pregnancy trimesters[mh] OR trimester ${ }^{*}[\mathrm{tw}]$

\section{Embase - search conducted 22 October 2012}

\#4\#1 AND \#2 AND \#3

\#3'pregnancy'/exp OR pregnan*:ab,ti OR 'prenatal care'/exp OR prenatal:ab,ti OR 'maternal behaviour'/exp OR matern*:ab,ti OR 'mother'/exp OR mother*ab,ti OR trimester*ab,ti

\#2'disorders of carbohydrate metabolism'/exp OR diabetes:ab,ti OR diabetic:ab,ti OR 'glucose blood level'/exp OR 'blood glucose monitoring'/exp OR 'blood glucose':ab,ti OR 'blood sugar':ab,ti OR hypoglycem*:ab,ti OR hyperglycem*:ab,ti OR 'glucose tolerance test'/exp OR 'glucose tolerance'/exp \#1'qualitative research'/exp OR 'qualitative analysis'/exp OR qualitative:ab,ti OR 'interview'/exp OR interview:ab,ti OR interviews:ab,ti OR 'focus group':ab,ti OR 'focus groups':ab,ti OR 'grounded theory'/exp OR 'grounded theory':ab,ti OR 'content analysis'/exp OR 'content analysis':ab,ti OR 'thematic analysis':ab,ti OR 'thematic analysis'/exp OR 'nursing research'/exp 


\section{Cinahl - search conducted 22 October 2012}

S4 S1 and S2 and S3

S3 (MH "Mothers") OR (MH "expectant mothers") OR mother\$ OR (MH "Pregnancy Trimesters") OR (MH "Pregnancy") OR (MH "Postnatal Period") OR (MH "Periconceptual Period") OR trimester OR Pregnan\$ OR Matern\$

S2 (MH "Blood Glucose") OR (MH "Blood Glucose Monitoring") OR (MH "Blood Glucose SelfMonitoring") OR "diabetes and pregnancy" OR (MH "Diabetes Mellitus, Gestational") OR (MH "Diabetes Mellitus") OR (MH "Pregnancy in Diabetes") OR (MH "Prediabetic State") OR "gestational diabetes" OR "gestational diabetic" OR diabetic

S1 (MH "Qualitative Studies+") or "Action Research" or "Ethnographic Research" or "Ethnological Research" or "Ethnonursing Research" or "Grounded Theory" or "Naturalistic Inquiry" or "Phenomenological Research" or phenomenology or "focus group" or (MH Interviews+) or "qualitative research" or (MH "Discourse Analysis") OR (MH "Thematic Analysis") OR (MH "Content Analysis") OR (MH "Focus group")

\section{PsychINFO - search conducted 22 October 2012}

\section{S1 and S2 and S3}

S3 DE "Qualitative Research" OR DE "Empirical Methods" OR DE "Grounded Theory" OR DE "Interviews" OR DE "Observation Methods" OR DE "Grounded Theory" OR DE "Interviews" OR DE "Hermeneutics" OR DE "Phenomenology" OR qualitative OR experience OR perception OR understand OR understanding OR belief

S2 DE "Diabetes" OR DE "Diabetes Mellitus" OR DE "Diabetes" OR DE "Diabetes Mellitus" OR DE "Glucose" OR DE "Sugars" OR DE "Blood Sugar" OR diabetes OR diabetic OR diabetics OR "gestational diabetes" OR "gestational diabetics" or "pregnancy in diabetics" OR "gestational diabetic" S1 (DE "Pregnancy") OR (DE "Obstetrical Complications") OR (DE "Pregnancy Outcomes") OR (DE "Expectant Mothers") OR (DE "Mothers") OR pregnancy OR maternal OR maternity OR prenatal OR gestational OR pregnant 


\section{Academic Search Premier - search conducted 22 October 2012}

S1 and S2 and S3

S3 (MH "Qualitative Studies+") or "Action Research" or "Ethnographic Research" or "Ethnological Research" or "Ethnonursing Research" or "Grounded Theory" or "Naturalistic Inquiry" or "Phenomenological Research" or phenomenology or "focus group" or (MH Interviews+) or "qualitative research" or (MH "Discourse Analysis") OR (MH "Thematic Analysis") OR (MH "Content Analysis") OR (MH "Focus group")

S2 (MH "Blood Glucose") OR (MH "Blood Glucose Monitoring") OR (MH "Blood Glucose SelfMonitoring") OR "diabetes and pregnancy" OR (MH "Diabetes Mellitus, Gestational") OR (MH "Diabetes Mellitus") OR (MH "Pregnancy in Diabetes") OR (MH "Prediabetic State") OR "gestational diabetes" OR "gestational diabetic" OR diabetic

S1 (MH "Mothers") OR (MH "expectant mothers") OR mother\$ OR (MH "Pregnancy Trimesters") OR (MH "Pregnancy") OR (MH "Postnatal Period") OR (MH "Periconceptual Period") OR trimester OR Pregnan\$ OR Matern\$

\section{Biosis Previews - search conducted 23 October 2012}

\# 4 \#3 AND \#2 AND \#1

\# 3 TS=Diabet ${ }^{\star}$ OR TS=(glucose metabolism disorders) OR TS=prediabet ${ }^{\star}$ OR TS=(blood glucose) OR TS=(blood glucose self-monitoring) OR TS=(blood glucose) OR TS=(blood sugar $\left.{ }^{\star}\right)$ OR $T S=($ glucose tolerance test) OR TS=(glucose tolerance) $O R T S=$ hypoglycem* OR TS=hyperglycem* OR TS=(gestational diabet $\left.{ }^{\star}\right)$

\# 2 TS=Pregnan* OR TS=pregnancy OR TS=(prenatal care) OR TS=prenatal OR TS=(pregnancy in diabetes) OR TS=matern* OR TS=(maternal behaviour) OR TS=mother* OR TS=mothers OR $\mathrm{TS}=($ pregnancy trimesters $) \mathrm{OR}$ TS=trimester ${ }^{*}$

\# 1 TS=Experience OR TS=interview* OR TS=(focus group*) OR TS=anecdot* OR TS=(qualitative research) OR TS=qualitative OR TS=(grounded theor ${ }^{*}$ ) 


\section{Ethos - search conducted 23 October 2012}

Experience or Qualitative AND Diabetes or Diabetic AND Pregnancy or Pregnant

Index to Thesis - Search conducted 23 October 2012

(experience) OR (qualitative) AND (diabetes) AND (pregnancy)

Mednar - search conducted 23 October 2012

pregnan* $^{*}$ and diabet* and (qualitative or experienc ${ }^{*}$ )

Proquest dissertations and theses - search conducted 23 October 2012

( $\mathrm{TI}, \mathrm{AB}\left(\right.$ pregnan $\left.^{*}\right)$ OR TI,AB(prenatal) OR TI,AB(mater*) OR TI,AB(mother $\left.{ }^{*}\right)$ OR TI,AB(trimester $\left.{ }^{*}\right)$ ) AND (TI,AB(disorders of carbohydrate metabolism) OR TI,AB(diabet $\left.{ }^{\star}\right)$ OR TI,AB(glucose blood level ${ }^{*}$ ) OR $\mathrm{TI}, \mathrm{AB}$ (blood glucose monitoring) OR $\mathrm{Tl}, \mathrm{AB}$ (blood glucose) $\mathrm{OR} \mathrm{Tl}, \mathrm{AB}$ (blood sugar) $\mathrm{OR}$ $\mathrm{TI}, \mathrm{AB}\left(\right.$ hypoglycaemia*) $\quad \mathrm{OR} \quad \mathrm{TI}, \mathrm{AB}\left(\right.$ hyperglycemia*$\left.^{*}\right) \quad \mathrm{OR} \quad \mathrm{Tl}, \mathrm{AB}$ (glucose tolerance)) $\mathrm{AND}$ ( $\mathrm{TI}, \mathrm{AB}$ (qualitative) $\mathrm{OR} \mathrm{TI}, \mathrm{AB}$ (interview*) $\mathrm{OR} \mathrm{TI}, \mathrm{AB}$ (focus group*) $\mathrm{OR} \mathrm{TI}, \mathrm{AB}$ (grounded theory) $\mathrm{OR}$ $\mathrm{TI}, \mathrm{AB}$ (content analysis) $\mathrm{OR} \quad \mathrm{TI}, \mathrm{AB}$ (thematic analysis) $\mathrm{OR} \quad \mathrm{TI}, \mathrm{AB}$ (nursing research) $\mathrm{OR}$ $\mathrm{TI}, \mathrm{AB}($ experience* $))$ 


\title{
Appendix II: Appraisal instrument
}

\author{
QARI Appraisal instrument
}

\section{JBI QARI Critical Appraisal Checklist for Interpretive \& Critical Research}

Reviewer . . . . . . . . . . . . . . .

Author Year

Record Number

1. Is there congruity between the stated philosophical perspective and the research methodology?

2. Is there congruity between the research methodology and the research question or objectives?

3 . Is there congruity between the research methodology and the methods used to collect data?

4. Is there congruity between the research methodology and the representation and analysis of data?

5 . Is there congruity between the research methodology and the interpretation of results?

6. Is there a statement locating the researcher culturally or theoretically?

7. Is the influence of the researcher on the research, and vice-versa, addressed?

8. Are participants, and their voices, adequately represented?

9. Is the research ethical according to current criteria or, for recent studies, and is there evidence of ethical approval by an appropriate body?

10. Do the conclusions drawn in the

research report flow fom the analysis, of interpretation, of the data?

Yes No Unclear Not Applicable

Overall appraisal:

Include $\square \quad$ Exclude

Seek furher info.

Comments (including reason for exclusion) 
Appendix lla - Final Assessment Table

\begin{tabular}{|c|c|c|c|c|c|c|c|c|c|c|}
\hline Citation & Q1 & Q2 & Q3 & Q4 & Q5 & Q6 & Q7 & Q8 & Q9 & Q10 \\
\hline Brooks $2002^{32}$ & $U$ & $\mathrm{Y}$ & $\mathrm{Y}$ & Y & Y & $\mathrm{N}$ & $\mathrm{N}$ & $\mathrm{Y}$ & Y & Y \\
\hline Sheffer $2000^{46}$ & Y & Y & Y & Y & Y & $\mathrm{N}$ & $\mathrm{N}$ & Y & Y & Y \\
\hline Berg $2005^{39}$ & Y & Y & Y & Y & Y & Y & $U$ & Y & Y & Y \\
\hline Berg \& Honkasalo $2000^{40}$ & Y & Y & Y & Y & Y & Y & $U$ & Y & U & Y \\
\hline Carolan et al, $2012^{42}$ & Y & Y & Y & Y & Y & Y & N & Y & Y & Y \\
\hline Evans \& O'Brien, $2005^{43}$ & Y & Y & Y & Y & Y & N & N & Y & Y & Y \\
\hline Hamel $2003^{47}$ & Y & Y & Y & Y & Y & Y & Y & Y & Y & Y \\
\hline Hirst et al $2012^{33}$ & $U$ & Y & Y & Y & Y & Y & N & Y & Y & Y \\
\hline Hjelm et al $2005^{35}$ & $U$ & Y & Y & Y & Y & U & N & Y & Y & U \\
\hline Hjelm et al $2007^{36}$ & $U$ & $U$ & Y & $Y$ & Y & $\mathrm{N}$ & $U$ & $Y$ & Y & U \\
\hline Hjelm et al $2008^{37}$ & U & Y & Y & Y & Y & U & U & Y & Y & Y \\
\hline Horrocks 200948 & Y & Y & Y & Y & Y & Y & Y & Y & Y & Y \\
\hline Lavender et al $2010^{44}$ & Y & Y & Y & Y & Y & Y & U & Y & Y & Y \\
\hline Persson et al $2010^{49}$ & Y & Y & Y & Y & Y & U & Y & Y & Y & Y \\
\hline Neufeld $2011^{38}$ & $U$ & Y & Y & $Y$ & Y & U & $U$ & Y & Y & Y \\
\hline Richmond 200945 & Y & Y & Y & Y & Y & U & U & Y & U & Y \\
\hline Stenhouse et al $2012^{50}$ & $U$ & Y & Y & $Y$ & $Y$ & Y & $U$ & Y & Y & Y \\
\hline
\end{tabular}




\begin{tabular}{|c|c|c|c|c|c|c|c|c|c|c|}
\hline Hjelm K et al $2012^{34}$ & u & $\mathrm{Y}$ & $\mathrm{Y}$ & $\mathrm{Y}$ & Y & U & U & Y & Y & Y \\
\hline Lawson \& Rajaram 199451 & U & Y & Y & Y & Y & $\mathrm{N}$ & $\mathrm{N}$ & Y & U & Y \\
\hline Bandyopadhyay et al $2011^{30}$ & U & Y & Y & Y & U & U & $\mathrm{N}$ & $\mathrm{N}$ & Y & Y \\
\hline Carolan $2013^{41}$ & Y & Y & Y & Y & Y & Y & Y & Y & Y & Y \\
\hline Bieda $2009^{31}$ & Y & Y & Y & Y & Y & U & U & Y & Y & Y \\
\hline$\%$ & 54.55 & 95.45 & $\begin{array}{l}100.0 \\
0\end{array}$ & $\begin{array}{l}100.0 \\
0\end{array}$ & 95.45 & 40.91 & 18.18 & 95.45 & 86.36 & 90.91 \\
\hline
\end{tabular}




\section{Appendix III: Data extraction instruments}

QARI data extraction instrument

JBI QARI Data Extraction Form for Interpretive \& Critical Research

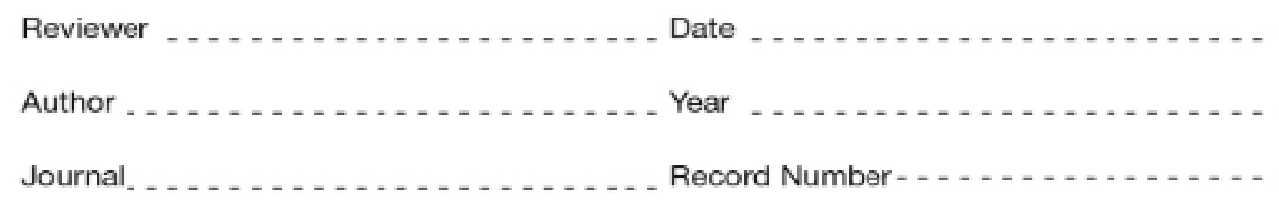

Study Description

Methodology

Method

Phenomena of interest

Setting

Geographical

Cultural

Participants

Data analysis

Authors Conclusions

Comments

Complete

Yes $\square$

No $\square$ 


\begin{tabular}{|l|l|l|l|l|}
\hline \multirow{2}{*}{ Findings } & $\begin{array}{c}\text { Illustration from } \\
\text { Publication } \\
\text { (page number) }\end{array}$ & Unequivocal & Credible & Unsupported \\
\hline & & & & \\
\hline & & & & \\
\hline & & & & \\
\hline & & & & \\
\hline & & & & \\
\hline & & & & \\
\hline & & & & \\
\hline & & & & \\
\hline & & & & \\
\hline & & & & \\
\hline & & & & \\
\hline & & & & \\
\hline
\end{tabular}

Extraction of findings complete

Yes $\square$

No $\square$ 


\title{
Appendix IV: Qari graph - Alternative presentation of synthesised findings and metasynthesis
}

\author{
Synthesised finding 1 - Health professionals should be aware that their attitudes and practices in \\ the care of women with diabetes during pregnancy needs to be empathetic and based upon a \\ collaborative model of care.
}

Health professionals were seen to be either supportive and accessible or unsupportive for a variety of reasons. These included being judgmental of the woman, not providing relevant information, timewasting, and not acknowledging women's knowledge of diabetes.

Health professionals concentrated on their individual area of expertise rather than treating the woman as a complete individual. For example, diabetes nurse concentrated on diabetes only and the midwife on pregnancy only, which was seen to be negative. Health professionals did not always provide enough information in a timely or appropriate fashion to address women's concerns.

This metasynthesis was created from 2 categories, being "positive effects of health professionals" and "negative effects of health professionals", with a total of 29 Findings. Levels of credibility (as detailed for use with JBI-QARI) are also included for each finding.

Synthesised finding 2 - Women with perceived low adherence need time to adjust and education; these are major factors positively affecting women's motivation for adherence to treatment for diabetes in pregnancy.

With time women worked out routines and strategies to control their blood glucose. They expressed concern and anxiety for the wellbeing of their unborn baby and this often motivated them to control 
their blood glucose levels. Women with gestational diabetes expressed various emotions at the diagnosis including surprise and disbelief and women with pre-existing diabetes were concerned about their loss of diabetic control with pregnancy, their ability to care for existing children and their perception of their place in the family was challenged.

Barriers to adherence to treatment regimes included: the time spent managing their condition, frustration that blood glucose levels seemed unpredictable even though they complied to treatment regimes, concerns with blood glucose monitoring including concerns about blood loss, social isolation and pain associated with finger pricking, concern with the restrictive nature of the prescribed diet and exercise with difficulty with competing priorities with family and social obligations, and difficulties with insulin. Some acknowledged however that using insulin made control of their diabetes easier.

Enablers to good adherence to treatment regimes included support by family members and friends, concern about the wellbeing of their unborn child and the effect of their diabetes on the child and delivery of the child. Women with pre-existing diabetes felt that pregnancy conferred 'normality' on them. Women were informed of the causes of diabetes and concerned about their future with diabetes.

This metasynthesis was created from 4 categories, being "the restriction of diabetes impact a woman's lived experience", "diabetes caused a change in women's perception of self and their place in the family and of control of self", "being informed of the risks and causes of diabetes in pregnancy increases both anxiety and motivation" and "adherence to treatment improves with time, experience and support" with a total of 145 Findings. Levels of credibility (as detailed for use with JBI-QARI) are also included for each finding as illustrated in the QARI view graph below. 


\section{Synthesised Findings}

\section{Meta-Synthesis 1:}

\begin{tabular}{|l|l|l|}
\hline Finding & Category \\
\hline
\end{tabular}

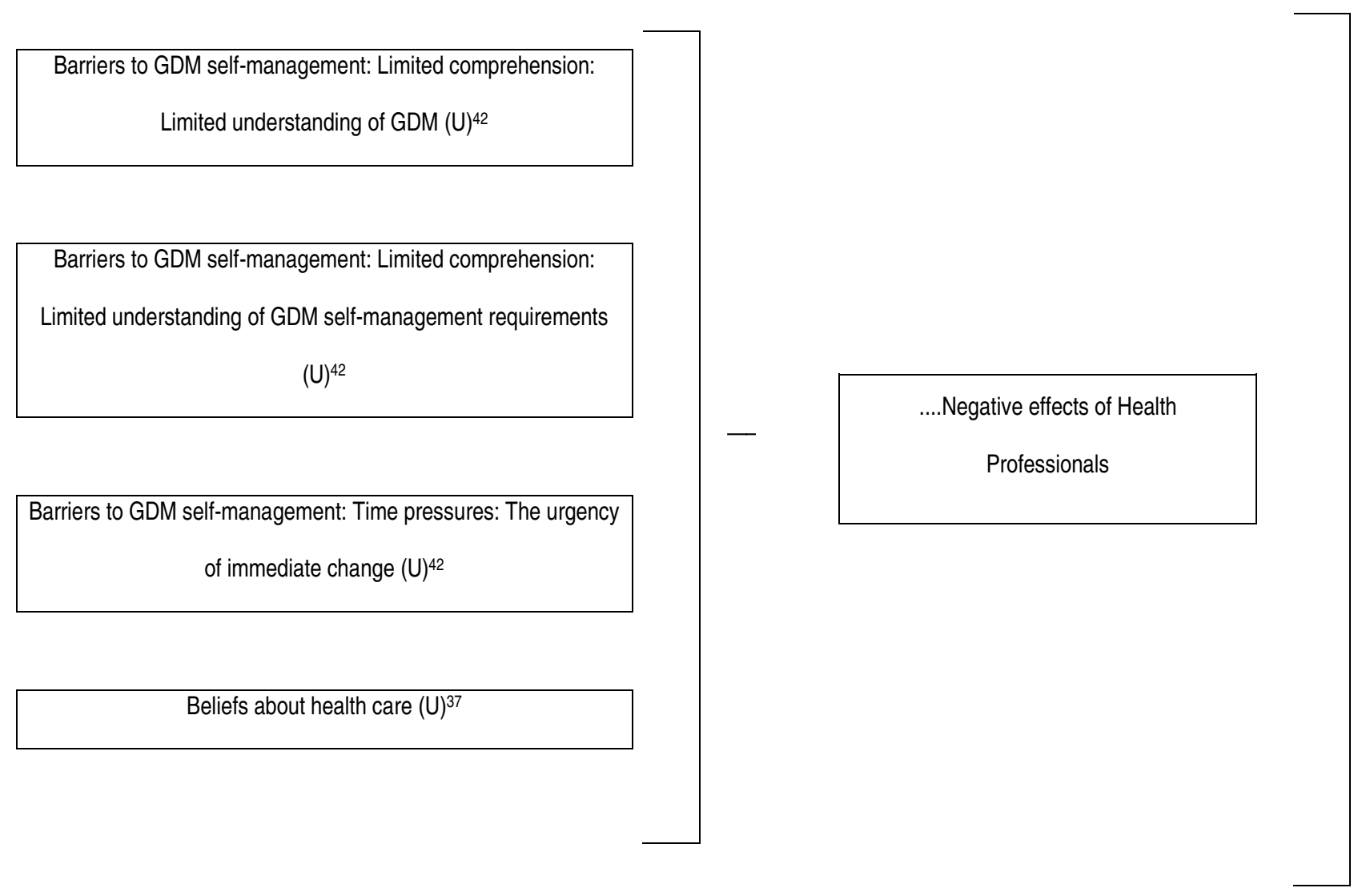

Health professionals should be aware that

their attitudes and practices in the care of

women with diabetes during pregnancy

needs to be empathetic and based upon a collaborative model of care.

Health professionals were seen to be

supportive and accessible or unsupportive

for a variety of reasons: being judgemental,

not having relevant information, time-

wasting, not acknowledging women's

knowledge of diabetes.

Health professionals concentrated on their individual area of expertise rather than

treating the woman as a complete individual 

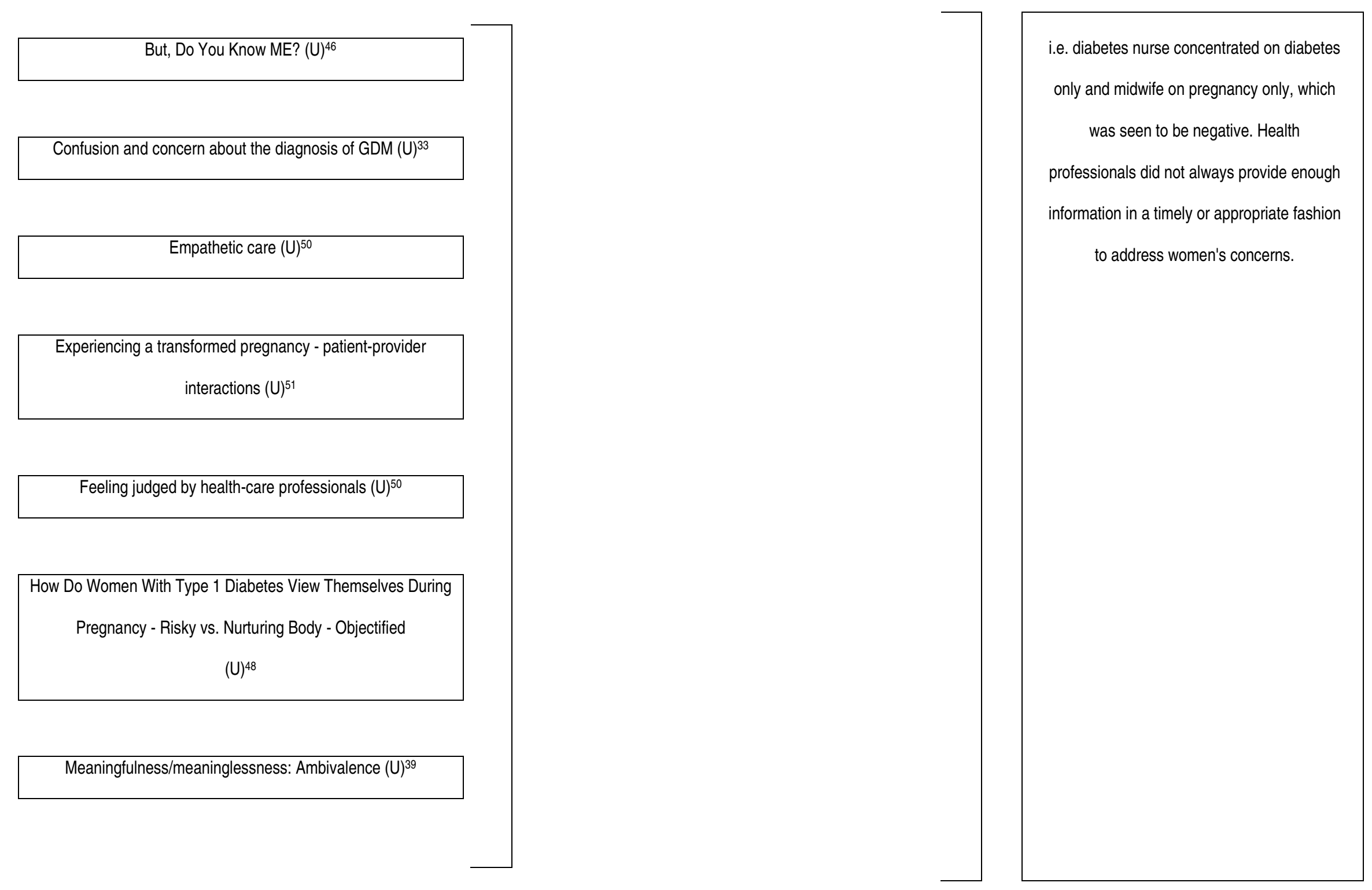

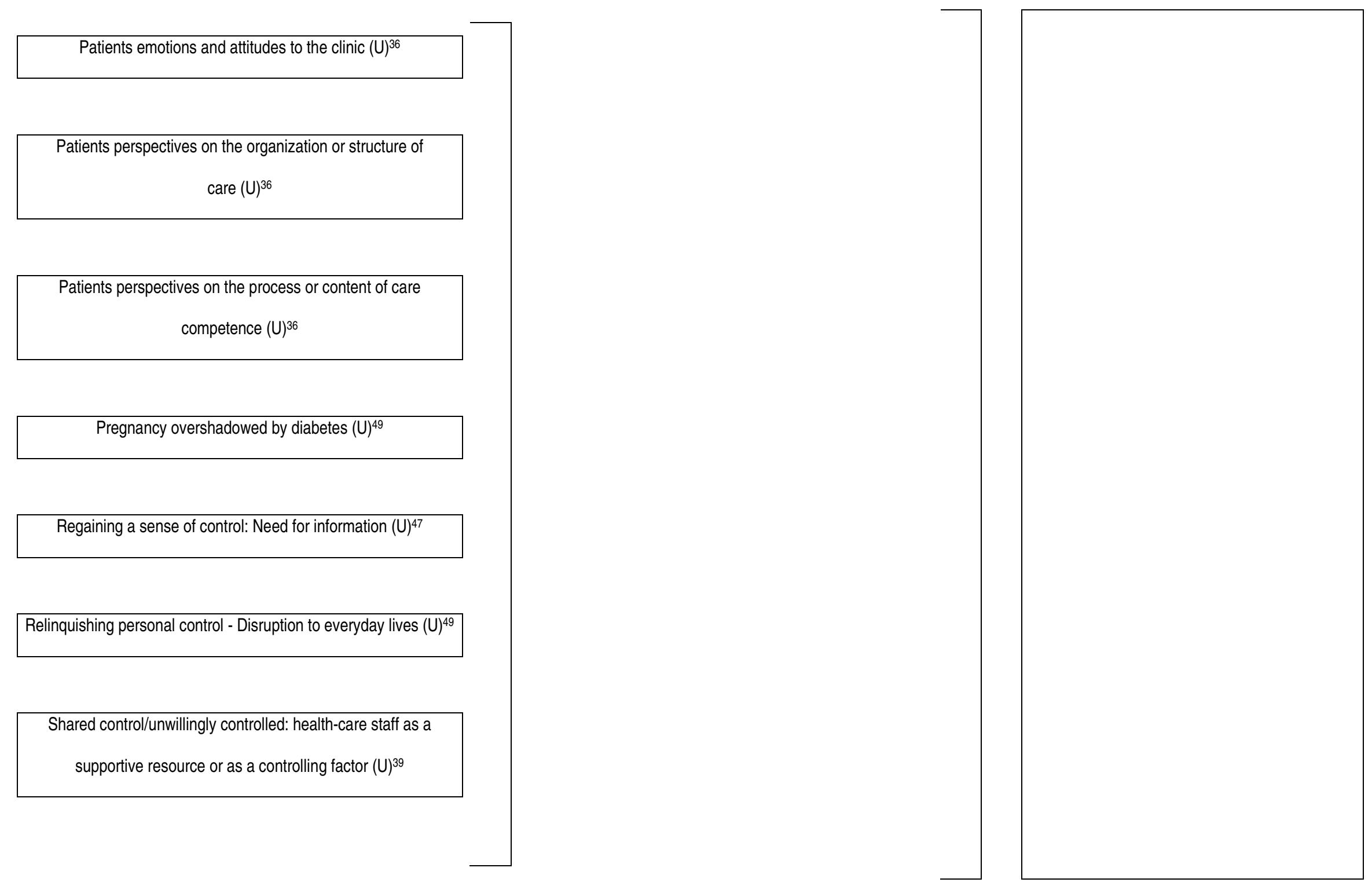

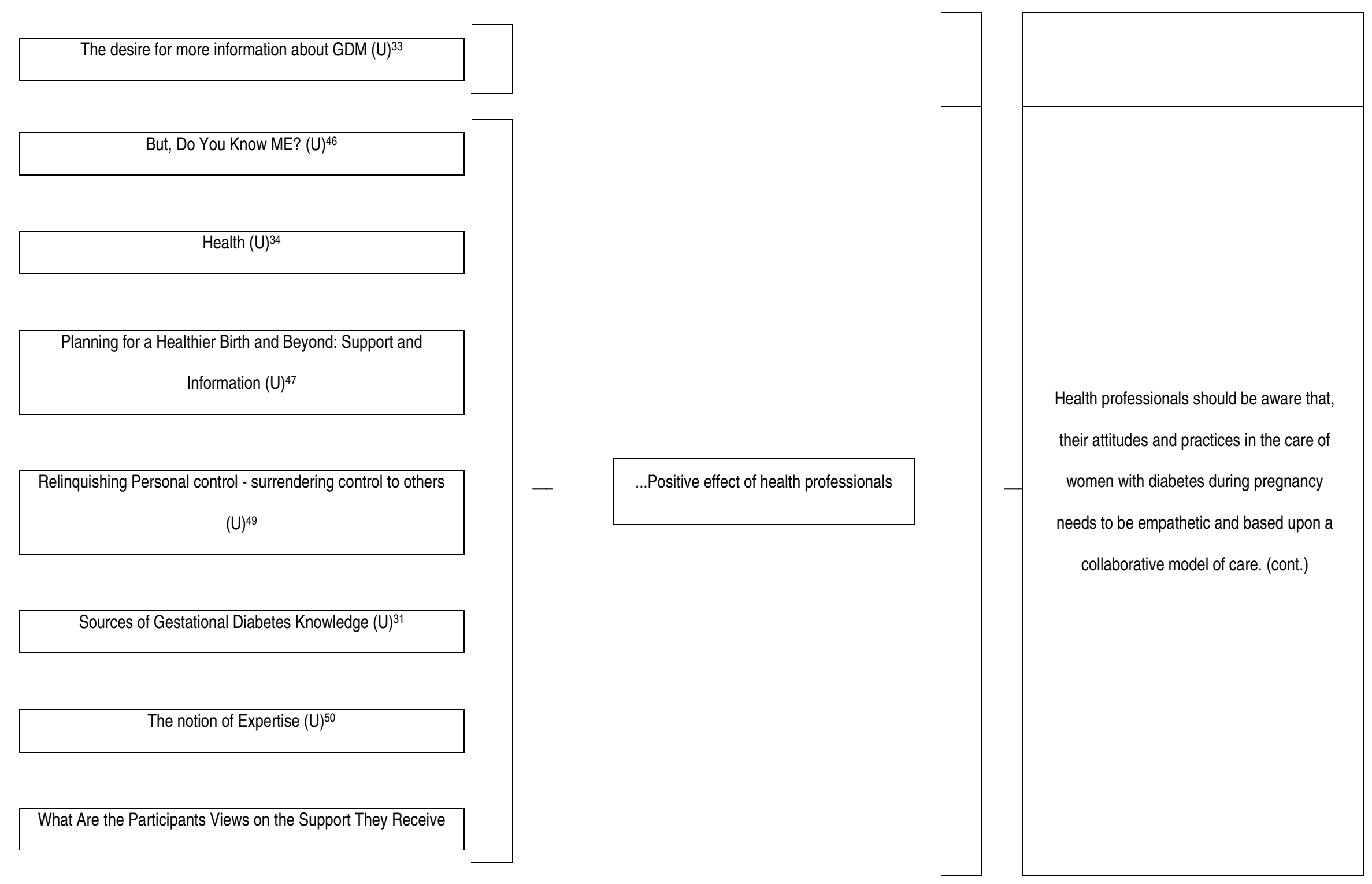
From Others - Supportive Networks (U) ${ }^{48}$

What Are the Participants Views on the Support They Receive

From Others - Supportive Networks -Professional Support How to Promote Self Care - Collaborative care $(\mathrm{U}){ }^{48}$

What Are the Participants Views on the Support They Receive

From Others - Supportive Networks -Professional Support How to

Promote Self Care - Holistic care (U) ${ }^{48}$

What Are the Participants Views on the Support They Receive

From Others - Supportive Networks -Professional Support How to

Promote Self Care - Specialist care (U) ${ }^{48}$

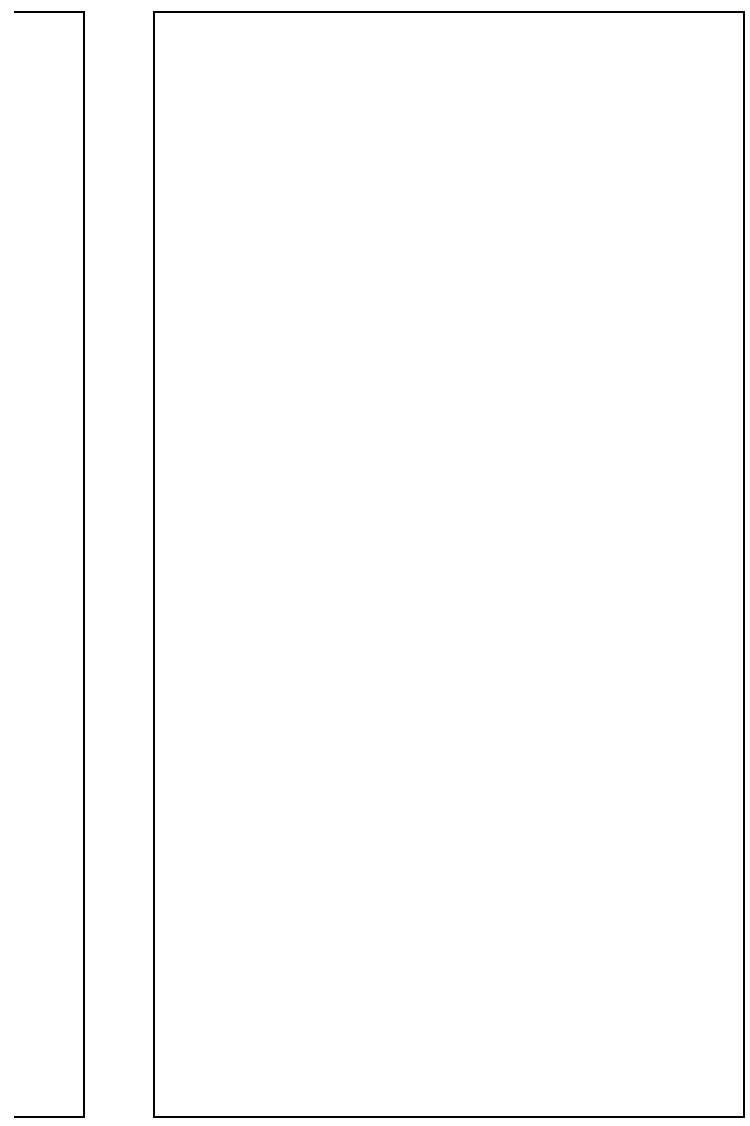

Meta-Synthesis 2: 


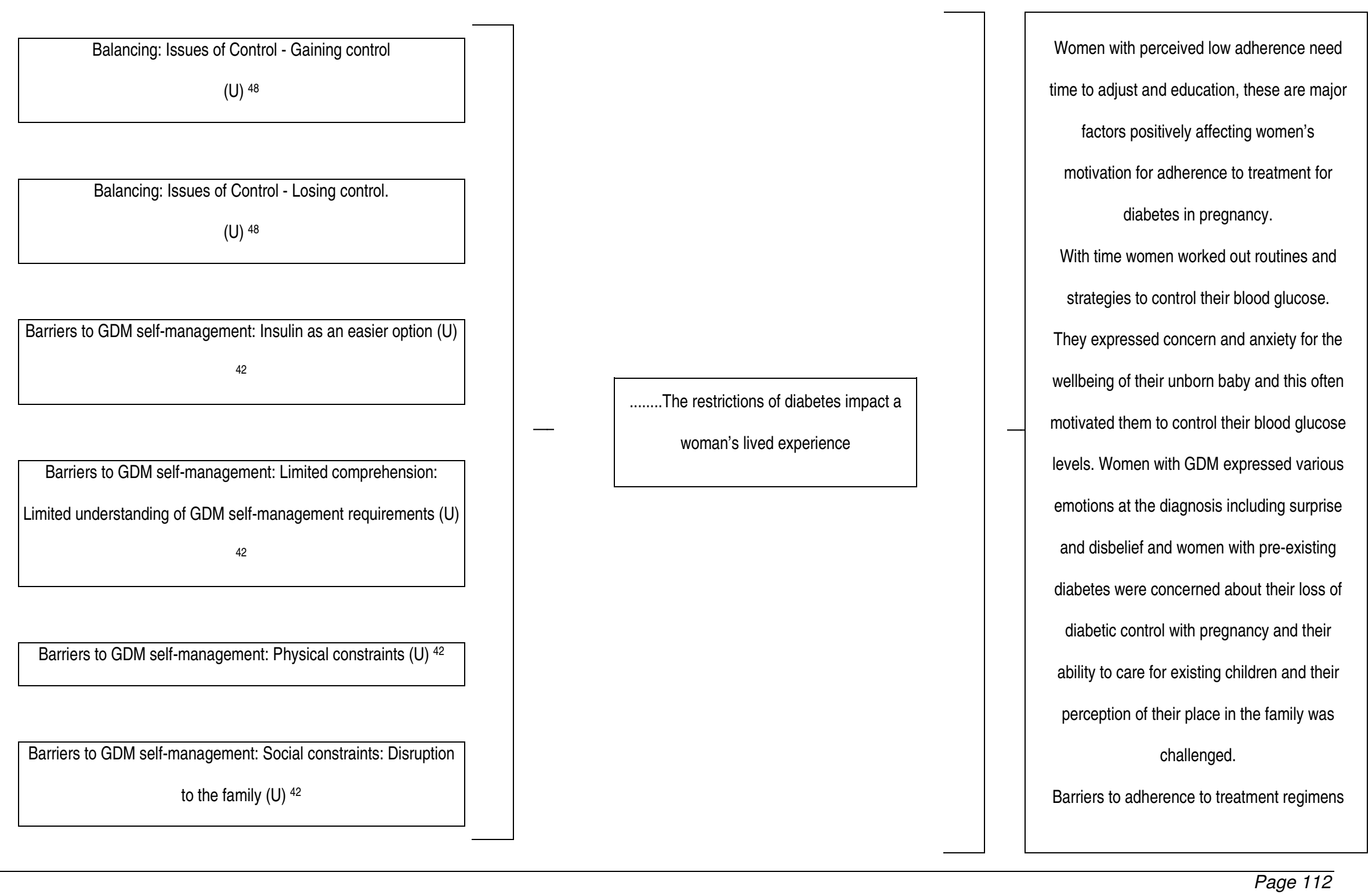

Page 112 


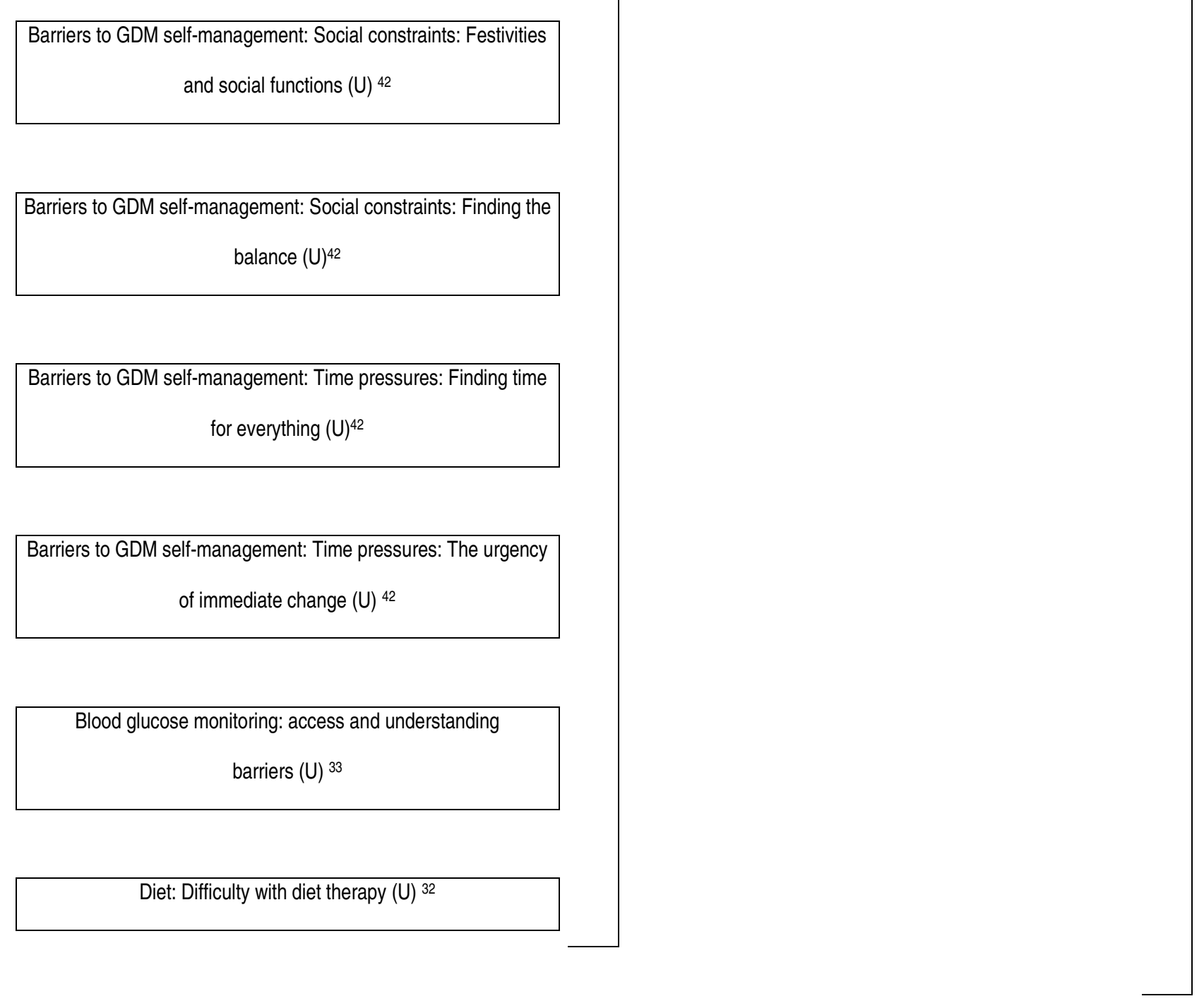

included: the time spent managing their condition, frustration that blood glucose levels seemed unpredictable even though they complied to treatment regimes, concerns with blood glucose monitoring including concerns about blood loss, social isolation and pain associated with finger

$$
\text { pricking, }
$$

concern with the restrictive nature of the prescribed diet and exercise with difficulty with competing priorities with family and social obligations, difficulties with insulin. Some acknowledged however that it made control of their diabetes easier.

Enablers to good adherence to treatment regimens included support by family members and friends, concern about the wellbeing of their unborn child and the effect of their diabetes on the child and delivery of the child, women with pre-existing diabetes 


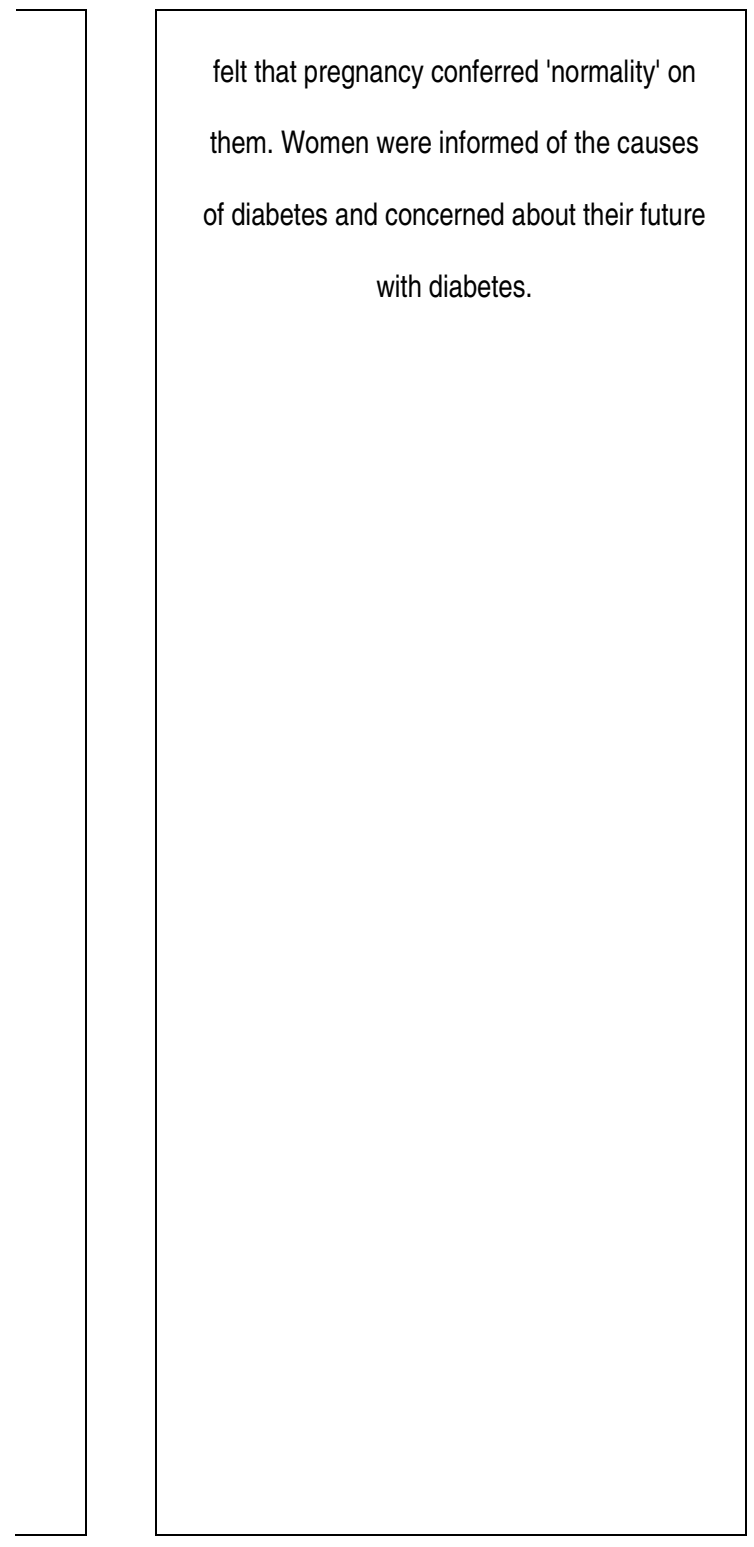



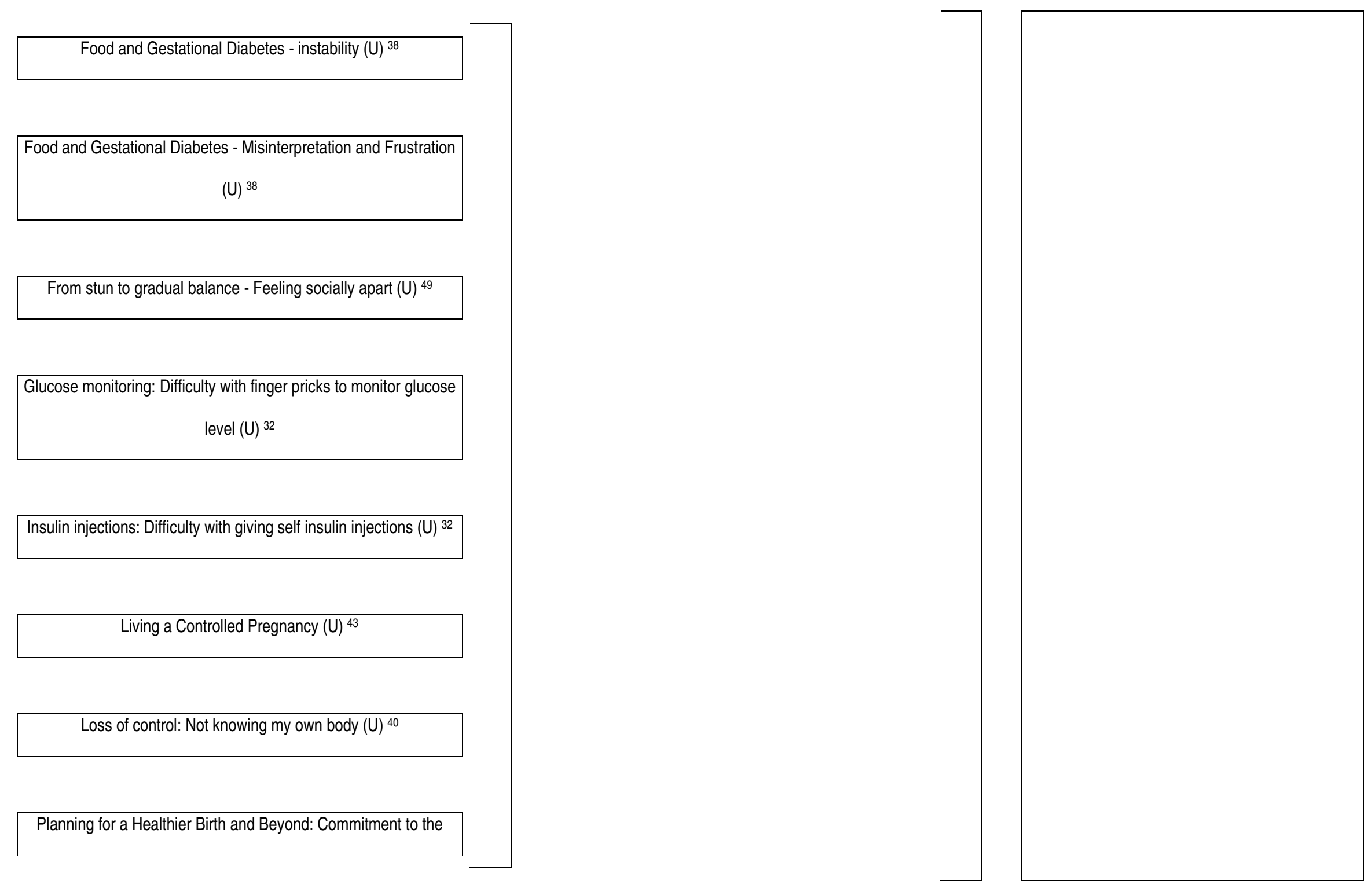


\begin{tabular}{|c|}
\hline Fetus's Well-Being (U) ${ }^{47}$ \\
\hline Planning for a Healthier Birth and Beyond: Support and \\
Information (U) ${ }^{47}$ \\
\hline Reconciliation/Conflict: Lack of self-understanding (U) ${ }^{39}$ \\
\hline Reconciliation/Conflict: opposition (U) ${ }^{39}$ \\
\hline Regaining a sense of control: Perceived threat (U) ${ }^{47}$ \\
\hline Relinquishing personal control - Disruption to everyday lives (U) ${ }^{44}$ \\
\hline Tide effects: Negative side effects associated with pregnancy and \\
insulin (U) ${ }^{32}$ \\
\hline
\end{tabular}

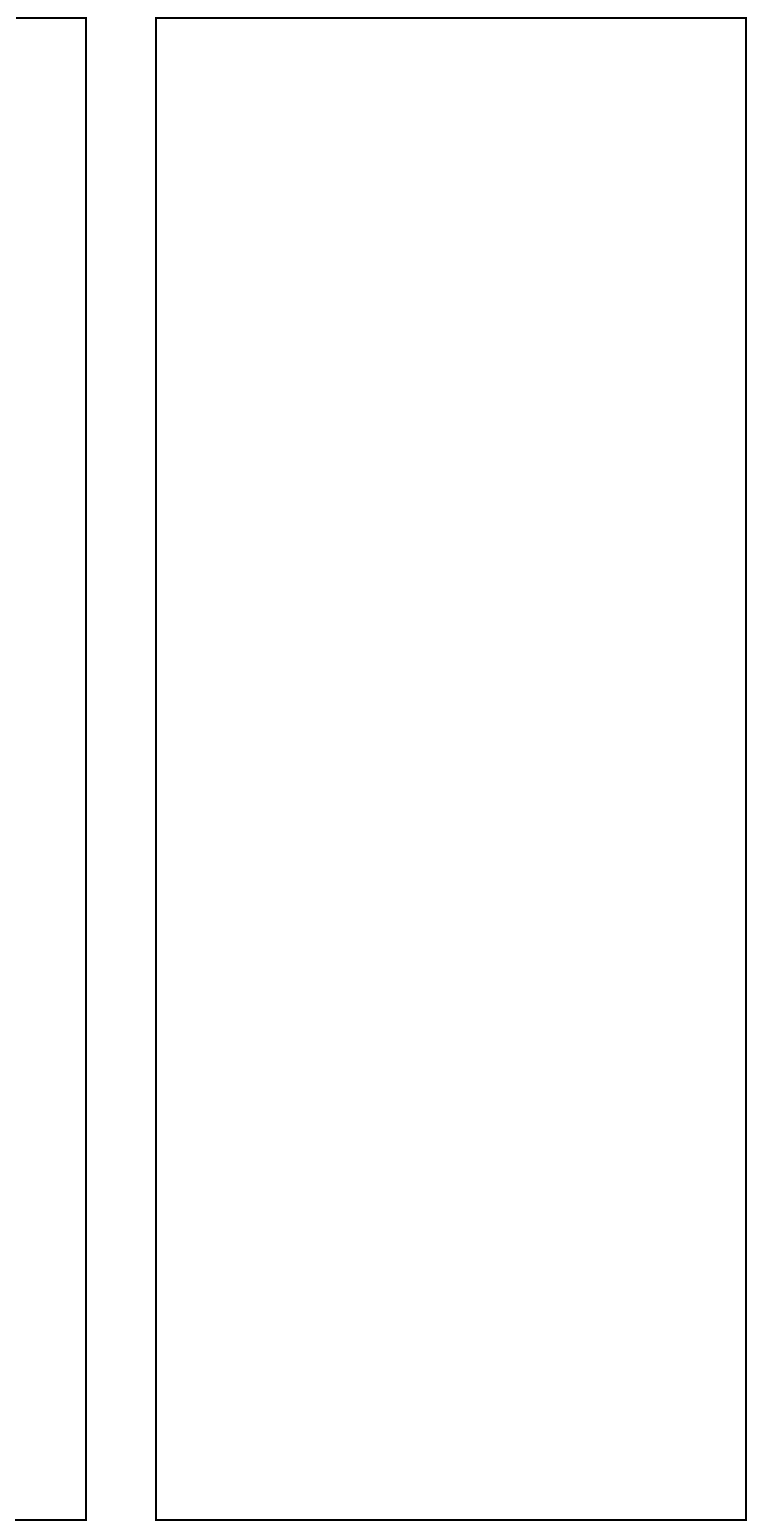




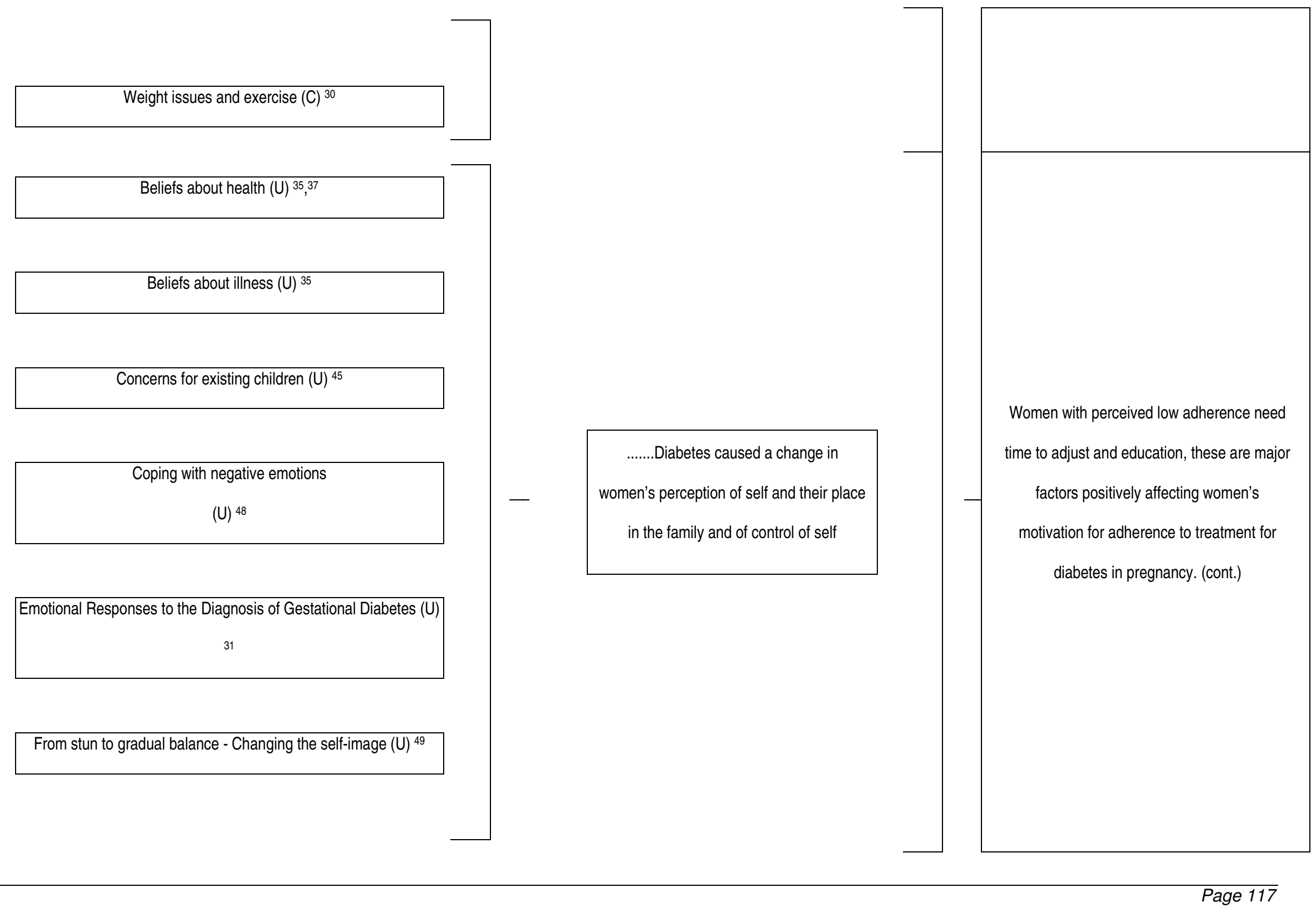



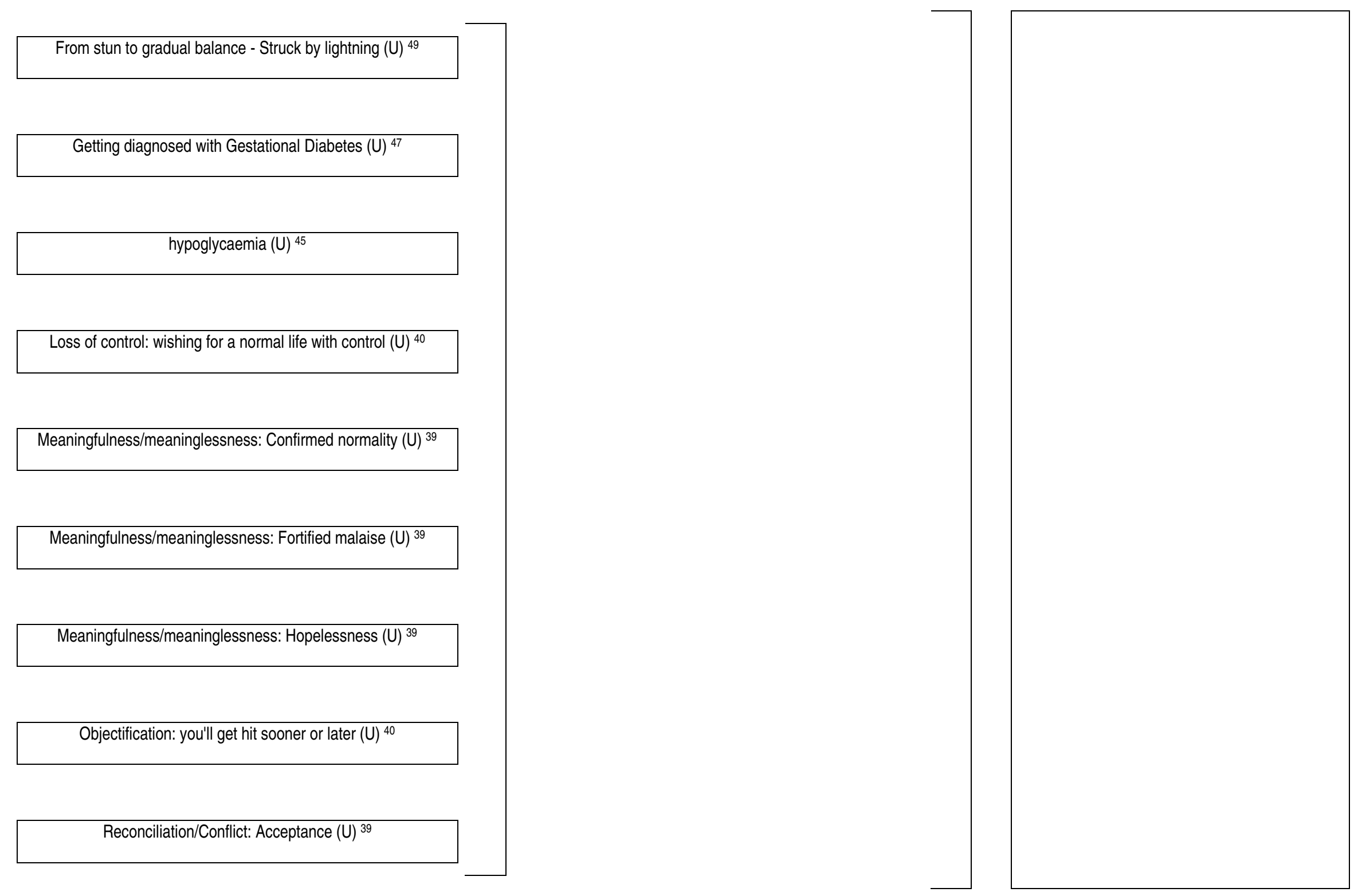


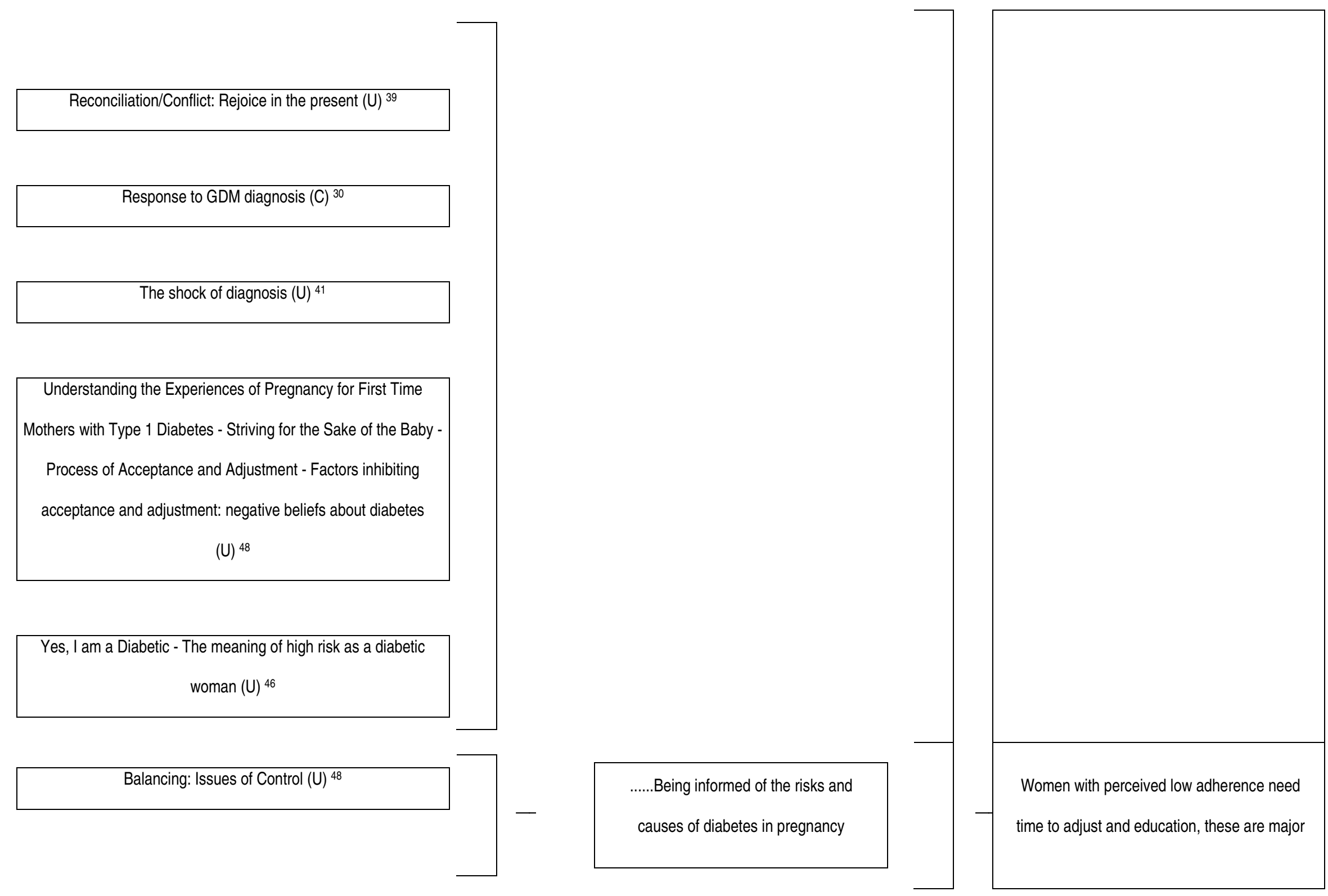




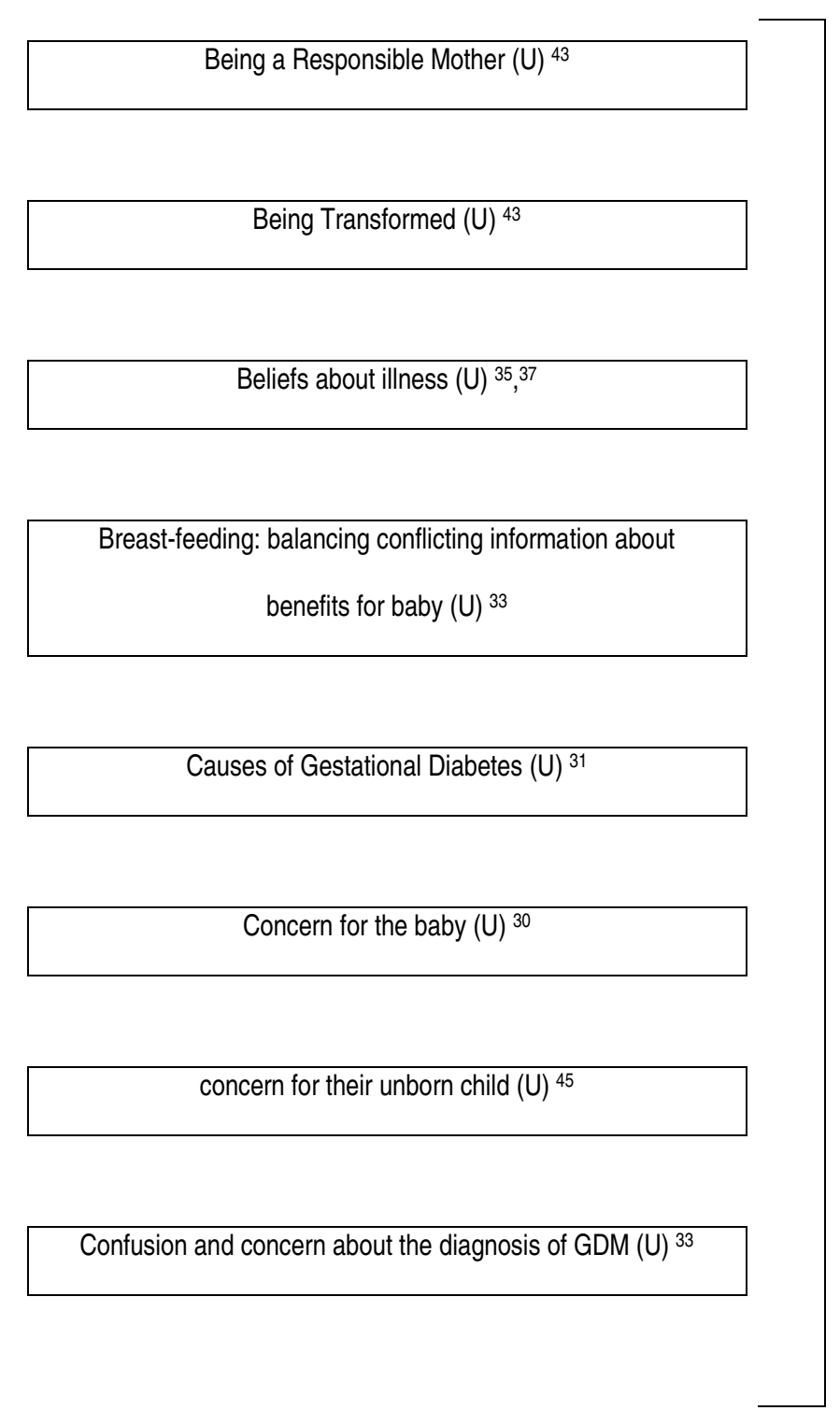

increases both anxiety and motivation

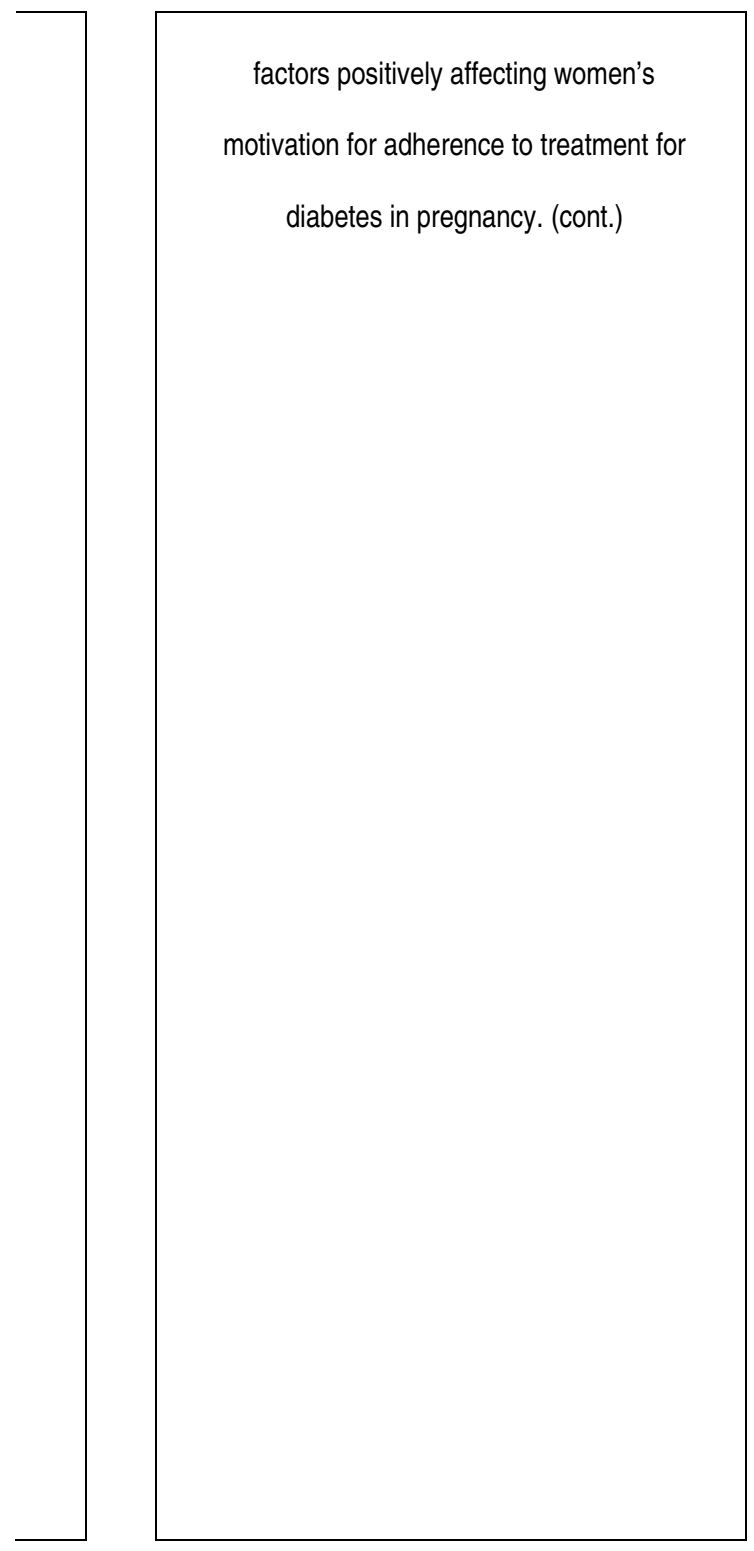



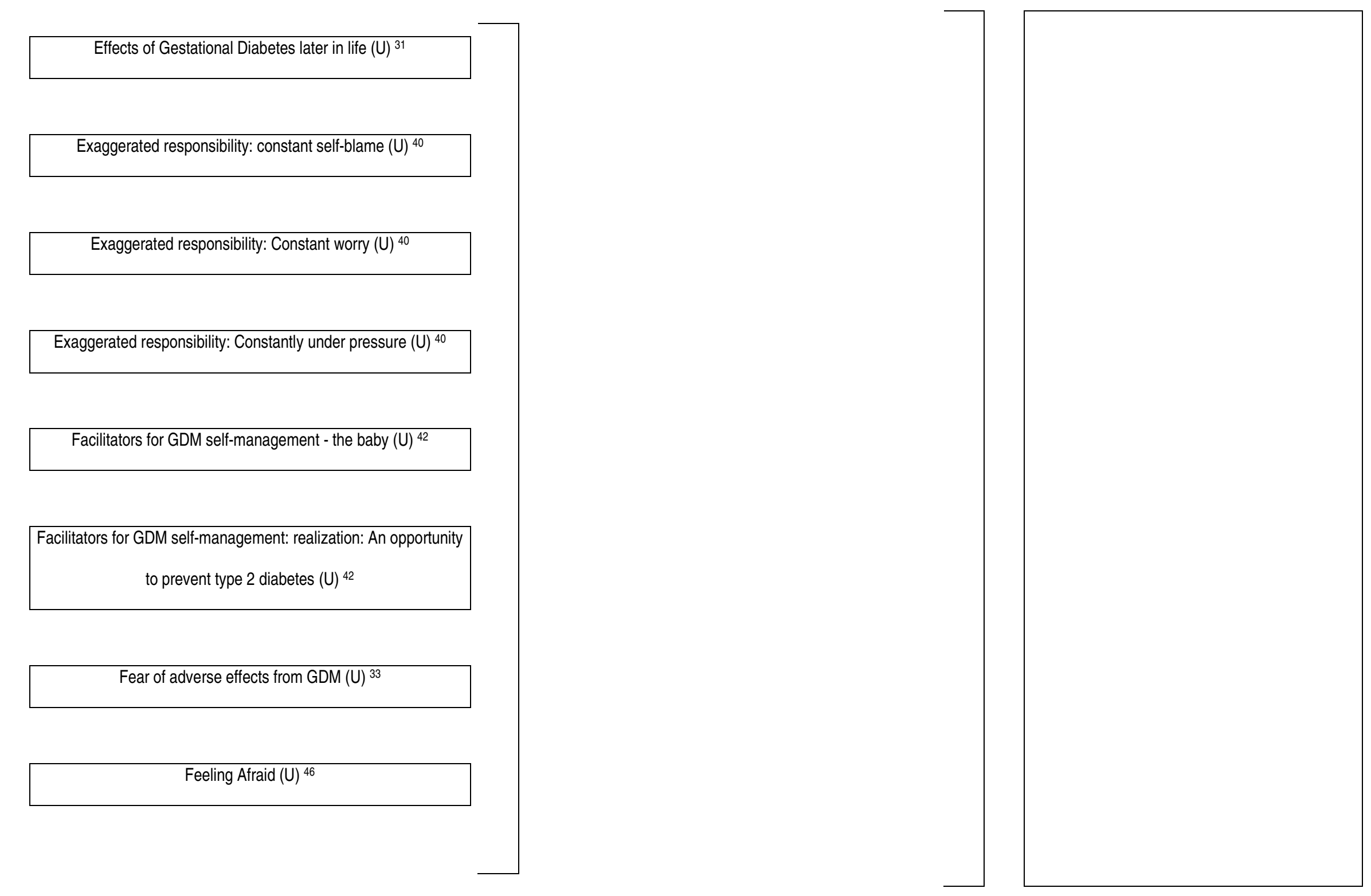

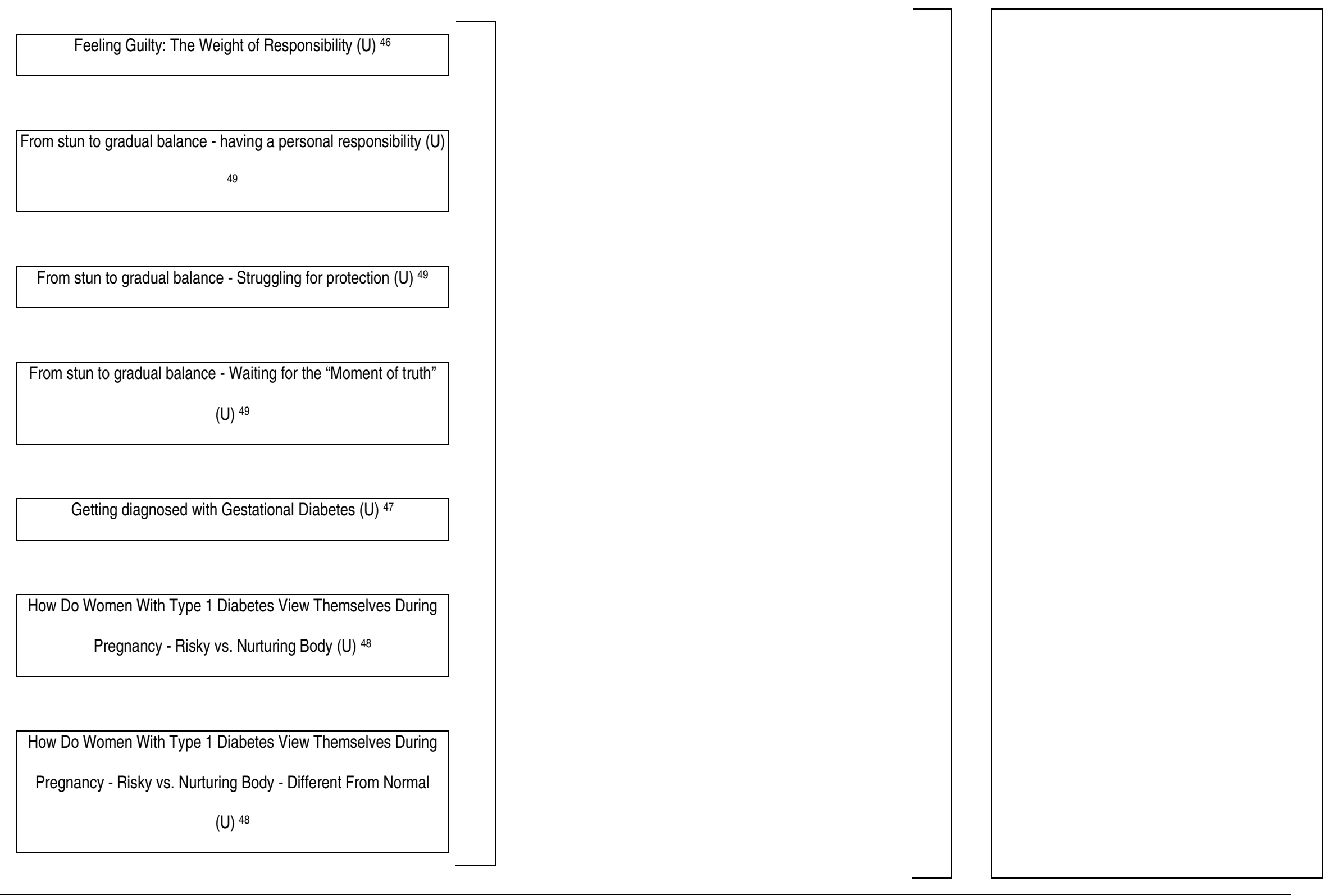

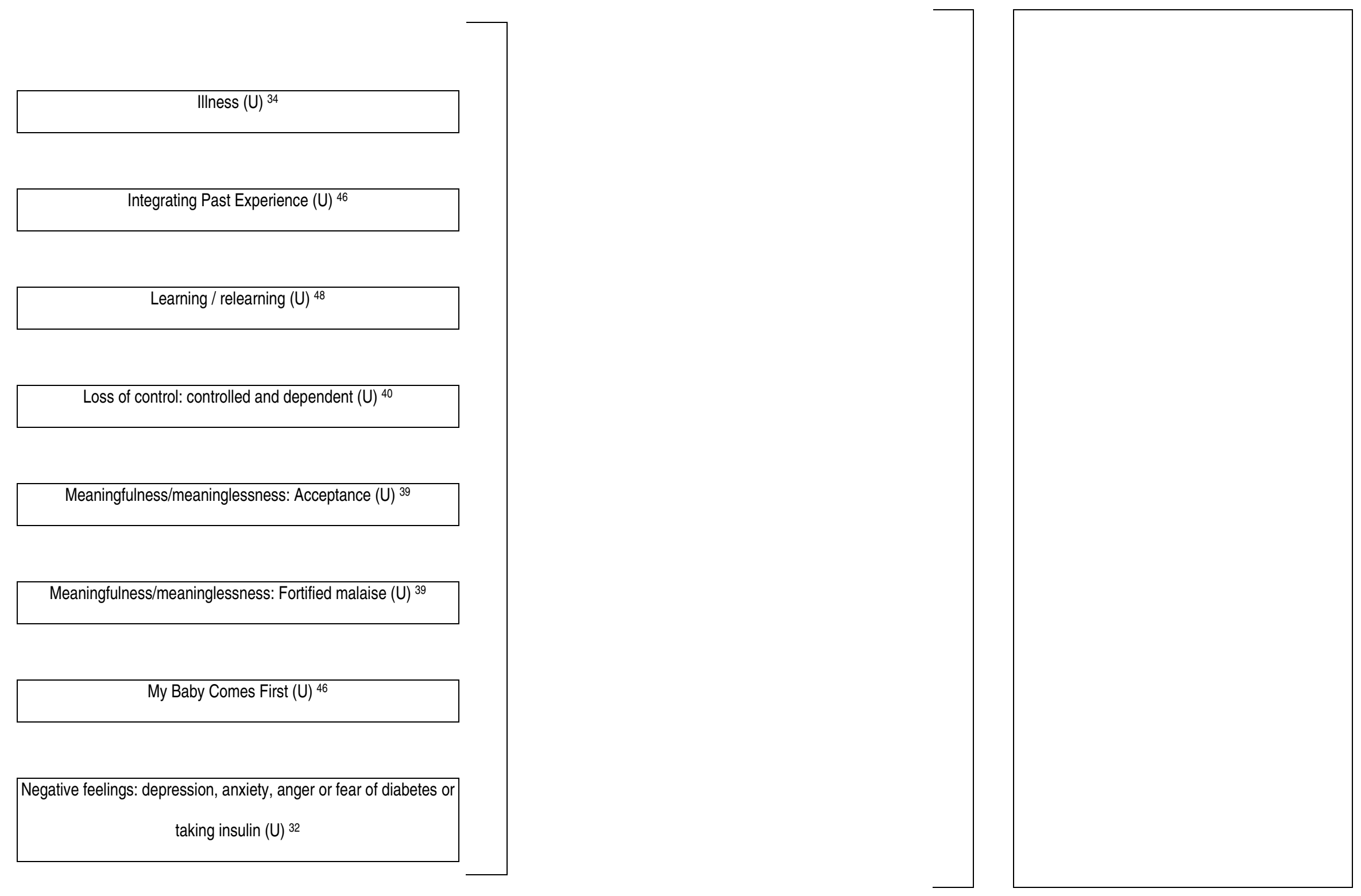

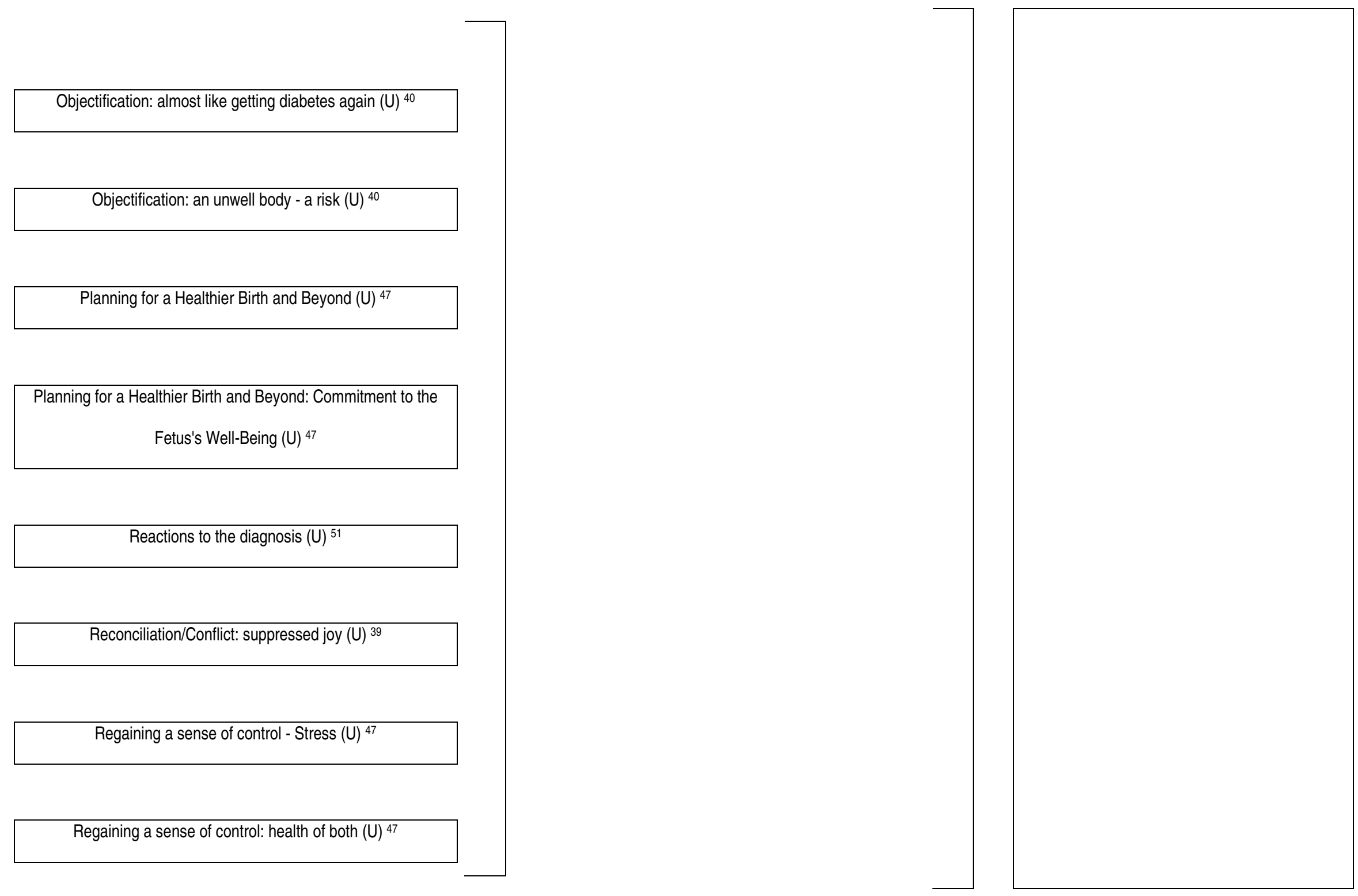

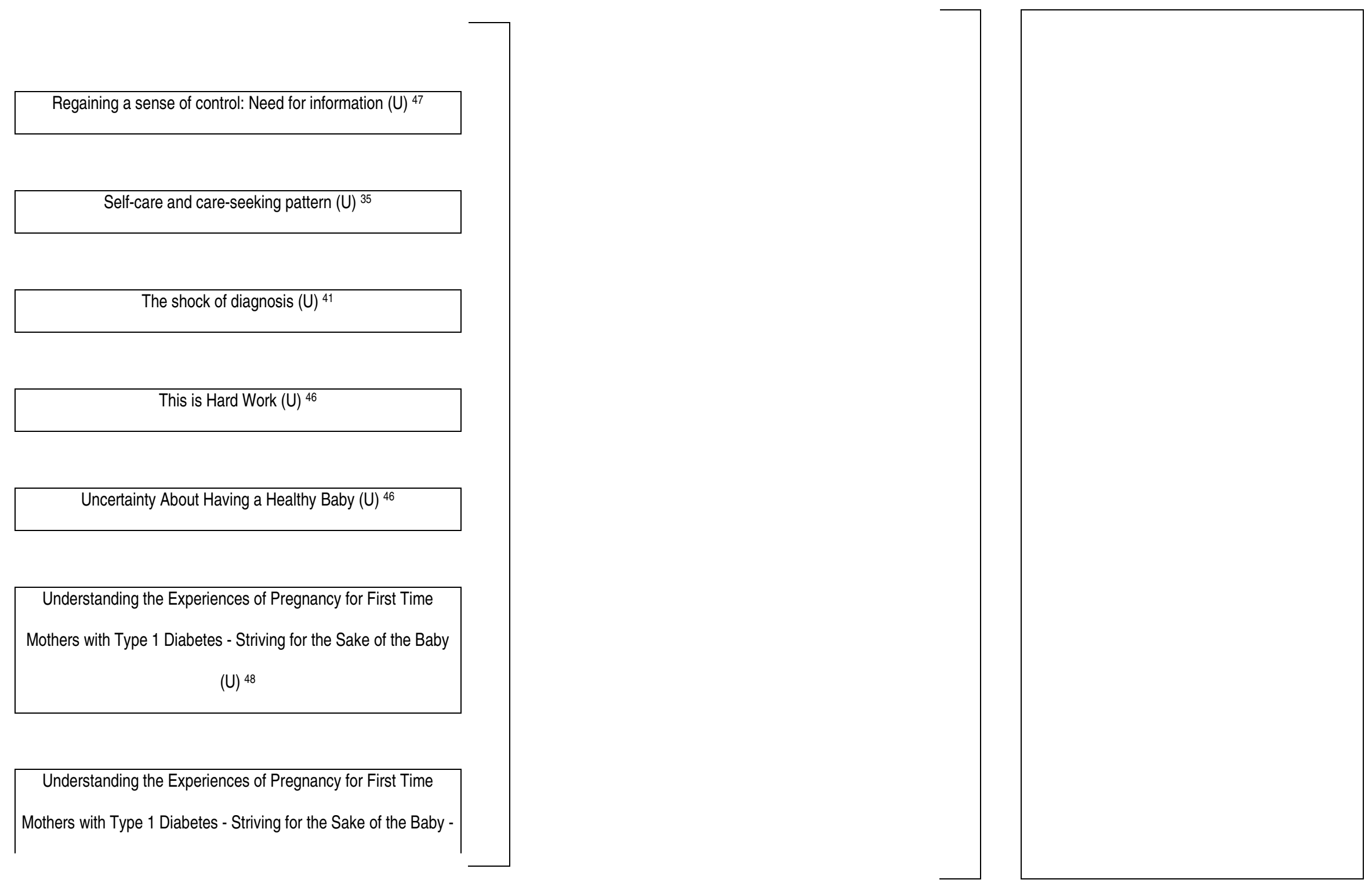
Process of Acceptance and Adjustment - Factors inhibiting acceptance and adjustment: fear

(U) ${ }^{48}$

Understanding the Experiences of Pregnancy for First Time
Mothers with Type 1 Diabetes - Striving for the Sake of the Baby -
Process of Acceptance and Adjustment - Factors promoting
acceptance and adjustment: engagement (U) ${ }^{48}$

\section{Understanding the Experiences of Pregnancy for First Time \\ Mothers with Type 1 Diabetes - Striving for the Sake of the Baby - \\ Process of Acceptance and Adjustment - Factors promoting \\ acceptance and adjustment: responsibility $(U){ }^{48}$}

Yes, I am a Diabetic - The meaning of high risk as a diabetic
woman (U) ${ }^{46}$

woman (U) ${ }^{46}$

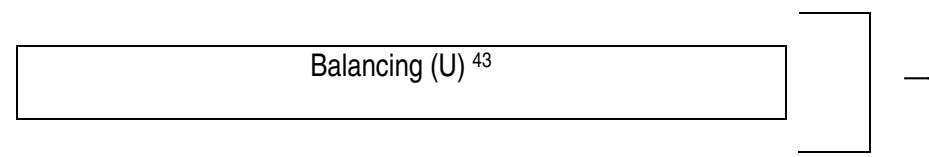

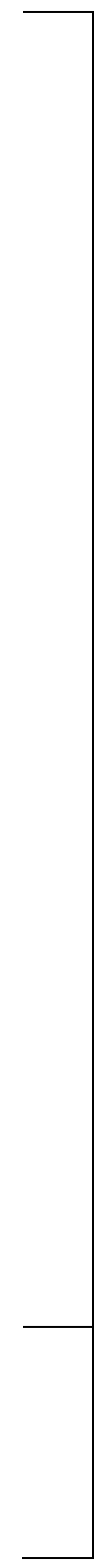

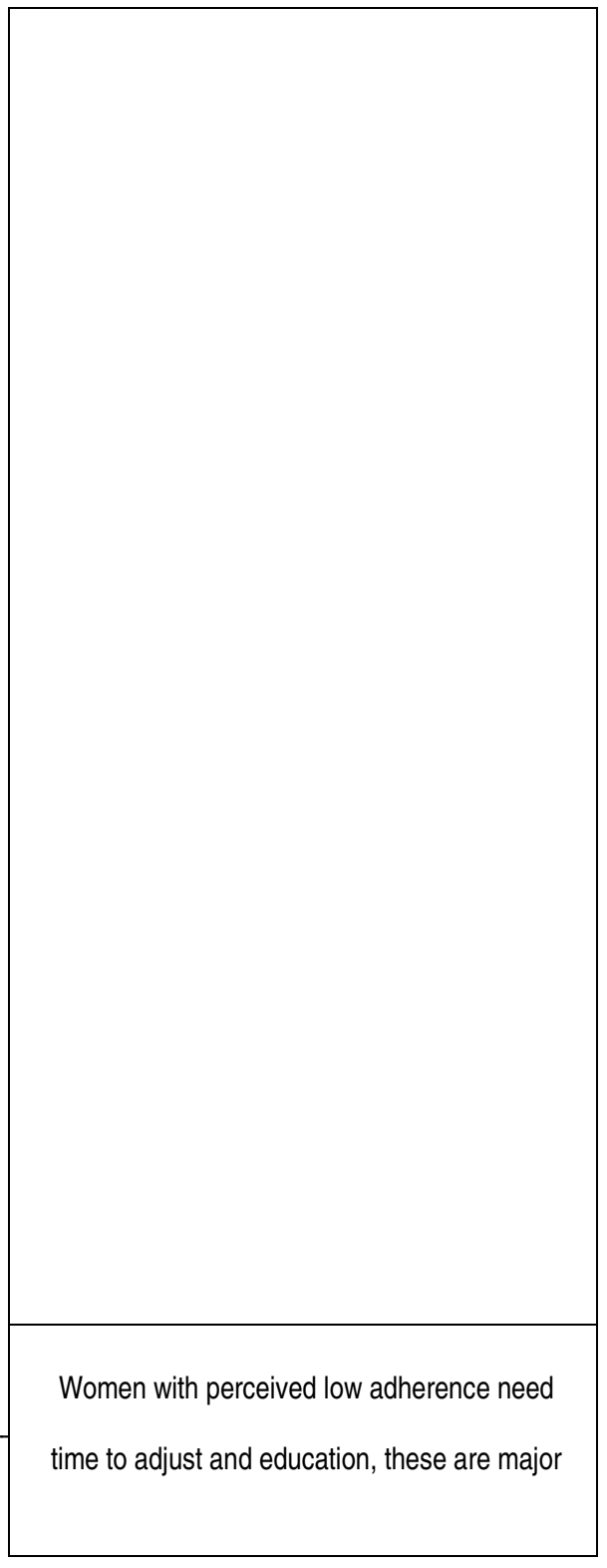

Page 126 

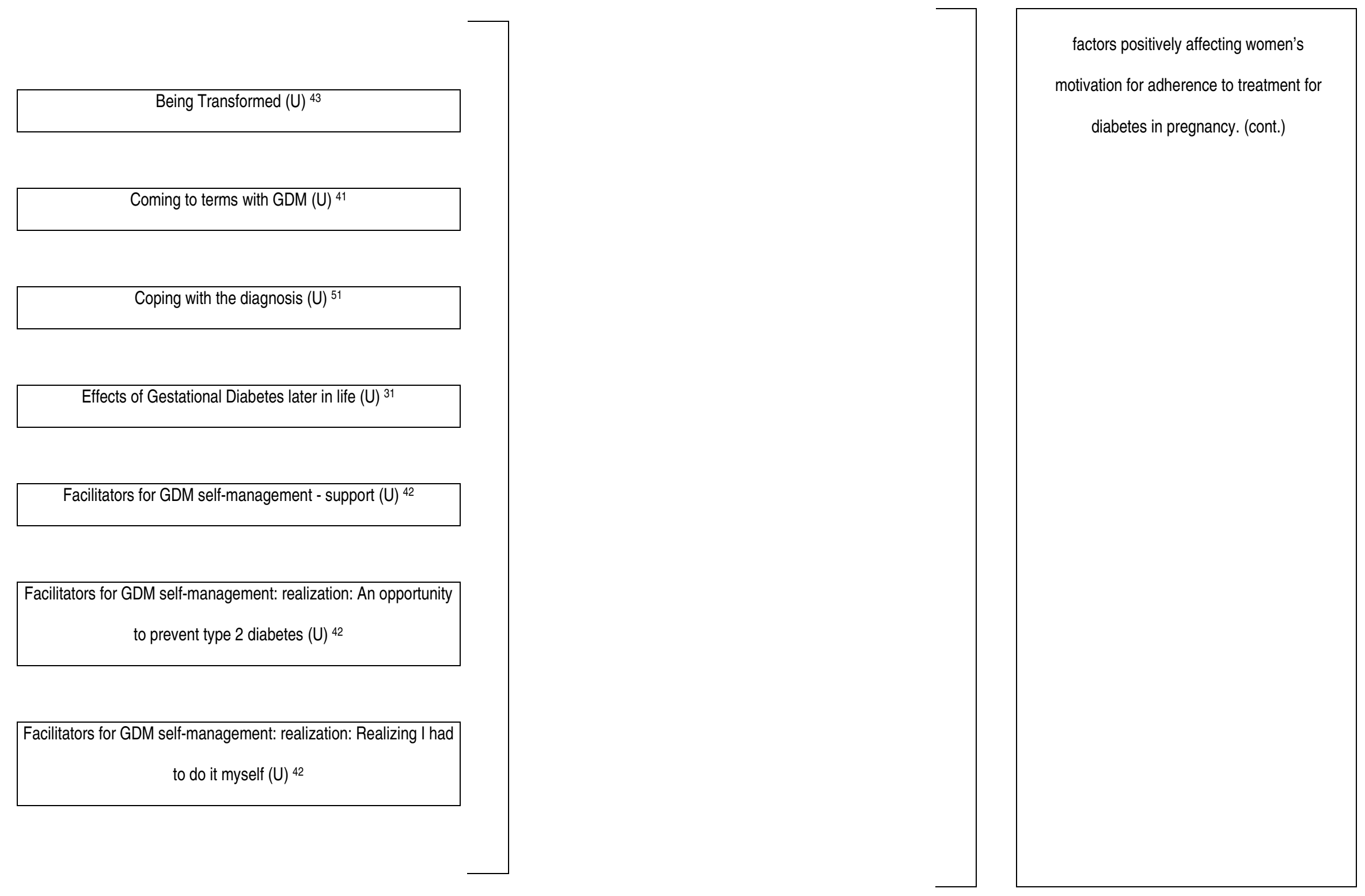

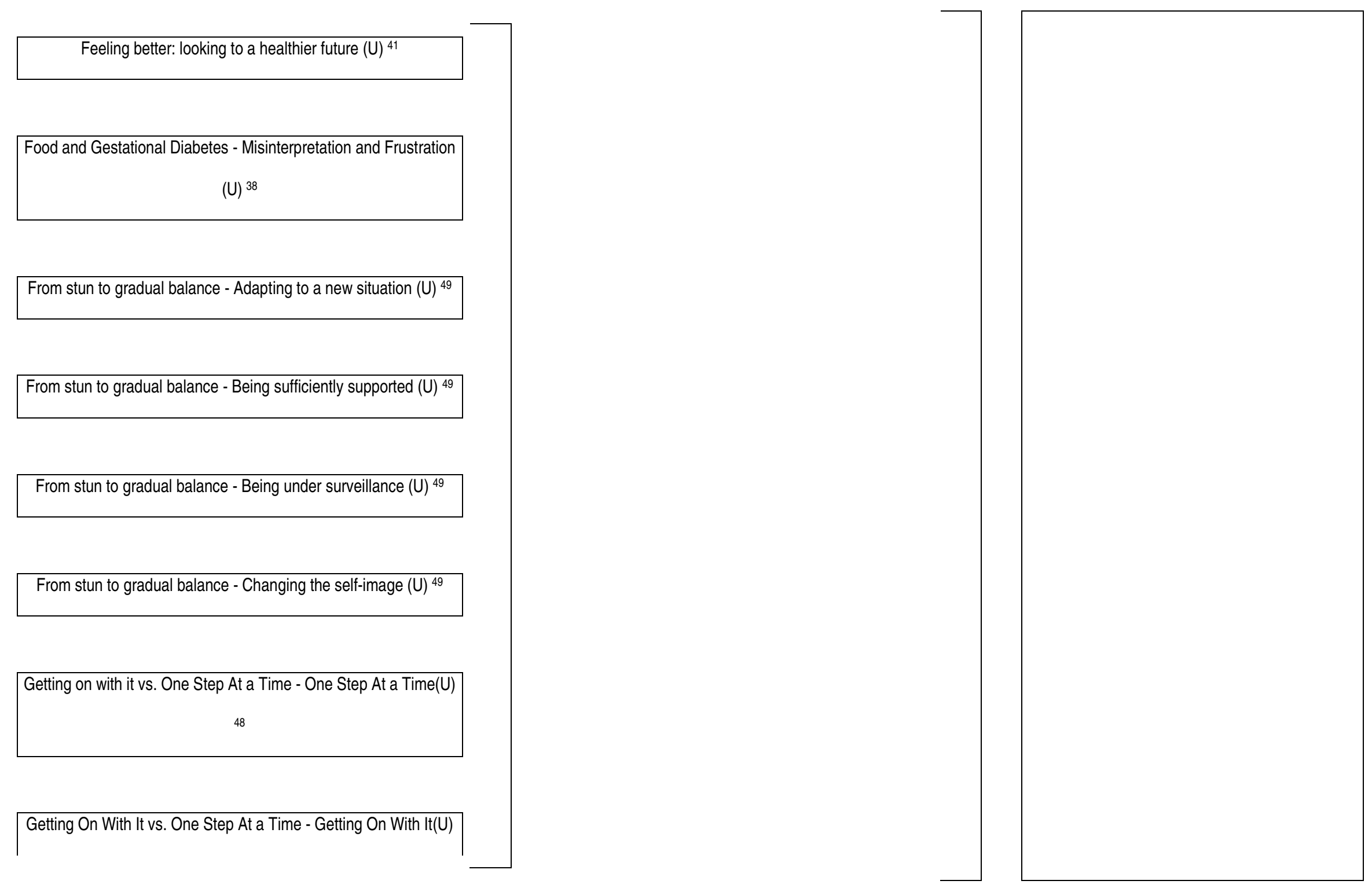

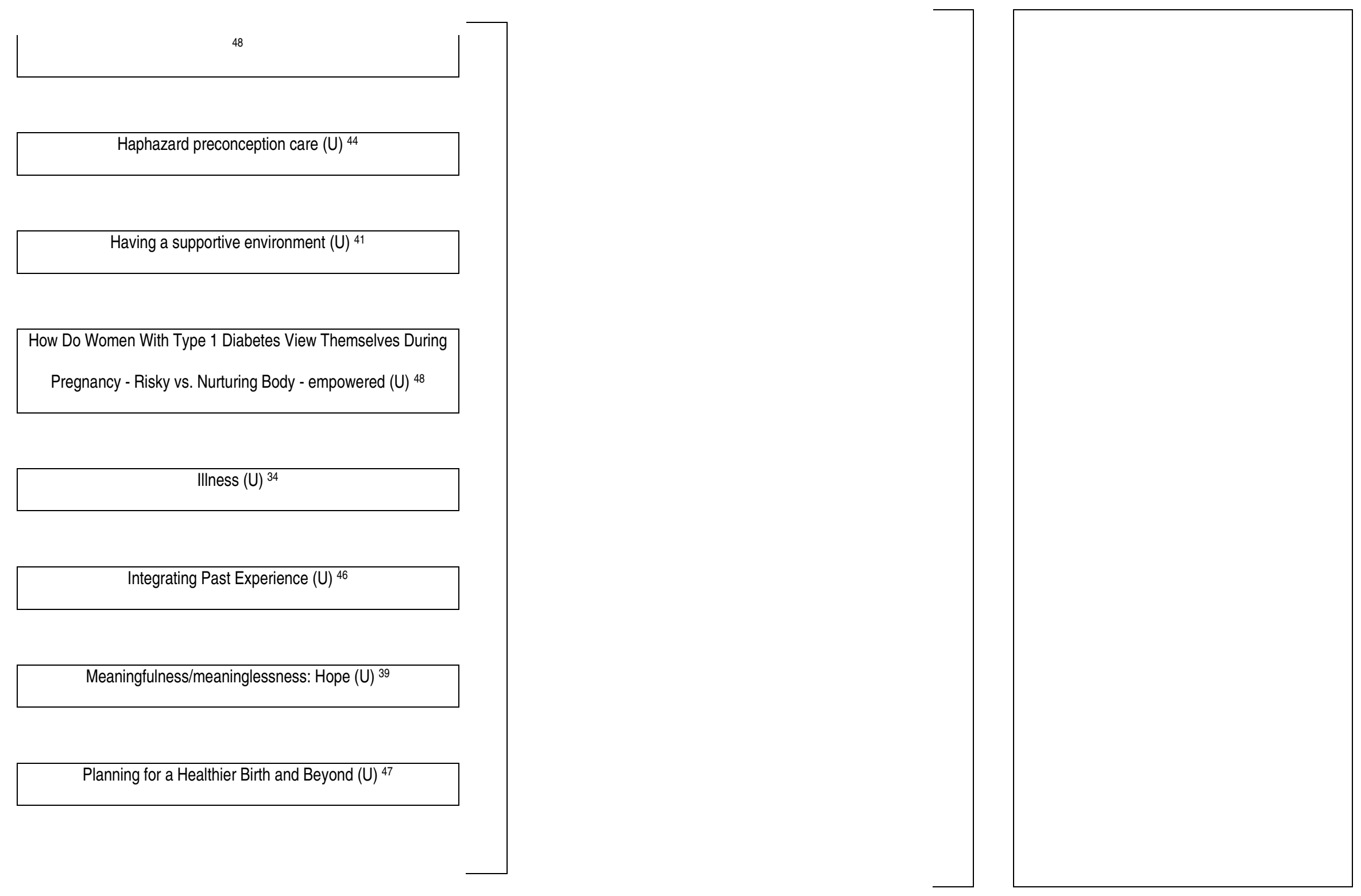

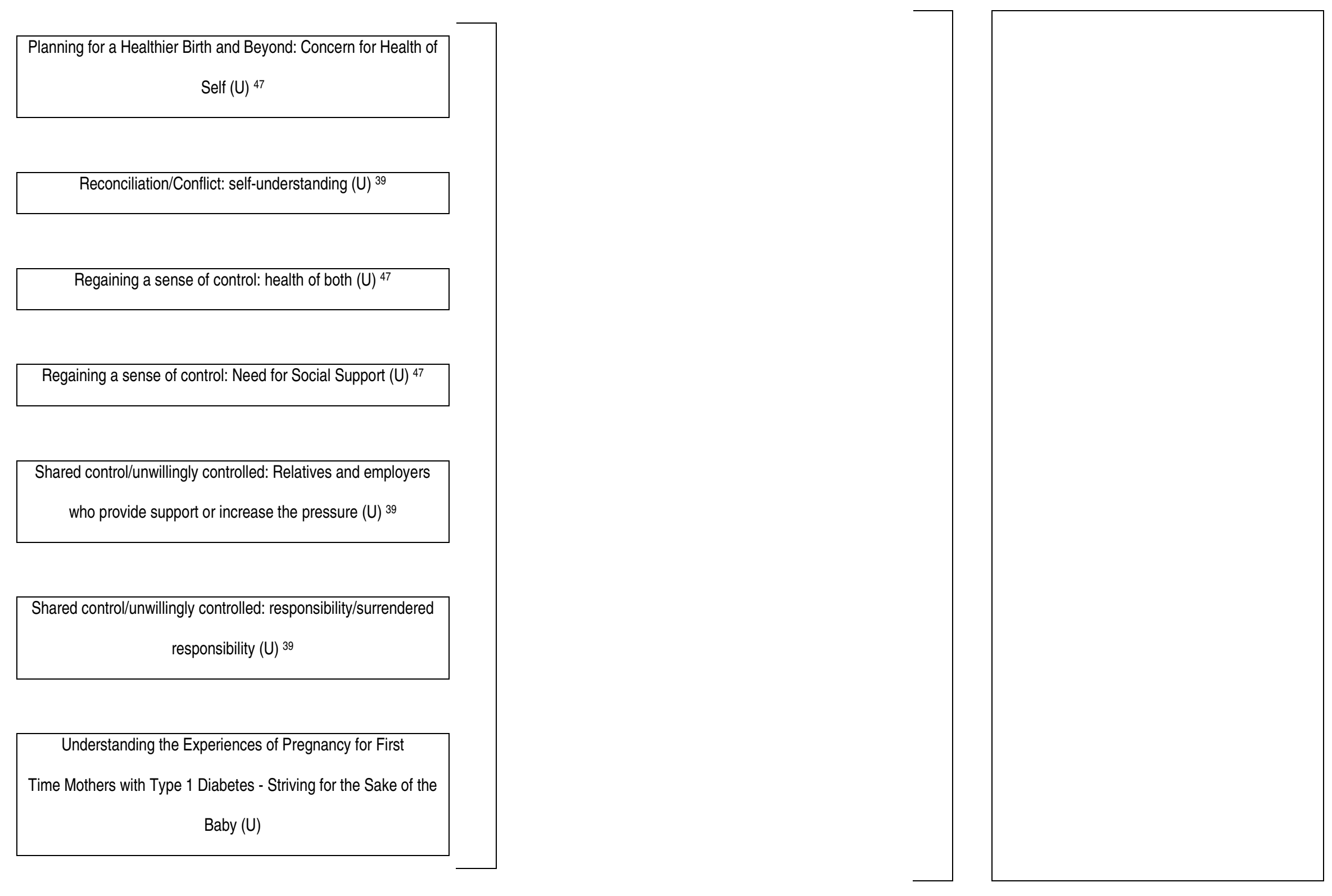

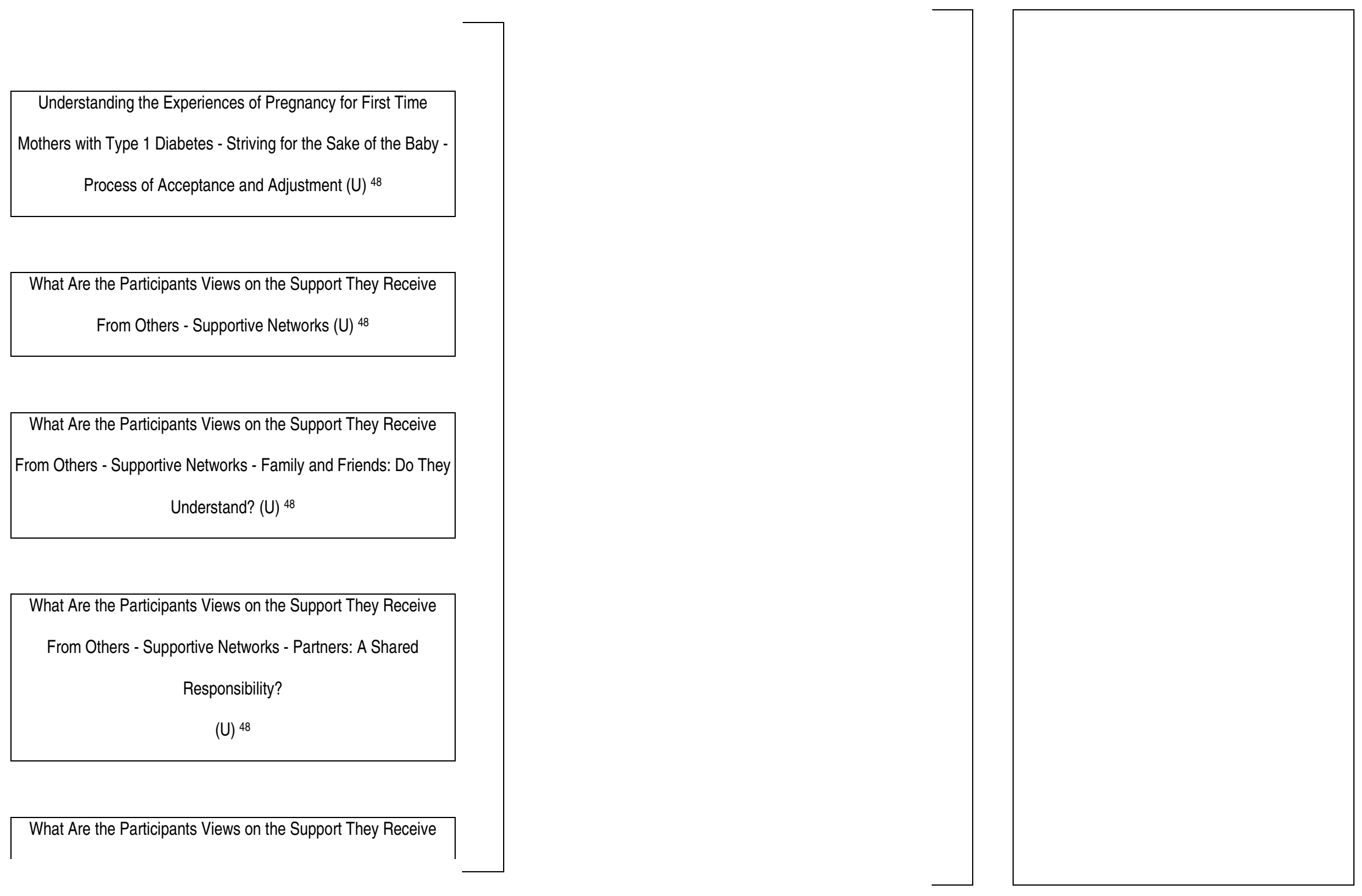
From Others - Supportive Networks -Professional Support How to Promote Self Care - Collaborative care (U) 48

Working it out and learning new strategies (U) ${ }^{41}$

Yes, I am a Diabetic - Diabetes as a background (U) ${ }^{46}$

Yes, I am a Diabetic - Diabetes as background and foreground (U)

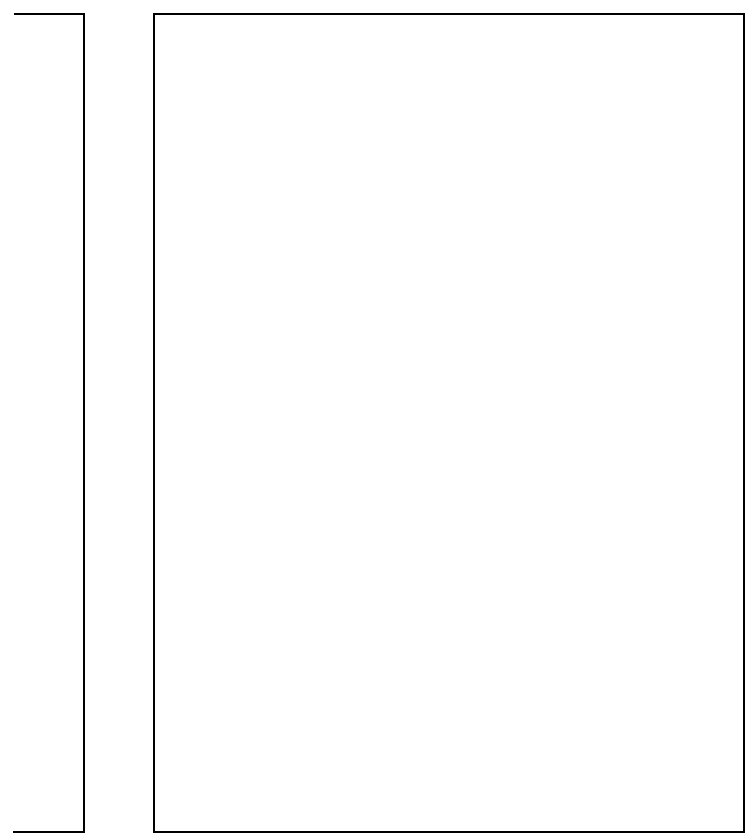

